\title{
Factors Influencing Survival, Productivity, and Population Growth of Eastern Wild Turkeys in Northeastern South Dakota
}

\author{
Reina M. Tyl \\ West Virginia University, rmt0010@mix.wvu.edu
}

Follow this and additional works at: https://researchrepository.wvu.edu/etd

Part of the Natural Resources and Conservation Commons

\section{Recommended Citation}

Tyl, Reina M., "Factors Influencing Survival, Productivity, and Population Growth of Eastern Wild Turkeys in Northeastern South Dakota" (2019). Graduate Theses, Dissertations, and Problem Reports. 4119.

https://researchrepository.wvu.edu/etd/4119

This Thesis is protected by copyright and/or related rights. It has been brought to you by the The Research Repository @ WVU with permission from the rights-holder(s). You are free to use this Thesis in any way that is permitted by the copyright and related rights legislation that applies to your use. For other uses you must obtain permission from the rights-holder(s) directly, unless additional rights are indicated by a Creative Commons license in the record and/ or on the work itself. This Thesis has been accepted for inclusion in WVU Graduate Theses, Dissertations, and Problem Reports collection by an authorized administrator of The Research Repository @ WVU. For more information, please contact researchrepository@mail.wvu.edu. 


\title{
FACTORS INFLUENCING SURVIVAL, PRODUCTIVITY, AND POPULATION GROWTH OF EASTERN WILD TURKEYS \\ (Meleagris gallopavo silvestris)
}

IN NORTHEASTERN SOUTH DAKOTA

\author{
Reina M. Tyl
}

Thesis submitted

to the Davis College of Agriculture, Natural Resources, and Design

at West Virginia University

in partial fulfillment of the requirements for the degree of

Master of Science in

Wildlife and Fisheries Resources

Christopher T. Rota, Ph.D., Chair

Chadwick P. Lehman, Ph.D.

Petra B. Wood, Ph.D.

Division of Forestry and Natural Resources

Morgantown, West Virginia

2019

Keywords: population ecology, eastern wild turkey, Meleagris gallopavo silvestris, survival, reproduction, radio telemetry, Bayesian statistics, matrix-projection model, life-stage simulation analysis, wildlife management, South Dakota 


\author{
ABSTRACT \\ Factors Influencing Survival, Productivity, and Population Growth \\ of Eastern Wild Turkeys (Meleagris gallopavo silvestris) in Northeastern South Dakota
}

Reina M. Tyl

The population of eastern wild turkeys in northeastern South Dakota appeared to be expanding soon after reintroduction in the 1990s, however, recent harvest trends suggest declining abundance in the region. Spring turkey hunting expenditures are projected to be around $\$ 6.5$ million in South Dakota, with about $\$ 3$ million of those expenditures occurring within the northeastern prairie region. However, the number of birds harvested during the spring prairie firearm season has been declining since 2010. Due to concerns about a declining population, the autumn hunting season was closed in 2014. The cause of the apparent decline is unclear. Updated demographic information is needed to assess the status of the population of wild turkeys in northeastern South Dakota and to determine the most effective management strategies for increasing abundance across the region. I captured and radio-marked 80 eastern wild turkey hens (43 adult and 37 yearling) in Grant County, South Dakota during the winter of 2017, and I radio-marked an additional 41 yearling hens during the winter of 2018. I monitored radio-marked hens for survival and productivity from February 2017 to April 2019. I used Bayesian methods to model hen survival, nesting rate, nest survival, re-nesting rate, clutch size, hatchability, and poult survival as a function of covariates. I used estimates of productivity to calculate the fecundity rate for both age-classes of wild turkeys. I incorporated estimates of hen survival and fecundity into a matrix projection model, and I performed perturbation analyses and conducted a life-stage simulation analysis (LSA) to assess the impact of each demographic parameter on population growth. Annual survival for both age-classes of wild turkey hens was about $62.5 \%$. The probability a hen would initiate a nest was $77.1 \%$ and the probability a nest would survive the 28 -day incubation period was $49.3 \%$. The probability a hen would initiate a second nest after a failed first nest attempt was $59.6 \%$ for adult hens and $25.1 \%$ for yearling hens. The mean clutch size for all nests was 10 eggs and the probability an egg would hatch was $87.1 \%$. The probability a poult survived the 28 -day post-hatch interval was $35.5 \%$ for poults reared by adult hens and $19.7 \%$ for poults reared by yearling hens. The population of eastern wild turkeys in northeastern South Dakota is currently stable-to-growing $(\lambda=1.107)$, and population growth is most greatly affected by changes in hen survival. Management activities should focus on improving hen survival by reducing the top two sources of mortality - mammalian predation and haying by agricultural equipment. Enhancing the quality of herbaceous and early successional habitats could reduce hen risk of mortality while conducting nesting and brood-rearing activities. Additionally, increased availability of suitable nesting habitat on the landscape could mean fewer hens will resort to nesting in alfalfa hayfields, where nest failure is certain and hens are at risk of mortality due to haying. Improving eastern wild turkey hen survival in northeastern South Dakota should increase abundance of wild turkeys and improve hunting opportunities in the region. 


\section{Acknowledgments}

I would like to thank the many people who have helped me during my time working on this project. I'd like to extend my sincere gratitude to my graduate advisor and the chair of my committee, Dr. Christopher Rota, for his guidance and statistical prowess. Dr. Rota was instrumental to the advancement of my analytical skills and my overall development as a researcher. I'd also like to thank my co-advisor, Dr. Chad Lehman, for sharing his breadth of knowledge of wild turkey ecology and for his guidance regarding the field methodology for this project. I am grateful for Dr. Lehman's encouragement and guidance as I began my search for post-graduation employment. I am thankful for the detailed feedback on my research proposal and thesis provided by my third committee member, Dr. Petra Wood. Dr. Wood's input helped bring my writing to the next-level, and I am thankful for her guidance throughout my time at West Virginia University.

I am indebted to the numerous employees of the South Dakota Game, Fish and Parks Department for their support throughout the fieldwork portion of this study, including supplying necessary equipment, assisting with turkey capture events, and performing aerial monitoring of radio-marked birds while I was back in West Virginia. I would especially like to thank Nick Rossman and Jacquie Ermer for expressing a need for a wild turkey study in northeastern South Dakota and helping to make this project a reality. I thank Nick Rossman and Nick Markl for their guidance throughout this project and for assisting with fieldwork whenever I needed extra hands on the ground. I am grateful for all of the other Game, Fish and Parks employees - Brady Neiles, Alem Solem, Eric Kraetsch, Alex Elias, Mark Grovijahn, Joseph Mayrose, and Aaron Hunt — and students from South Dakota State University - Samantha Fino, Jacob Comer, Rebecca Kolstrom, and Spencer Carstens - who assisted with wild turkey capture events. The captures would not have gone smoothly without their help.

I am grateful for the dedicated field technicians who worked long hours in the field and made my time working out in South Dakota enjoyable, including Megan Ahern, Neil Vruno, Jenna Wolf, and Kevin Ostrander. I'd like to thank my neighbor, and dedicated member of the National Wild Turkey Federation, Mike McKernan, for helping me make contact with landowners and for providing opportunities for me to speak at the local NWTF banquet and state NWTF convention. Most importantly, I'd like to thank all of the Codington, Deuel, Grant, and Roberts County landowners, and the Sisseton Wahpeton Oyate 
Tribe, for allowing me to access their lands to conduct fieldwork activities. This project would have been impossible without their cooperation. I am thankful for all of the organizations that provided the funding for this project, especially the South Dakota Department of Game, Fish and Parks, the National Wild Turkey Federation, and West Virginia University.

I am extremely grateful for the support from fellow members of the Rota Quantitative Ecology Lab, especially Brett Skelly and Gordon Dimmig who were always available to help me figure out how to fix the bugs in my R code. I would also like to thank my undergraduate advisor, Dr. Robert Gates, for helping me land my first wildlife research internship, giving me the opportunity to attend a Conservation Leaders for Tomorrow workshop, and for his guidance as I began to search for a graduate assistantship. It was through that first internship with the Ohio Department of Natural Resources' Division of Wildlife that I discovered my passion for population ecology and upland game bird research. Lastly, I'd like to thank my family, friends, and graduate students at West Virginia University for their unwavering support throughout this process. Whenever the stress of fieldwork or thesis writing became too much, I could always turn to them for words of encouragement. 


\section{Table of Contents}

$\begin{array}{lll}\text { Abstract } & \text { ii }\end{array}$

$\begin{array}{ll}\text { Acknowledgments } & \text { iii }\end{array}$

List of Tables $\quad$ vii

$\begin{array}{ll}\text { List of Figures } & \text { ix }\end{array}$

1 Introduction 1

2 Factors Influencing Survival of Eastern Wild Turkey Hens in Northeastern South

$\begin{array}{lc}\text { Dakota } & 6\end{array}$

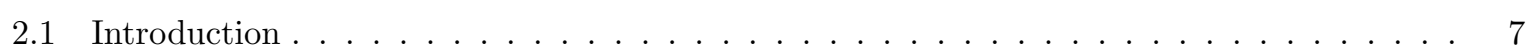

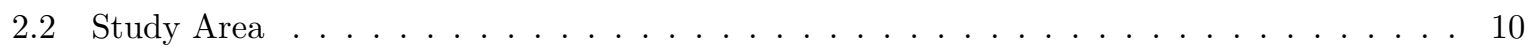

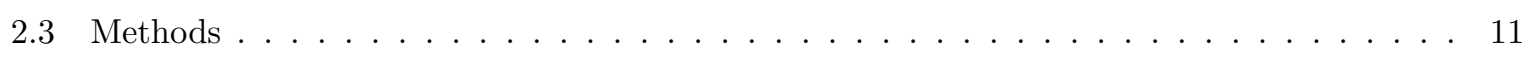

2.3.1 Capture and Radio-Telemetry . . . . . . . . . . . . . . . . . . 11

2.3 .2 Modeling Survival Probability . . . . . . . . . . . . . . . . . . . . . 12

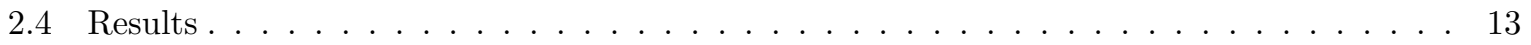

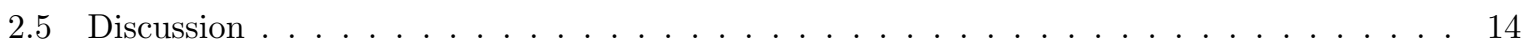

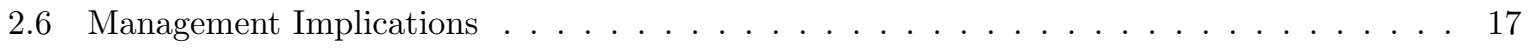

3 Factors Influencing Productivity of Eastern Wild Turkey Hens in Northeastern South

$\begin{array}{ll}\text { Dakota } & 28\end{array}$

3.1 Introduction . . . . . . . . . . . . . . . . . . . . . . . . . . . . . . . . 29

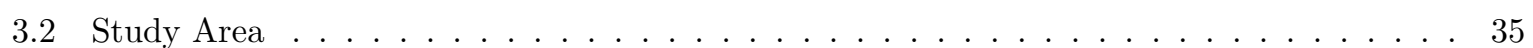

3.3 Methods . . . . . . . . . . . . . . . . . . . . . . . . . 37

3.3 .1 Capture and Radio-Telemetry . . . . . . . . . . . . . . . . . . . 37

$3.3 .2 \quad$ Nest Marking and Monitoring . . . . . . . . . . . . . . . . . . . . . 37

3.3 .3 Poult Monitoring . . . . . . . . . . . . . . . . . . . . . . . . . 38

3.3.4 Environmental and Spatial Covariate Estimation . . . . . . . . . . . . . . . 38 
3.3.5 Modeling Reproductive Parameters . . . . . . . . . . . . . . . . . . . . . . 40

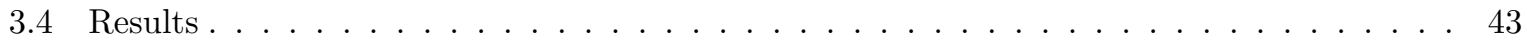

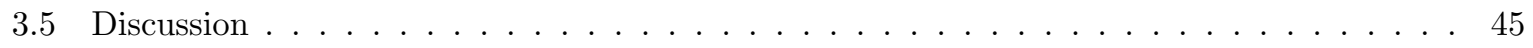

3.6 Management Implications . . . . . . . . . . . . . . . . . . . . . 50

4 Factors Influencing Eastern Wild Turkey Population Growth in northeastern South $\begin{array}{ll}\text { Dakota } & 68\end{array}$

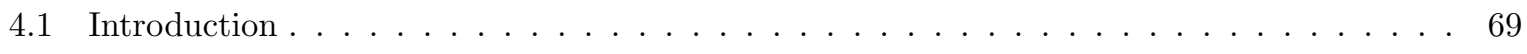

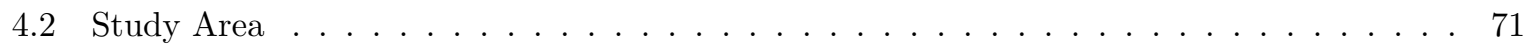

4.3 Methods . . . . . . . . . . . . . . . . . . . . . . 73

4.3.1 Vital Rate Parameter Estimates . . . . . . . . . . . . . . . . . . 73

4.3.2 Population Model and Perturbation Analyses . . . . . . . . . . . . . . . . . 73

4.4 Results . . . . . . . . . . . . . . . . . . . . . . . . 74

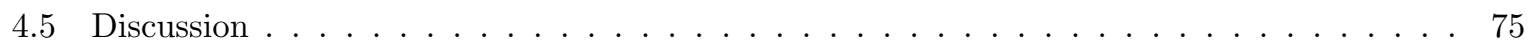

4.6 Management Implications . . . . . . . . . . . . . . . . . . . . . 76 


\section{List of Tables}

2.1 Population-level mean log-odds ratio (LOR), lower 95\% credible interval (CI) level, and upper $95 \%$ CI level for each covariate and interaction used to model daily survival probability of eastern wild turkey hens from February 2017 to April 2019 in northeastern South Dakota, USA . . . . . . . . . . . . . . . . . . . . . . . . . . . . . . . 19

2.2 Causes of mortality for eastern wild turkey hens in northeastern South Dakota, USA during each season from February 2017 to April 2019. . . . . . . . . . . . . . . . . . . 20

2.3 Annual survival probabilities of expanding and established populations of eastern wild turkey hens in the Midwest from published field studies compared to annual survival probabilities of hens in northeastern South Dakota, USA (current study). If two estimates are presented for a given study, the first estimate indicates yearling hen annual survival probability and the second estimate indicates adult hen annual survival probability. Ranges of estimates represent variation in annual survival probability within a sample of both yearling and adult hens. . . . . . . . . . . . . . . . . . . . . . . . . 2

3.1 Population-level mean log-odds ratio (LOR), lower $95 \%$ credible interval (CI) level, and upper $95 \%$ CI level for each covariate and interaction used to model nesting rate, nest survival, re-nesting rate, clutch size, hatchability, and poult survival during 2017 and 2018 for the population of eastern wild turkeys in northeastern South Dakota, USA. . . . 51

3.2 Causes of nest failure for nests laid by eastern wild turkey hens during 2017 and 2018 in northeastern South Dakota, USA . . . . . . . . . . . . . . . . . . . . . . . 52

3.3 Habitat types and sub-habitat types of nest sites selected by eastern wild turkey hens during 2017 and 2018 in northeastern South Dakota, USA. 
3.4 Estimates of nesting rate, re-nesting rate, nest success, clutch size, hatchability, and poult survival from a population of eastern wild turkeys in northeastern South Dakota (current study) compared to published estimates from field studies of eastern wild turkeys. If two estimates are presented for a given study, the first estimate indicates the value of that parameter for yearling hens and the second estimate indicates the value of that parameter for adult hens. Ranges of estimates represent variation in a parameter within a sample of both yearling and adult hens. . . . . . . . . . . . . . . . . . . . . 54

4.1 Minimum and maximum values of the 3,000 demographic parameter estimates used in the eastern wild turkey hen population model for northeastern South Dakota, USA. Estimates were calculated from data collected from February 2017 to April 2019. . . . . . . . . . . 78

4.2 Elasticities $(E)$ and coefficients of determination $\left(R^{2}\right)$ for lower-level reproductive rates, fecundity rates, and survival rates for eastern wild turkey hens from February 2017 to April 2019 in northeastern South Dakota, USA . . . . . . . . . . . . . . . . 79 


\section{List of Figures}

1.1 The range of the wild turkey about the time Europeans arrived. Figure is adapted from

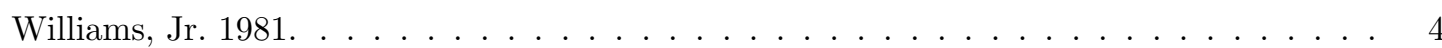

1.2 The range of the wild turkey in the United States at its lowest ebb-1948. Figure is adapted from Williams, Jr. 1981. . . . . . . . . . . . . . . . . . 5

2.1 Map of land ownership across Codington, Deuel, Grant, and Roberts Counties in northeastern South Dakota, USA. White areas within county boundaries indicate privately owned lands. . . . . . . . . . . . . . . . . . . . . . . . . 22

2.2 National Land Cover Database (2016) land cover classes for Codington, Deuel, Grant, and Roberts Counties in northeastern South Dakota, USA . . . . . . . . . . . . . . . . . 23

2.3 Annual survival probability of adult and yearling age-classes of eastern wild turkey hens from February 2017 to April 2019 in northeastern South Dakota, USA. . . . . . . . . . . . 24

2.4 Effect, on the log-odds scale, of the number of consecutive snow-covered days on daily survival probability of eastern wild turkey hens from February 2017 to April 2019 in northeastern South Dakota, USA. . . . . . . . . . . . . . . . . . 25

2.5 Comparison of total snow accumulation $(\mathrm{cm})(\mathrm{A})$ and mean daily air temperature $\left({ }^{\circ} \mathrm{C}\right)$ (B) throughout the winters (1-November through 30-April) observed by Lehman et al. 2001 (1996-1997, 1997-1998), Shields and Flake 2006 (1998-1999, 1999-2000), and "Current Study" (2016-2017, 2017-2018, 2018-2019) in northeastern South Dakota, USA. The 30-year average (1981-2010) total snow accumulation (101.1-cm) and mean daily air temperature $\left(-3.8^{\circ} \mathrm{C}\right)$ in northeastern South Dakota are illustrated by the horizontal, dashed lines (National Climatic Data Center, 2010) . . . . . . . . . . . . . . . . . . 26

2.6 Total precipitation (in the form of rainfall) accumulation during the springs (1-April to 30-June) of 2017 and 2018 in northeastern South Dakota, USA. The 30-year average (19812010) total precipitation accumulation during spring in Milbank, SD, USA (22.1-cm) is indicated by the dashed line (National Climatic Data Center, 2010). 
3.1 Map of the counties included in the Northeast Region of South Dakota, USA (Marshall, Roberts, Day, Grant, Clark, Codington, Deuel, and Hamlin Counties) and the counties included within the study area extent. . . . . . . . . . . . . . . . 55

3.2 Map of land ownership across Codington, Deuel, Grant, and Roberts Counties in northeastern South Dakota, USA. White areas within county boundaries indicate privately owned lands. . . . . . . . . . . . . . . . . . . . . . . . 56

3.3 National Land Cover Database (2016) land cover classes for Codington, Deuel, Grant, and Roberts Counties in northeastern South Dakota, USA. . . . . . . . . . . . . . . 57

3.4 Probability of nesting (A) and re-nesting (B) for yearling and adult eastern wild turkey hens during 2017 and 2018 in northeastern South Dakota, USA. . . . . . . . . . . . . . 58

3.5 Effect of hen weight $(\mathrm{kg})$ on the probability of nesting $(\mathrm{A})$ and re-nesting $(\mathrm{B})$ for yearling and adult eastern wild turkey hens during 2017 and 2018 in northeastern South Dakota,

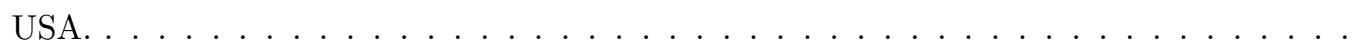

3.6 Probability of survival over a 28-day incubation period for nests laid by yearling and adult eastern wild turkey hens during 2017 and 2018 in northeastern South Dakota, USA. . . .

3.7 Effect, on the log-odds scale, of temperature $\left({ }^{\circ} \mathrm{C}\right)$ on days without precipitation (A) temperature on days with precipitation (B) precipitation $(\mathrm{mm})$ on cool days $(\mathrm{C})$ and precipitation on warm days (D) on daily nest survival probability for nests laid by eastern wild turkey hens during 2017 and 2018 in northeastern South Dakota, USA. Daily nest survival probability was lowest when the mean daily temperature was $19.2^{\circ} \mathrm{C}$ on days without precipitation $(\mathrm{A})$ and $24.8^{\circ} \mathrm{C}$ on days with precipitation $(\mathrm{B}) \ldots \ldots$. . . . . . 61

3.8 Effect, on the log-odds scale, of distance from the nearest road ( $\mathrm{m}$ ) on daily nest survival probability for nests laid by eastern wild turkey hens during 2017 and 2018 in northeastern South Dakota, USA. . . . . . . . . . . . . . . . . . . . . . 62

3.9 Mean clutch size for first and second nest attempts made by yearling and adult eastern wild turkey hens during 2017 and 2018 in northeastern South Dakota, USA. . . . . . . . . 63

3.10 Hatchability of eggs for all successful nest attempts made by yearling and adult eastern wild turkey hens during 2017 and 2018 in northeastern South Dakota, USA. . . . . . . . . 64

3.11 Probability of survival for poults over the 28-day post-hatch interval for broods reared by yearling and adult eastern wild turkey hens during 2017 and 2018 in northeastern South Dakota, USA . . . . . . . . . . . . . . . . . . . 65

3.12 Effect, on the log-odds scale, of brood age (number of days post-hatch) (A), age of the brood-rearing hen (B), daily rainfall accumulation $(\mathrm{mm})(\mathrm{C})$, and year of the study (D) on daily survival probability of eastern wild turkey poults during 2017 and 2018 in northeastern South Dakota, USA. . . . . . . . . . . . . . . . . . . 66 
3.13 Total precipitation accumulation during the springs (1-April to 30-June) of 2017 and 2018 in northeastern South Dakota, USA. The 30-year average (1981-2010) total precipitation accumulation during spring in Milbank, SD, USA $(22.1-\mathrm{cm})$ is indicated by the dashed line (National Climatic Data Center, 2010).

4.1 Map of land ownership across Codington, Deuel, Grant, and Roberts Counties in northeastern South Dakota, USA. White areas within county boundaries indicate privately owned lands. . . . . . . . . . . . . . . . . . . . . . . . 80

4.2 National Land Cover Database (2016) land cover classes for Codington, Deuel, Grant, and Roberts Counties in northeastern South Dakota, USA. . . . . . . . . . . . . . . . 81

4.3 Posterior density of asymptotic population growth rates $(\lambda)$ for the population of eastern wild turkey hens in northeastern South Dakota, USA from February 2017 to April 2019. The vertical, dashed line indicates the mean value of $\lambda( \pm 95 \%$ credible interval). Values $<1$ indicate declining abundance, whereas values $>1$ indicate increasing abundance. . . . 82

4.4 Realizations of estimated asymptotic population growth rates $(\lambda)$ of eastern wild turkey hens as a function of survival rates of juvenile (A), yearling (B), and adult (C) hens from February 2017 to April 2019 in northeastern South Dakota, USA. Scatter plots are based on 3,000 random realizations of estimated vital rates. . . . . . . . . . . . . . . . 83

4.5 Realizations of estimated asymptotic population growth rates $(\lambda)$ of eastern wild turkey hens as a function of fecundity rates of yearling (A) and adult (B) hens from February 2017 to April 2019 in northeastern South Dakota, USA. Scatter plots are based on 3,000 random realizations of estimated vital rates. . . . . . . . . . . . . . . . . . . . 8 84

4.6 Realizations of estimated asymptotic population growth rates $(\lambda)$ of eastern wild turkey hens as a function of lower-level reproductive parameters of yearling and adult hens during the nesting seasons of 2017 and 2018 in northeastern South Dakota, USA. Scatter plots are based on 3,000 random realizations of estimated vital rates. . . . . . . . . . . . .

4.7 Realizations of estimated asymptotic population growth rates $(\lambda)$ of eastern wild turkey hens as a function of the survival of poults in broods reared by yearling (A) and adult (B) hens during the brood-rearing seasons of 2017 and 2018 in northeastern South Dakota, USA. Scatter plots are based on 3,000 random realizations of estimated vital rates. . . . . 86

4.8 Number of hunting licenses sold, number of wild turkey hunting tags sold, number of wild turkeys harvested, and apparent hunter harvest success (\%) during the Spring Prairie Turkey Firearm seasons from 1985-2016 in South Dakota, USA. Figure is adapted from Huxoll 2016). . . . . . . . . . . . . . . . . . . . . . . . . 87 


\section{Chapter 1}

\section{Introduction}

The wild turkey (Meleagris gallopavo) is an economically and culturally important game species across its range. Historical records of the wild turkey in North America show that turkey populations extended as far north as southern Maine, southern Ontario, and central South Dakota, as south as central Mexico, and as west as central Arizona in the United States and the Pacific Ocean in Mexico (Williams, Jr., 1981) (Figure 1.1). When Europeans first arrived in America, wild turkeys were abundant and immediately became an important source of food (Williams, Jr., 1981). The turkey became a symbol for the Thanksgiving feast and was highly regarded (Williams, Jr., 1981). During the 1800s, a sizable commercial market for the wild turkey had been created, and subsequent overexploitation of entire populations for food eliminated the wild turkey from large portions of its range (Williams, Jr., 1981).

The lowest wild turkey numbers in the U.S. were reached between 1900 and 1950 (Williams, Jr., 1981). By the 1940s, wild turkey populations only inhabited about $12 \%$ of their original range in the eastern United States, and by 1948 turkeys had been extirpated from 15 states (Williams, Jr., 1981) (Figure 1.2). Since the 1950s, there has been an extensive effort to restore wild turkey populations in the United States and Canada (Williams, Jr., 1981). Due to many successful reintroductions and introductions, wild turkeys have returned to much of their historical range and new populations have been established outside of their original range (Williams, Jr., 1981).

There are 6 recognized subspecies of wild turkey across North America-Eastern (M. g. silvestris), Florida (M. g. osceola), Rio Grande (M. g. intermedia), Merriam's (M. g. merriami), Gould's (M. g. mexicana), and south Mexican (M.g. gallopavo) (Stangel et al., 1992). While subspecies are often viewed as discrete and separate entities, the exact boundaries of subspecies' ranges are subjective as interbreeding commonly occurs (Williams, Jr., 1981; Stangel et al., 1992). Wild turkeys require a combination of trees and grassland throughout their lifetime (Williams, Jr., 1981; Porter, 1992). Trees provide food, daytime resting and escape cover, and nighttime roosting areas (Porter, 1992). Grasslands provide nesting cover and are an important foraging environment for poults searching for insects (Porter, 1992). 
The eastern wild turkey is the most widespread of all of the subspecies of wild turkey and occupies a range of diverse habitats (Williams, Jr., 1981; Porter, 1992). The original range of the eastern wild turkey extended from northern Florida to South Dakota where forested riparian corridors provided adequate cover and permanent water (Schorger, 1966) (Figure 1.1). While the original range of eastern wild turkeys in South Dakota is unknown, the last known populations occupied southeastern South Dakota and extended as far northwest as the mouth of the Cheyenne River (Mosby, 1975). Wild turkeys were extirpated from South Dakota by the early 1900s (Over and Thoms, 1921).

In 1948, reestablishment of wild turkeys in South Dakota began with introductions of Merriam's wild turkeys to the Black Hills region (Peterson and Richardson, 1975). In the late 1940s and 1950s, populations of both Merriam's and Rio Grande wild turkeys were introduced into the western, southcentral, and eastern parts of South Dakota (Peterson and Richardson, 1975; Knupp, 1990). Rio Grande, Merriam's, and hybrid populations introduced in eastern South Dakota failed to maintain adequate numbers and were causing livestock feed depredation issues (Lehman, 1998).

In the 1990s, eastern wild turkeys were reintroduced into southeastern South Dakota along the James River and into northeastern South Dakota where there were established populations of Rio Grande and hybrid wild turkeys (Leif, 2001; Lehman, 1998). Because eastern wild turkeys were historically the only subspecies of turkey with established populations in South Dakota (Williams, Jr., 1981), Lehman (1998) determined that this subspecies was most likely better adapted to conditions in northeastern South Dakota than Rio Grande and hybrid wild turkeys. In 1999, another population of eastern wild turkeys was translocated to Grant County, South Dakota in an effort to further establish a sustainable population of wild turkeys in the northeastern part of the state (Shields, 2001).

Establishment of a growing population of eastern wild turkeys in Grant County, South Dakota appeared to be successful in the years immediately following reintroduction (Shields, 2001); however, recent harvest trends suggest declining abundance in the region. Harvest of wild turkeys during the spring prairie turkey season declined from a high of 5,809 males in 2010 down to 2,482 males in 2016 (Huxoll, 2016). Spring turkey hunting generates roughly $\$ 6.5$ million annually for South Dakota and spring prairie hunting generates nearly $\$ 3$ million for local economies (Flake et al., 2006). Over one third of the spring male harvest in the northeastern region occurs in Grant County, making wild turkeys an economically and culturally important resource for hunters in the area (Huxoll, 2016).

The cause of the apparent decline in eastern wild turkey abundance in northeastern South Dakota is unclear. The northeastern region has seen extensive land-use changes since eastern wild turkeys were introduced to the area. Many Conservation Reserve Program (CRP) grasslands have been converted to row-crop agriculture, which could potentially have negative effects on the availability of nesting and brood-rearing habitat (Porter, 1992; Reitsma et al., 2013). Hen, nest, and brood survival may be negatively affected by the abundance of precipitation that occurs in late winter and during the spring and 
summer nesting and brood-rearing seasons (42-cm, $\sim 70 \%$ of the annual precipitation, National Climatic Data Center 2010; Lehman 1998; Lehman et al. 2007, 2008b).

Estimates of demographic rates can be used to determine the overall stability of a population. For populations of wild turkeys, demographic rates of interest include estimates of age-specific annual and seasonal survival and cause-specific mortality rates. Age-specific measures of productivity, such as nesting rate, re-nesting rate, nest survival, clutch size, hatchability, and poult survival, are important for determining the reproductive contribution of adult and yearling hens to the population. Measures of productivity can be combined with young-of-the-year juvenile hen survival to estimate recruitment of hens into the breeding population (i.e., fecundity).

Demographic rates can be combined into matrix projection models to determine if a population is growing, declining, or stable (Caswell, 2001). The population growth rate $(\lambda)$ provides insight into the status of a population and informs managers if management activities are, or are not, having the desired effect on the population. Perturbation analyses, such as calculating elasticities and performing a life-stage simulation analysis (LSA), can be used to determine which matrix elements or lower-level demographic rates have the greatest effect on the population growth rate to help guide management decisions (Wisdom et al., 2000; Caswell, 2001). For example, if measures of productivity, such as nest and brood survival, have the greatest effect on population growth, managers can concentrate efforts on improving productivity to have the largest impact on the population growth rate.

In the chapters that follow, I discuss factors influencing survival, productivity, and population growth of the eastern wild turkey population in northeastern South Dakota. First, I discuss the estimation of hen survival rates from field-collected data as a function of environmental and intrinsic (i.e., hen age, study year) variables. I determine which factors have an influence on hen survival and if those effects improve or impair survival. I also calculate estimates of age-specific annual survival. Next, I discuss the estimation of productivity rates from field-collected data. Specifically, I calculate age-specific estimates of nesting rate, nest survival, re-nesting rate, clutch size, hatchability, and poult survival as a function of environmental, spatial, and intrinsic variables.

Finally, I calculate estimates of age-specific fecundity from productivity parameters and combine estimates of fecundity and survival into a matrix projection model. From the matrix projection model, I estimate the finite rate of population change $(\lambda)$ to determine if the population is growing, declining, or stable. I perform perturbation analyses to assess which matrix elements and lower-level vital rates have the greatest effect on the population growth rate. This assessment of the demographic performance of the eastern wild turkey population in northeastern South Dakota is necessary to inform management activities and harvest regulations for this economically important game species. 


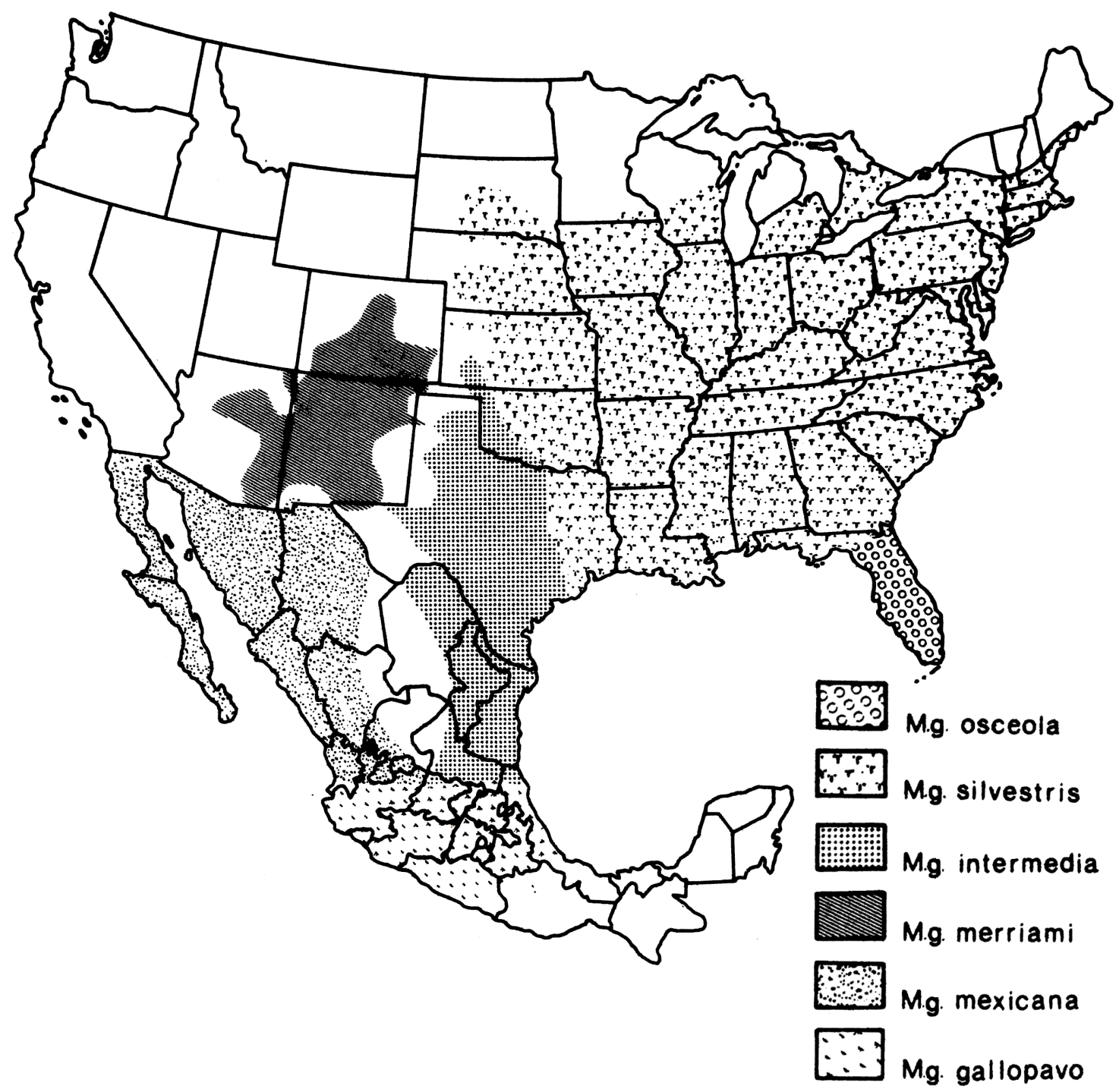

Figure 1.1: The range of the wild turkey about the time Europeans arrived. Figure is adapted from Williams, Jr. 1981. 




Figure 1.2: The range of the wild turkey in the United States at its lowest ebb-1948. Figure is adapted from Williams, Jr. 1981. 


\title{
Chapter 2
}

\section{Factors Influencing Survival of}

\section{Eastern Wild Turkey Hens in}

\section{Northeastern South Dakota}

\begin{abstract}
The population of eastern wild turkeys (Meleagris gallopavo silvestris) in northeastern South Dakota appeared to be expanding soon after reintroduction in the 1990s, however, recent harvest trends suggest declining abundance in the region. Spring turkey hunting expenditures are projected to be around $\$ 6.5$ million in South Dakota, with about $\$ 3$ million of those expenditures occurring within the northeastern prairie region. However, the number of birds harvested during the spring prairie firearm season has been declining since 2010. Due to concerns about a declining population, the autumn hunting season was closed in 2014. The cause of the apparent decline is unclear. Updated information about the factors influencing hen survival is needed to assess the status of the population of wild turkeys in northeastern South Dakota and to determine the most effective management strategies for increasing abundance across the region. I captured and radio-marked 80 eastern wild turkey hens (37 yearling and 43 adult) in Grant County, South Dakota during the winter of 2017, and I radio-marked an additional 41 yearling hens during the winter of 2018. I monitored radio-marked hens for survival from February 2017 to April 2019. I used Bayesian methods to model daily hen survival probability as a function of covariates. Annual survival did not differ between age-classes and was $62.0 \%$ for yearling and $62.9 \%$ for adult hens, respectively. While the amount of snowfall observed during this study period was greater than the 30year average, I observed a positive relationship between the number of consecutive days with snow on the ground and daily survival probability of hens. Coyotes are the main predators of wild turkeys in
\end{abstract}


this area. I hypothesized that snow cover reduces the effectiveness of coyotes to capture wild turkeys because winter flocking behavior leads to increased vigilance and coyotes are highly visible against a white, snow-covered background. The annual survival estimate from this study was lower than previous estimates of annual survival from this study area, suggesting that a reduction in hen survival could be the source of the suspected decline in abundance in northeastern South Dakota. Improving eastern wild turkey hen survival in northeastern South Dakota should increase abundance of wild turkeys and improve hunting opportunities in the region.

\section{$2.1 \quad$ Introduction}

Estimates of survival, combined with estimates of productivity, can provide insight into the status of a population. Accurate estimates of survival are important for determining the proportion of a population that is lost over a period of time. Annual survival estimates can be incorporated into matrix projection models to determine if a population is growing, declining, or stable (Caswell, 2001). Across the range of eastern wild turkeys, annual survival is an important factor influencing population growth (Suchy et al., 1983; Vangilder and Kurzejeski, 1995; Rolley et al., 1998; Alpizar-Jara et al., 2001). Low survival rates decrease the number of individuals available to breed and can reduce recruitment into the breeding population (Suchy et al., 1983; Vangilder and Kurzejeski, 1995; Rolley et al., 1998; Alpizar-Jara et al., 2001).

Survival of eastern wild turkeys is influenced by a variety of factors. The effect of hen age and time of year (i.e., season) on survival probability has been studied extensively in the past (Vander Haegen et al., 1988; Roberts et al., 1995; Vangilder and Kurzejeski, 1995; Wright et al., 1996; Hubbard et al., 1999a; Lehman et al., 2001; Shields and Flake, 2006; Kane et al., 2007; Pollentier et al., 2014b). Additionally, climate, in the form of severe winter weather - extended periods of time with cold temperatures - and excessive rainfall during the spring and summer, impact hen survival (Austin and DeGraff, 1975; Wunz and Hayden, 1975; Porter, 1977, 1978; Porter et al., 1980; Healy, 1992; Haroldson et al., 1998; Lehman et al., 2001; Shields and Flake, 2006; Kane et al., 2007).

A long-standing assumption is that, at the northern edge of their range, distribution of wild turkeys is limited by the severity of winter and the presence of available roosting habitat (Williams, Jr., 1981; Porter, 1992). Schorger (1966) noted that the historic northern limit of the range of wild turkeys "ebbed and flowed" depending on winter severity. Persistent, deep snow-cover can make finding food difficult, by not only covering up on-the-ground food sources, but by making movement energetically expensive and therefore limiting foraging ability (Austin and DeGraff, 1975; Porter, 1977, 1978; Healy, 1992). Prolonged periods of time with turkeys expending more energy foraging than they are able to consume can lead to starvation (Austin and DeGraff, 1975; Wunz and Hayden, 1975; Porter et al., 1980). However, 
recent evidence suggests that eastern wild turkeys may tolerate harsh winter conditions better than other subspecies, allowing them to occupy areas north of other subspecies' ranges (Lehman et al., 2001).

Haroldson et al. (1998) determined that the metabolic rate of wild turkeys increased with decreasing air temperature when air temperatures were lower than $10.9^{\circ} \mathrm{C}$. Therefore, hens have to increase their daily intake of food to meet the thermo-regulatory demands brought on by cold temperatures (Haroldson et al., 1998). If turkeys are unable to consume enough food to meet the energetic demands of thermoregulating at cold temperatures, starvation can occur (Haroldson et al., 1998).

Some studies report lowest seasonal survival during the autumn (Shields and Flake, 2006), while other studies found lowest survival during periods associated with reproduction (i.e., spring and summer) (Vander Haegen et al., 1988; Roberts et al., 1995; Vangilder and Kurzejeski, 1995; Wright et al., 1996; Lehman et al., 2001; Pollentier et al., 2014b). Several studies attribute low survival rates during the nesting and brood-rearing seasons to high levels of predation, as hens are especially vulnerable to mammalian predators while spending time on the ground incubating nests and tending to pre-flight offspring (Vander Haegen et al., 1988; Kurzejeski et al., 1987; Roberts et al., 1995; Wright et al., 1996; Lehman et al., 2001; Pollentier et al., 2014b). The high spring survival rate found by Humberg et al. (2009) was attributed to high rates of nest loss, which prevented hens from incubating and brood-rearing. Additionally, Vangilder and Kurzejeski (1995) did not observe substantial hen mortality associated with nesting and brood-rearing. Instead, the low spring survival rates were attributed to the breakup of winter flocks and subsequent shifts to spring home ranges (Vangilder and Kurzejeski, 1995).

For populations of wild turkeys in the Midwest, it is not uncommon for adult and yearling age-classes of eastern wild turkeys to exhibit similar survival probabilities (Roberts et al., 1995; Vangilder and Kurzejeski, 1995; Wright et al., 1996; Hubbard et al., 1999a; Shields and Flake, 2006; Kane et al., 2007; Delahunt, 2011; Pollentier et al., 2014b). However, for a population in Massachusetts, Vander Haegen et al. (1988) reported higher rates of annual survival for adult hens than for yearling hens. It has been hypothesized that yearling survival rates may be lower than adult survival rates because yearling hens are known to disperse farther than adults (Vander Haegen et al., 1988), and dispersal often leads to increased risk of predation (Johnson and Gaines, 1990).

Precipitation can have negative effects on hen survival because mammalian predators (i.e., coyotes, red fox) use olfactory cues to locate nests (Storaas, 1988). There is evidence to suggest that incubating hens are more easily located by predators during wet periods (Roberts et al., 1995; Roberts and Porter, 1998b; Lehman et al., 2008b).

Mammalian predation is widely reported as a major source of wild turkey mortality (Porter, 1978; Kurzejeski et al., 1987; Lehman et al., 2001; Leif, 2001; Shields and Flake, 2006; Humberg et al., 2009; Restani et al., 2009; Pollentier et al., 2014b). Avian predation (Lehman et al., 2001; Shields and Flake, 2006; Pollentier et al., 2014b), intestinal infections or disease (Leif, 2001; Pollentier et al., 2014b), and 
weather (Lehman et al., 2001; Pollentier et al., 2014b) have also been noted as sources of turkey mortality in the Midwest. Human-caused mortality, in the form of hunter harvest (legal and illegal, Kurzejeski et al. 1987; Pollentier et al. 2014b), hay-mowing equipment (Leif, 2001; Shields and Flake, 2006; Pollentier et al., 2014b), and vehicle collisions (Kurzejeski et al., 1987; Shields and Flake, 2006; Pollentier et al., $2014 b$ ), are also common sources of mortality.

Two previous studies examined eastern wild turkey survival in northeastern South Dakota since their reintroduction in 1990 (Lehman, 1998; Shields, 2001). The first study, conducted from 1996-1998 by Lehman (1998), determined that hen survival was lowest during the spring-summer (i.e., due to high mortality while nesting and brood-rearing) and highest during the autumn. Lehman (1998) also found that hen survival during winter increased when hens had access to supplemental food sources. The second study, conducted from 1999-2000 by Shields (2001), determined that hen survival did not differ by hen age-class, study year, or season. The survival rates published by Shields (2001) were some of the highest survival rates reported for eastern wild turkey hens in the Midwest at that time. These high survival rates gave the impression that the population of eastern wild turkeys in northeastern South Dakota was steadily growing.

Establishment of a growing population of eastern wild turkeys in northeastern South Dakota appeared to be successful in the years immediately following reintroduction (Shields, 2001); however, recent harvest trends suggest an apparent decline in abundance in the region. Harvest of wild turkeys during the spring prairie turkey season declined from a high of 5,809 males in 2010 down to 2,482 males in 2016 (Huxoll, 2016). The cause of the apparent decline in eastern wild turkey abundance in northeastern South Dakota is unclear.

Since it has been documented that survival of wild turkey hens has a strong influence on population growth of eastern wild turkeys across their range (Suchy et al., 1983; Vangilder and Kurzejeski, 1995; Rolley et al., 1998; Alpizar-Jara et al., 2001), there is a need to update the survival rate information for eastern wild turkeys in northeastern South Dakota. The objectives of this study are to: (1) determine the effect of intrinsic (i.e., hen age, study year) and environmental covariates on daily survival probability; (2) estimate annual survival probabilities for adult and yearling age-classes; and (3) determine the leading causes of mortality of eastern wild turkey hens in northeastern South Dakota. I hypothesize that daily survival probability will be negatively related to snow-depth and the persistence of snow cover; will be negatively related to precipitation; will be positively related to temperature; will be lowest during the spring and summer seasons; and will not differ between age-classes and years of the study. Based on the results of this study, I will suggest management recommendations that could improve survival of eastern wild turkey hens in northeastern South Dakota. 


\section{$2.2 \quad$ Study Area}

The study was conducted in Codington, Deuel, Grant, and Roberts counties in northeastern South Dakota. The study area was split between the Minnesota River-Red River Lowland in the eastern half of the study area and Coteau des Prairies physiographic region in the western half (Flint, 1955; Johnson et al., 1995). The Coteau begins in the northwest and extends in a southeasterly direction across the study area (Miller et al., 1979). On top of the Coteau, the relief is gently undulating to hilly while down in the Lowlands the land is nearly level (Flint, 1955; Miller et al., 1979). Elevations ranged from over 600-m above mean sea level on top of the Coteau to about 300-m above sea level in the Lowland (Miller et al., 1979). Most of the study area consisted of privately owned lands with some state owned (e.g. Game Production Areas) and federally owned (e.g. Waterfowl Production Areas) lands scattered throughout (Figure 2.1). The Lake Traverse Indian Reservation overlaps the western and northern extent of the study area where tribally owned lands are common (Figure 2.1).

Northeastern South Dakota is in a humid continental climate region, with mean annual precipitation of $61-\mathrm{cm}$ and mean annual temperature of $6.4^{\circ} \mathrm{C}$ across the study area (National Climatic Data Center, 2010). Average seasonal snowfall for the region is 101-cm, and, on average, there are 17 days of at least 5 -in. $(\sim 13-\mathrm{cm})$ of snow on the ground, but the number of snow-covered days varies greatly from year to year (National Climatic Data Center, 2010). Snow can accumulate up to half a meter in depth during the winter months; however, snow depth is often variable across the study area as wind creates deep snow-drifts as well as wind-swept areas (Miller et al., 1979).

Agriculture dominates the land use in the study area, with most land being used for either cropland, rangeland, or to grow alfalfa or hay for livestock feed (Miller et al., 1979) (Figure 2.2). Most of the grain farming (i.e., corn and soybeans) occurs in the Lowland (Miller et al., 1979). The highlands of the Coteau support native tallgrass prairie which is used primarily for rangeland; however, scattered fields of hay and alfalfa are located in the highlands as well (Miller et al., 1979) (Figure 2.2). Common grasses include warm-season grasses such as big bluestem (Andropogon gerardii), little bluestem (Schizachyrium scoparium), Indiangrass (Sorghastrum nutans), switchgrass (Panicum virgatum), and sideoats grama (Bouteloua curtipendula) (Johnson and Larson, 2007). Common cool-season grasses include smooth brome (Bromus inermis), Kentucky bluegrass (Poa pratensis), western wheatgrass (Pascopyrum smithii), and green needlegrass (Stipa viridula) (Johnson and Larson, 2007). Numerous forbs and patches of western snowberry (Symphoricarpos occidentalis) are scattered throughout the pasture-lands (Johnson and Larson, 2007). Forested areas along the east-facing breaks where the Coteau descends into the Lowlands are dominated by bur oak (Quercus macrocarpa) on the drier slopes (Leatherberry et al., 2000) (Figure 2.2). More mesic areas are dominated by elm-ash (Fraxinus spp.; Ulmus spp.) forests (Leatherberry et al., 2000) that are intermixed with trembling aspen (Populus tremuloides), box elder (Acer negundo), eastern cottonwood (Populus deltoides), and sugar maple (Acer saccharum) (Knupp 
Moore and Flake, 1994).

Potential predators of wild turkey hens within the study area included several mammalian species, such as coyote (Canis latrans) and red fox (Vulpes vulpes) (Flake et al., 2006; Lehman et al., 2007). Wild turkeys are also at risk of avian predation due to the presence of bald eagles (Haliaeetus leucocephalus), golden eagles (Aquila chrysaetos), and great-horned owls (Bubo virginianus) (Lehman, 1998; Flake et al., 2006; Lehman et al., 2007).

\subsection{Methods}

\subsubsection{Capture and Radio-Telemetry}

I located flocks of eastern wild turkeys during the winter (1 Jan-31 Mar) of 2017 and 2018 by searching for signs of turkeys (i.e., scat, feathers, tracks) near forested riparian corridors commonly used for roosting. I scouted for turkey flocks in the morning and evening during peak foraging hours in order to spot flocks out in open habitats (i.e., row-crop agricultural fields). I also communicated with landowners in the area to determine if they had seen flocks of turkeys on their property recently. Once I determined the location of a flock, and secured the proper permissions from the landowner, I baited turkeys into capture locations with corn and sunflower seeds spread out over bales of straw. I set up a trail camera at each bait site to determine if wild turkey hens were visiting the bait pile and which times of day the hens were visiting the bait pile. Once hens were regularly visiting the bait pile, I set up capture equipment at the bait site.

I captured wild turkeys using rocket nets (Thompson and Delong, 1967; Wunz, 1984). Following capture, I aged female turkeys as adult ( $>1$ year old) or yearling ( $<1$ year old) based on presence or absence of barring on the 9th and 10th primary feathers (Williams, Jr., 1961) and weighed birds to the nearest $0.1 \mathrm{~kg}$. I secured 80-g very high frequency (VHF) radio telemetry transmitters (Advanced Telemetry Systems, Isanti, MN, USA) using a shock cord harness and backpack-mount. Transmitters were $<3 \%$ of the hens' body weight to reduce the risk of the transmitter interfering with survival and reproduction (Fair et al., 2010). Transmitters were equipped with an activity signal, short-term nonmoving signal, and mortality signal set to activate after 8 hours of inactivity. I used R-1000 telemetry receivers (Communications Specialists, Orange, CA, USA) to listen to the signals from radio-marked wild turkeys. I monitored turkeys at 7 and 10 days post-capture to observe any possible capture-related mortality events and on a monthly basis until April 1st. I monitored turkeys 6 days per week during the spring and summer (1 Apr-31 Jul); however, turkeys that were incubating nests were monitored daily. I monitored turkeys monthly during the autumn and winter (1 Aug-31 Mar). When a mortality signal was detected, I located the transmitter and determined the cause-of-death. Cause-of-death was determined based on the condition of the carcass (if found), the condition of the transmitter, and any available sign 
around the area where the transmitter was located. If a cause-of-death could not be confidently assigned, I designated the cause as "unknown." All handling, marking, and monitoring procedures were approved by the Animal Care and Use Committee (Permit No. 1606003205; South Dakota State Permit 37).

\subsubsection{Modeling Survival Probability}

I assumed survival of individual $i$ during day $t$ was a Bernoulli random variable:

$$
y_{i t} \sim \operatorname{Bernoulli}\left(y_{i(t-1)} p_{i t}\right)
$$

where $y_{i t}=1$ if an individual $i$ survived day $t, y_{i t}=0$ if an individual $i$ died during day $t$, and where $p_{i t}$ represented daily survival probability (Royle and Dorazio, 2008). I further assumed a logit-linear model for daily survival probability which I model as a function of age-class (adult or yearling), year of the study (2017-2018 or 2018-2019), season (winter: 1-Jan to 31-Mar, spring: 1-Apr to 30-Jun, summer: 1-Jul to 30-Sep, or autumn: 1-Oct to 31-Dec), incubating or not incubating, daily rain accumulation (mm; hereafter "precipitation"), daily mean temperature $\left({ }^{\circ} \mathrm{C}\right.$; hereafter "temperature"), depth of snow on the ground each day (mm; hereafter "snow-depth"), and number of consecutive days with $>3$-cm of snow on the ground (hereafter "consecutive snow-covered days"). I modeled interactions between temperature and season, precipitation and season, and snow-depth and consecutive snow-covered days. Hens occupying the "yearling" age class during the first year of the study transitioned to the "adult" age class on April 1, 2018 (Lehman et al., 2001). Consecutive snow-covered days only included days with at least $3-\mathrm{cm}$ of snow on the ground because snow less than 3-cm in depth was not accurately detectable by the weather station (i.e., we assumed 0 snow cover when there was $<3-\mathrm{cm}$ standing snow). Data for the environmental covariates (e.g. precipitation, temperature, snow-depth, and consecutive snow-covered days) were retrieved from the National Climactic Data Center's archive of weather data via Climate Data Online (CDO) (National Climatic Data Center, 2010). The covariate data was downloaded from one weather station in Milbank, South Dakota (Latitude: $45.2266^{\circ}$, Longitude: $-96.6233^{\circ}$, Elevation: 384.1m) whose period of record covered $100 \%$ of the duration of this study. While environmental covariates may vary over the study area due to changes in micro-climate, I assumed the information gathered from the weather station was generally representative of conditions observed each day.

I start capture days for all individuals at time $t=0$ and began modeling survival probability at 1 day post-capture at time $t=1$. I accounted for repeated observations on individual nests by fitting a random coefficients model (Hobbs and Hooten, 2015). I assumed each coefficient $\beta_{j i}$ was a Gaussian random variable:

$$
\beta_{j i} \sim \operatorname{Gaussian}\left(\mu_{j}, \tau_{j}\right)
$$


where $\mu_{j}$ and $\tau_{j}$ represented the population-level mean and variance, respectively, of the model coefficients $j$ for each individual $i$.

I fit this model using Bayesian methods. I assumed a flat prior distribution for the population-level mean of the intercept coefficient and assumed logistic $(0,1)$ prior distributions for the population-level means of all other slope coefficients. I selected inverse gamma $(1,1)$ prior distributions for precision parameters $\tau_{j}$, which provided little prior information. I fit this model with JAGS version 4.3.0 (Plummer, 2003) via the jagsUI version 1.4.9 interface (Kellner, 2018) in program $\mathrm{R}$ version 3.5.1 (R Core Team, 2018). I ran 3 chains for each model using trace plots to determine an adequate burn-in period and subsequently ran models until I achieved reasonable convergence ( $\hat{R} \leq 1.1$; Gelman et al. 2013). If the $95 \%$ credible interval (CI) for the population-level log-odds ratio (LOR) for a model covariate or interaction did not overlap 0 , I concluded that the covariate had an effect on daily survival probability.

\subsection{Results}

I captured 43 adult and 37 yearling wild turkey hens during the winter of 2017 and an additional 42 yearling wild turkey hens during the winter of 2018 to replace birds lost during the first year of the study. Eight yearling hens captured during the first year of the study transitioned to the adult age-class for the second year of the study. Survival probabilities were estimated from a total of 122 wild turkeys and were comprised of 776 daily intervals from February 16, 2017 through April 2, 2019 for a total of 41,574 days where an individual turkey was at risk of death. Annual survival probability for adult hens was $0.629(95 \% \mathrm{CI}=0.494,0.757)$ and did not differ from yearling hens $(0.620 ; 95 \% \mathrm{CI}=0.488,0.743)$ (Figure 2.3).

The number of consecutive snow-covered days had a positive effect on daily survival probability (Table 2.1; Figure 2.4). Daily survival probability did not vary between age-classes, seasons, or years of the study and was not affected by whether or not a hen was incubating a nest (Table 2.1). Daily survival probability was not affected by precipitation, temperature, or snow-depth (Table 2.1).

Of the 75 mortality events during the study period, the leading cause of death was mammalian predation $(n=39 ; 52 \%)$. Being caught up in haying equipment while incubating a nest $(n=7 ; 9 \%)$ was the second-greatest cause of mortality (Table 2.2). Other causes included avian predation, disease, legal harvest (bearded hens only), vehicle collisions, euthanization, and capture-related causes (Table 2.2). A cause of death could not be confidently assigned to 12 mortality events (Table 2.2). Most of the mortality events designated as "unknown" occurred during the fall and winter when, due to monitoring the hens for survival on a monthly basis, a mortality signal could have been detected several weeks after the mortality event occurred. 


\subsection{Discussion}

Annual survival estimates during this study period (approximately $62 \%$ for both age-classes) were lower than estimates of annual survival for recently translocated populations of eastern wild turkeys in eastern (Leif, 2001) and northeastern South Dakota (Lehman et al., 2001; Shields and Flake, 2006) (Table 2.3). Additionally, annual survival during this study was lower than established populations of eastern wild turkeys in southcentral Iowa (Hubbard et al., 1999a), northern Indiana (Humberg et al., 2009), and southern Illinois (Delahunt, 2011) (Table 2.3). In Chapter 4, I determined that this population of eastern wild turkeys is most greatly affected by variation in adult hen survival. Since these annual survival estimates are lower than previous estimates from northeastern South Dakota, and some other established populations in the Midwest, hen survival could be driving the apparent population decline.

Newly translocated populations of wild turkeys often experience a period of growth after introduction when densities are low and as birds expand from the introduction site into nearby suitable habitats (Porter, 1978; Vangilder et al., 1987; Wright et al., 1996). The high annual survival rates for the newly introduced populations of eastern wild turkeys in eastern and northeastern South Dakota are typical of an expanding population of wild turkeys (Lehman et al., 2001; Leif, 2001; Shields and Flake, 2006). While these estimates of annual survival are lower than previous estimates from expanding populations in northeastern South Dakota (Lehman et al., 2001; Shields and Flake, 2006), they are greater than some other estimates from expanding, and established, populations in the Midwest (Porter, 1978; Kurzejeski et al., 1987; Wright et al., 1996; Kane et al., 2007; Switzer and Tucker, 2009; Pollentier et al., 2014b) (Table 2.3).

While there is evidence in the literature to suggest that severe winter weather-extended periods of deep snow and cold temperatures - has deleterious effects on wild turkey survival (Porter et al., 1983; Austin and DeGraff, 1975; Wunz and Hayden, 1975), this study did not illustrate those effects. On average, total snow accumulation observed during this study was greater than the 30-year average (Figure 2.5). However, I did not observe any "winter-related" causes of mortality, such as starving or freezing to death (Table 2.2). The leading cause of mortality during the study period was mammalian predation; however, only 7 of the 37 mammalian predation events occurred during the autumn and winter (Table 2.2) and even fewer occurred while there was snow on the ground.

The positive effect of persistent snow-cover (i.e., number of consecutive snow-covered days) can potentially be attributed to decreased effectiveness of mammalian predators, specifically coyotes, of capturing live-prey when there is snow on the ground. Snow makes locomotion more difficult and energetically costly for coyotes, forcing them to travel slowly over long distances to find food (Crête and Larivière, 2003). Because it is energetically costly to move quickly to capture live-prey, coyotes often switch to feeding on primarily carrion during winter months (Sperry, 1934; Ozoga and Harger, 1966; Bekoff and Wells, 1980; Patterson et al., 1998; Gese et al., 1996). Spears et al. (2003) published observations that 
provide evidence to suggest that winter flocking behavior provides turkeys with a detection and deterrent system to facilitate escape from predation when confronted by coyotes. Turkey flocks were observed engaging in mobbing behavior to deter coyotes from attacking the flock (Spears et al., 2003). Not only does flocking behavior provide the numbers to intimidate predators, but flocking behavior leads to increased vigilance as there are more eyes around to detect predators (Spears et al., 2003). In addition to increased vigilance, when there is limited vegetative cover and a blanket of white snow on the ground, the tawny coat of coyotes becomes highly visible in open agricultural landscapes, making coyotes easily detectable by wintering flocks of turkeys (Deelen and Gosselink, 2006). Because snow cover leads to decreased effort on behalf of coyotes to capture live-prey, and because snow makes coyotes highly visible to flocks of wild turkeys, the threat of mammalian predation in this study area may be decreased during periods of snow-leading to a positive effect of persistent snow-cover on wild turkey survival (Figure 2.4).

The belief that severe winter weather has deleterious effects on turkey survival exists because, historically, the northern limit of the wild turkey range was dictated by the presence of persistent, deep snow and limited available winter food sources (Schorger, 1966). However, due to widespread increases in the production of cultivated crops (i.e., corn and soybeans) over the last decade, waste grain left in agricultural fields after harvest has become prevalent and provides a reliable source of food for wild turkeys during the winter months (Porter et al., 1980; Healy, 1992; Lehman et al., 2001; Shields and Flake, 2006; Kane et al., 2007). The presence of widely available supplemental food sources may offset the negative effects of severe winter conditions or mast failures (Porter et al., 1980; Healy, 1992). Because of this, Midwestern winters may now be less limiting than previously thought.

Since the energetic requirements of wild turkeys increases as temperatures decline below $10.9^{\circ} \mathrm{C}$ (Haroldson et al., 1998), I expected cold winter temperatures to lead to decreased survival via increased risk of starvation. However, winter mean daily air temperatures observed during this study were, on average, similar to the 30-year average daily air temperature during winter (Figure 2.5). Because winter temperatures were not below average and winter food sources were widely available, it is likely that wild turkeys within this study were able to meet the increased energetic requirements (Porter et al., 1980; Healy, 1992). Therefore, I did not see an effect of temperature on daily survival probability of eastern wild turkeys in northeastern South Dakota.

Consistent with previous studies of eastern wild turkey hen survival, I found that hen survival did not differ between age-classes (Roberts et al., 1995; Vangilder and Kurzejeski, 1995; Wright et al., 1996; Shields and Flake, 2006; Delahunt, 2011; Pollentier et al., 2014b) or years (Wright et al., 1996; Leif, 2001; Humberg et al., 2009; Switzer and Tucker, 2009; Delahunt, 2011). However, Hubbard et al. (1999a) found differences between yearling and adult hen survival in southcentral Iowa. It has been hypothesized that yearling survival rates would be lower than adult survival rates because yearling hens are known to disperse farther than adults (Vander Haegen et al., 1988), and dispersal often leads to increased risk of 
predation (Johnson and Gaines, 1990). Similar to several previous studies, I did not detect any seasonal differences in daily survival probability (Kurzejeski et al., 1987; Wright et al., 1996; Lehman et al., 2001; Shields and Flake, 2006; Humberg et al., 2009; Switzer and Tucker, 2009). However, Pollentier et al. (2014b) found that survival was lowest during the spring and attributed this low survival rate to high levels of predation. Since hens are especially vulnerable to mammalian predators while spending time on the ground incubating nests (Vander Haegen et al., 1988; Kurzejeski et al., 1987; Roberts et al., 1995; Wright et al., 1996; Lehman et al., 2001; Pollentier et al., 2014b), I expected to find a negative effect of incubating a nest on hen survival, however, I failed to detect an effect.

Since mammalian predators use olfactory cues to locate nests (Storaas, 1988), and wet conditions enhance growth of scent-causing bacteria (Syrotuck, 2000), Roberts and Porter (1998b) and Lehman et al. (2008b) found evidence to suggest that incubating hens are more easily detected and located by mammalian predators during wet periods. Therefore, several studies hypothesize that precipitation decreases survival of incubating hens (Roberts et al., 1995; Roberts and Porter, 1998b; Lehman et al., $2008 b$ ). I expected that hen survival would be negatively affected by precipitation (in the form of rainfall), especially during the spring while hens are engaging in nesting activities and spending extended periods of time on the ground. However, precipitation did not have an effect on daily survival probability of hens. Since the spring nesting seasons observed during this study were, on average, drier-than-normal (Figure 2.6), it is possible that there was not enough opportunity for precipitation-facilitated predation events to occur and, therefore, have a negative effect on hen survival.

Predation was the leading cause of mortality during this study (Table 2.2), and the majority of those predation events were attributed to mammalian predators. Red fox (Vulpes vulpes) contributed to 4 out of 39 mammalian predation events; however, the majority of predation events were attributed to coyote (Canis latrans). Great horned owls (Bubo virginianus) caused at least 1 predation event. Previous studies of eastern wild turkey hens have also identified predation as the leading cause of mortality (Kurzejeski et al., 1987; Vander Haegen et al., 1988; Wright et al., 1996; Hubbard et al., 1999a; Lehman et al., 2001; Leif, 2001; Shields and Flake, 2006; Humberg et al., 2009; Switzer and Tucker, 2009; Delahunt, 2011; Pollentier et al., 2014b). Lehman et al. (2001) determined that all spring predation events were a direct result of nesting and brood rearing activities, since all spring predation events occurred either while the hen was incubating a nest or while a hen was rearing a brood that was $<1$-week old. While I did not detect an effect of incubating a nest on hen survival, eight mammalian predation events, and 1 avian predation event, occurred while a hen was actively incubating a nest (Table 2.2).

Haying by agricultural equipment was the second leading cause of mortality (9\%; Table 2.2), and all hens that were killed by a haying event were actively incubating a nest at the time. While haying of grassland habitats occurred during this study period (accounting for the loss of 3 nests), all hen mortality due to haying occurred within alfalfa hayfields. Other sources of mortality included capture- 
related causes (i.e., strangulation by transmitter shock-cord harness), disease, legal harvest (of bearded hens), and vehicle collisions. While it is not legal to harvest beardless hens within the study area, bearded hens can be legally harvested during the spring bearded-only hunting season.

\subsection{Management Implications}

Since the rate of population change for eastern wild turkeys in northeastern South Dakota is greatly affected by variation in hen survival (see results from Chapter 4), and current annual survival rate estimates are lower than previous estimates from this area (Lehman et al. 2001; Shields and Flake 2006, Table 2.3), managers should focus on increasing annual survival of wild turkey hens by eliminating human-caused sources of mortality. Haying of alfalfa during the nesting season was a major source of hen mortality during this study (Table 2.2). During both years of the study, hens laid 12 nests within alfalfa fields; however, no nests that were laid in alfalfa fields successfully hatched. Seven of the nests laid within alfalfa (58.3\%) resulted in a hen mortality event when the alfalfa was cut for hay. Based on the onset of incubation, in 2017, $75 \%$ of all nests would have hatched by July 3rd, and in 2018, $75 \%$ of all nests would have hatched by July 9th. Delaying the cutting of alfalfa until the after the first week of July, could reduce the risk of hen mortality due to haying equipment since the majority of hens will be done incubating by this time. If hay must be cut before this time, installing a flushing bar on the cutting equipment can increase hen survival by pushing hens off of their nests and allowing them to escape (Klonglan et al., 1959). Klonglan et al. (1959) found that for pheasant populations in Iowa, the use of flushing bars on haying equipment reduced hen mortality by $38 \%$.

Several previous studies identified adult hen survival as an important factor influencing population growth, and have shown that if autumn harvest decreases annual hen survival at an additive level, eastern wild turkey populations may become susceptible to population declines (Suchy et al., 1983; Vangilder and Kurzejeski, 1995; Rolley et al., 1998; Alpizar-Jara et al., 2001). I did not directly assess the effect of autumn hunting mortality on the survival of eastern wild turkey hens in northeastern South Dakota because the autumn hunting season has been closed since 2014 due to concerns that the population is in decline. However, Little and Kienzler (1990) estimated adult and subadult survival rates before and after a autumn, either-sex hunting season was implemented in Iowa and concluded that autumn harvest mortality of eastern wild turkey hens in the open, agriculturally dominated landscape was likely additive. Additional mortality sources for hens in the form of hunter harvest will likely have a negative effect on annual hen survival and could lead to a declining population.

Two bearded hens were legally harvested during the 2017 spring bearded-only hunting season. If concerns of a declining population persist, designating a "male-only" season would eliminate legal harvest of hens altogether. Reducing human-caused sources of mortality for wild turkey hens will improve overall 
annual survival probability. Improvements to hen survival, by eliminating human-caused sources of mortality, could alleviate any persisting concerns of declining abundance of the population of eastern wild turkeys in northeastern South Dakota. 
Table 2.1: Population-level mean log-odds ratio (LOR), lower 95\% credible interval (CI) level, and upper 95\% CI level for each covariate and interaction used to model daily survival probability of eastern wild turkey hens from February 2017 to April 2019 in northeastern South Dakota, USA.

\begin{tabular}{lccc}
\hline Covariate & LOR & Lower CI Level & Upper CI Level \\
\hline (Intercept) $^{1}$ & 8.328 & 6.809 & 10.038 \\
Hen Age: Adult & -0.135 & -1.007 & 0.716 \\
Study Year: 2017-2018 & 0.248 & -1.077 & 1.634 \\
Study Year: 2018-2019 & 0.278 & -1.201 & 1.793 \\
Season: Spring & -0.162 & -1.588 & 1.134 \\
Season: Summer & 0.794 & -1.398 & 3.326 \\
Season: Autumn & 1.371 & -0.288 & 3.273 \\
Incubating & -0.310 & -1.419 & 1.349 \\
Precipitation & 1.525 & -0.152 & 3.473 \\
Temperature & -0.226 & -1.284 & 0.745 \\
Snow-Depth & 0.940 & -0.463 & 2.720 \\
Consecutive Snow-Covered Days & 1.498 & 0.120 & 3.452 \\
\hline
\end{tabular}

\footnotetext{
${ }^{1}$ References for Hen Age: Yearling, Study Year: 2016-2017, and Season: Winter are contained within the model intercept.
} 
Table 2.2: Causes of mortality for eastern wild turkey hens in northeastern South Dakota, USA during each season from February 2017 to April 2019.

\begin{tabular}{lccccccc}
\hline Cause of Death & Winter & Spring & Summer & Autumn & Total & Percentage & Incubating \\
\hline Mammalian Predation & 8 & 24 & 6 & 1 & 39 & $52 \%$ & 8 \\
Avian Predation & 2 & 2 & 1 & & 5 & $7 \%$ & 1 \\
Disease & & 4 & & & 4 & $5 \%$ & \\
Hayed & & 7 & & & 7 & $9 \%$ & 7 \\
Legal Harvest & & 2 & & & 2 & $3 \%$ & \\
Vehicle Collision & & 2 & & & 2 & $3 \%$ & 1 \\
Euthanized & & & & 1 & 1 & $1 \%$ & \\
Capture Related & 1 & 1 & & 1 & 3 & $4 \%$ & \\
Unknown & 3 & 2 & & 7 & 12 & $16 \%$ & \\
\hline Total & 14 & 44 & 7 & 10 & 75 & & 17 \\
\hline
\end{tabular}


Table 2.3: Annual survival probabilities of expanding and established populations of eastern wild turkey hens in the Midwest from published field studies compared to annual survival probabilities of hens in northeastern South Dakota, USA (current study). If two estimates are presented for a given study, the first estimate indicates yearling hen annual survival probability and the second estimate indicates adult hen annual survival probability. Ranges of estimates represent variation in annual survival probability within a sample of both yearling and adult hens.

\begin{tabular}{llcl}
\hline \multirow{3}{*}{ Expanding } & State & Annual Survival Probability & Citation \\
& South Dakota & $62.0 \%, 62.9 \%$ & (Current Study) \\
& Wisconsin & $48.6 \%$ & \\
& South Dakota & $77.7 \%$ & Porter 1978 \\
& South Dakota & $72.1 \%$ & Leif 2001 \\
& South Dakota & $69.7 \%$ & Shields and al. 2001 \\
& Minnesota & $16.7-29.7 \%$ & Kane et al. 2007 \\
& South Dakota & $45-55 \%$ & Switzer and Tucker 2009 \\
Established & & & \\
& Missouri & $43.5 \%$ & Kurzejeski et al. 1987 \\
& Wisconsin & $52.7 \%$ & Wright et al. 1996 \\
& Iowa & $71.3 \%, 67.6 \%$ & Hubbard et al. 1999a \\
& Indiana & $77.7 \%$ & Humberg et al. 2009 \\
& Illinois & $70.5 \%$ & Delahunt 2011 \\
& Wisconsin & $40.4 \%, 60.7 \%$ & Pollentier et al. 2014b \\
\hline
\end{tabular}




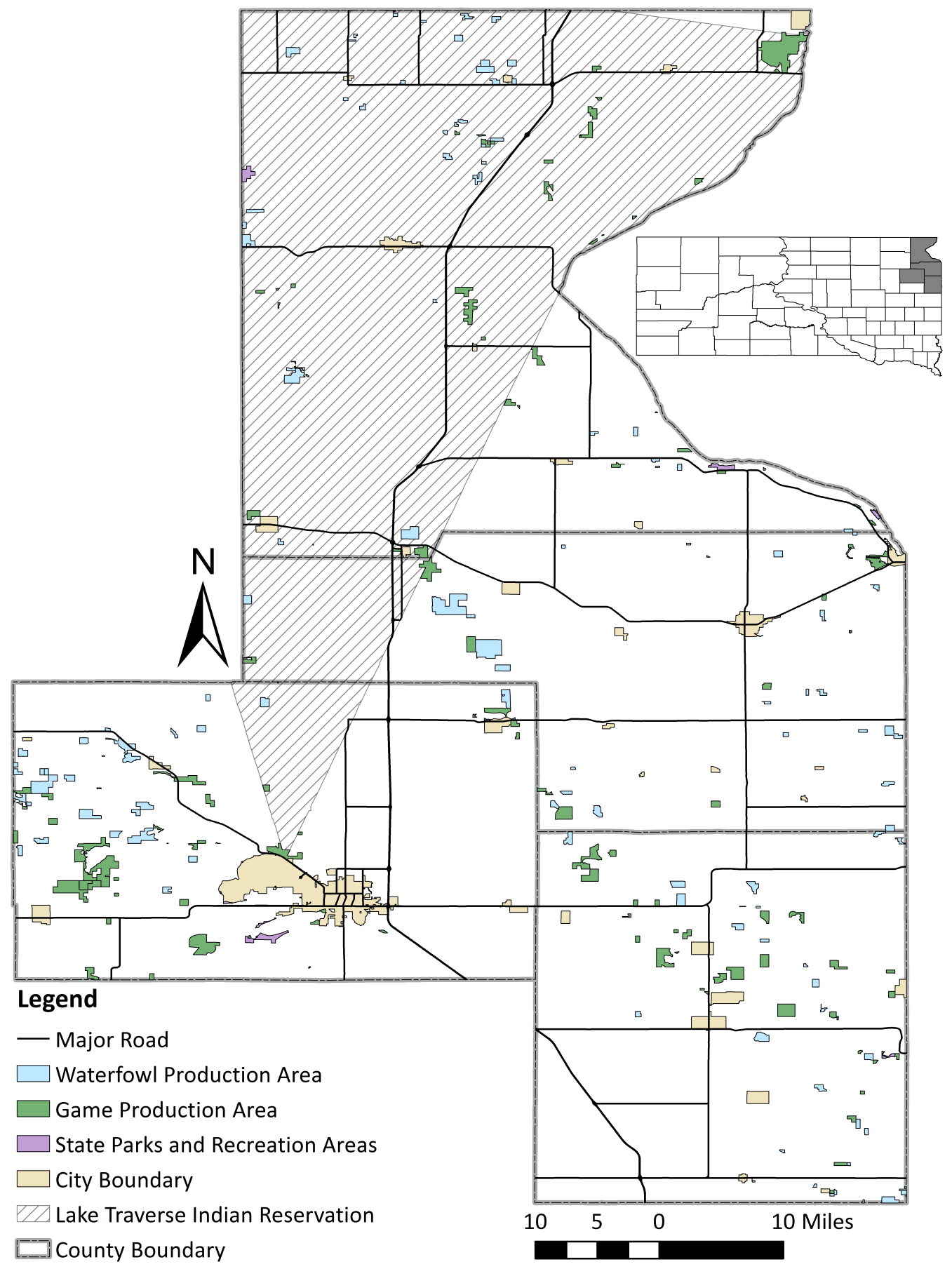

Figure 2.1: Map of land ownership across Codington, Deuel, Grant, and Roberts Counties in northeastern South Dakota, USA. White areas within county boundaries indicate privately owned lands. 


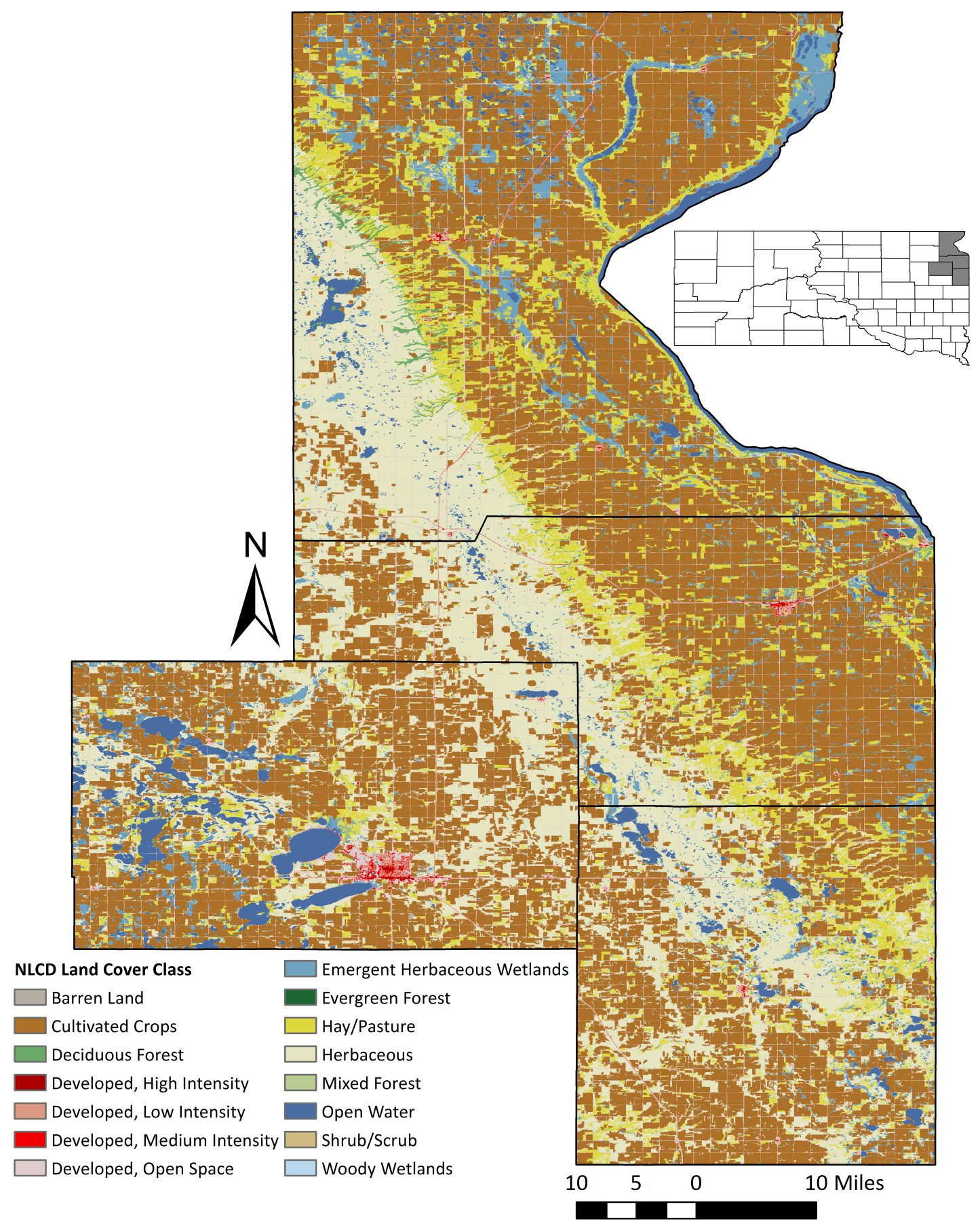

Figure 2.2: National Land Cover Database (2016) land cover classes for Codington, Deuel, Grant, and Roberts Counties in northeastern South Dakota, USA. 


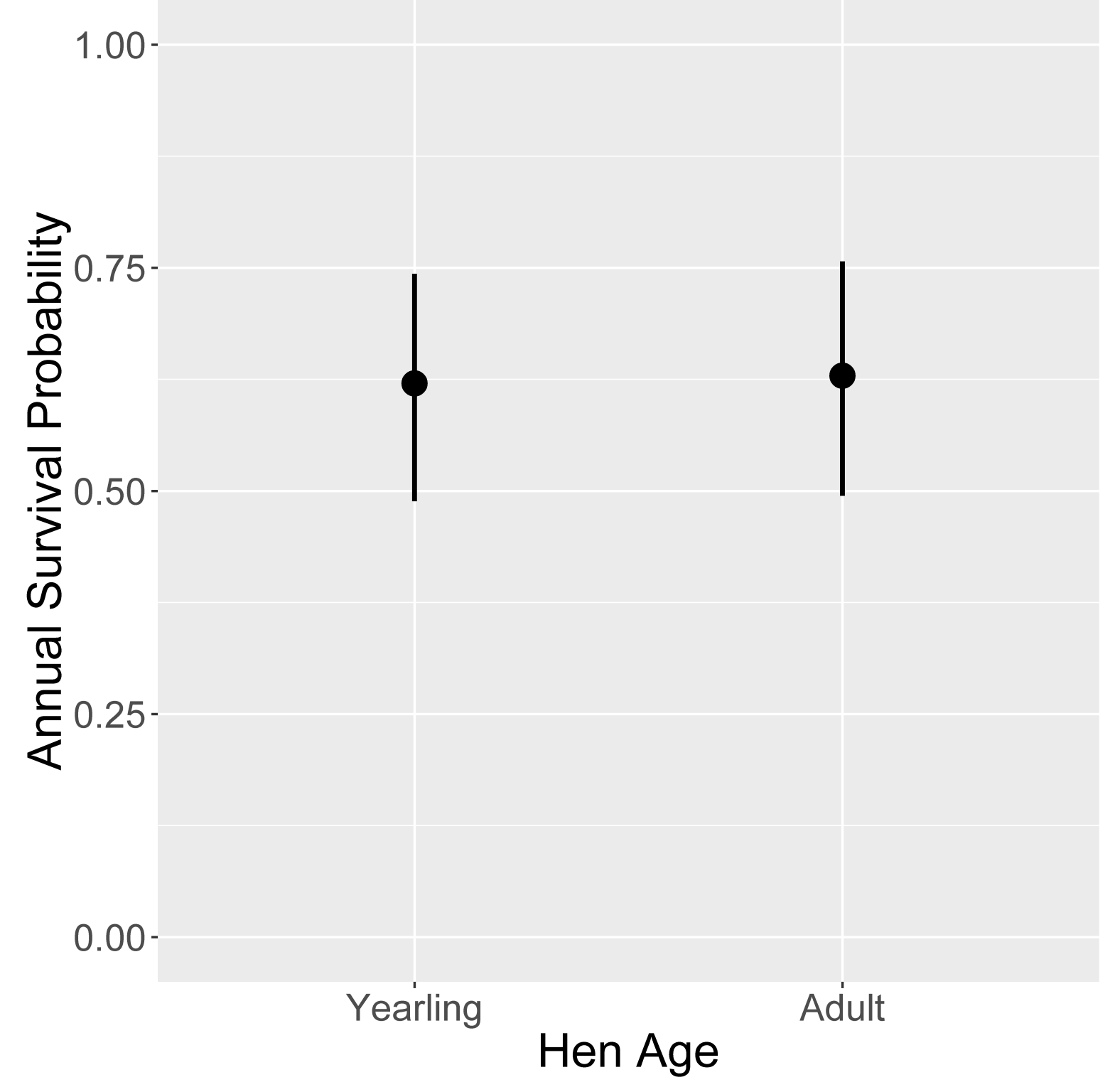

Figure 2.3: Annual survival probability of adult and yearling age-classes of eastern wild turkey hens from February 2017 to April 2019 in northeastern South Dakota, USA. 


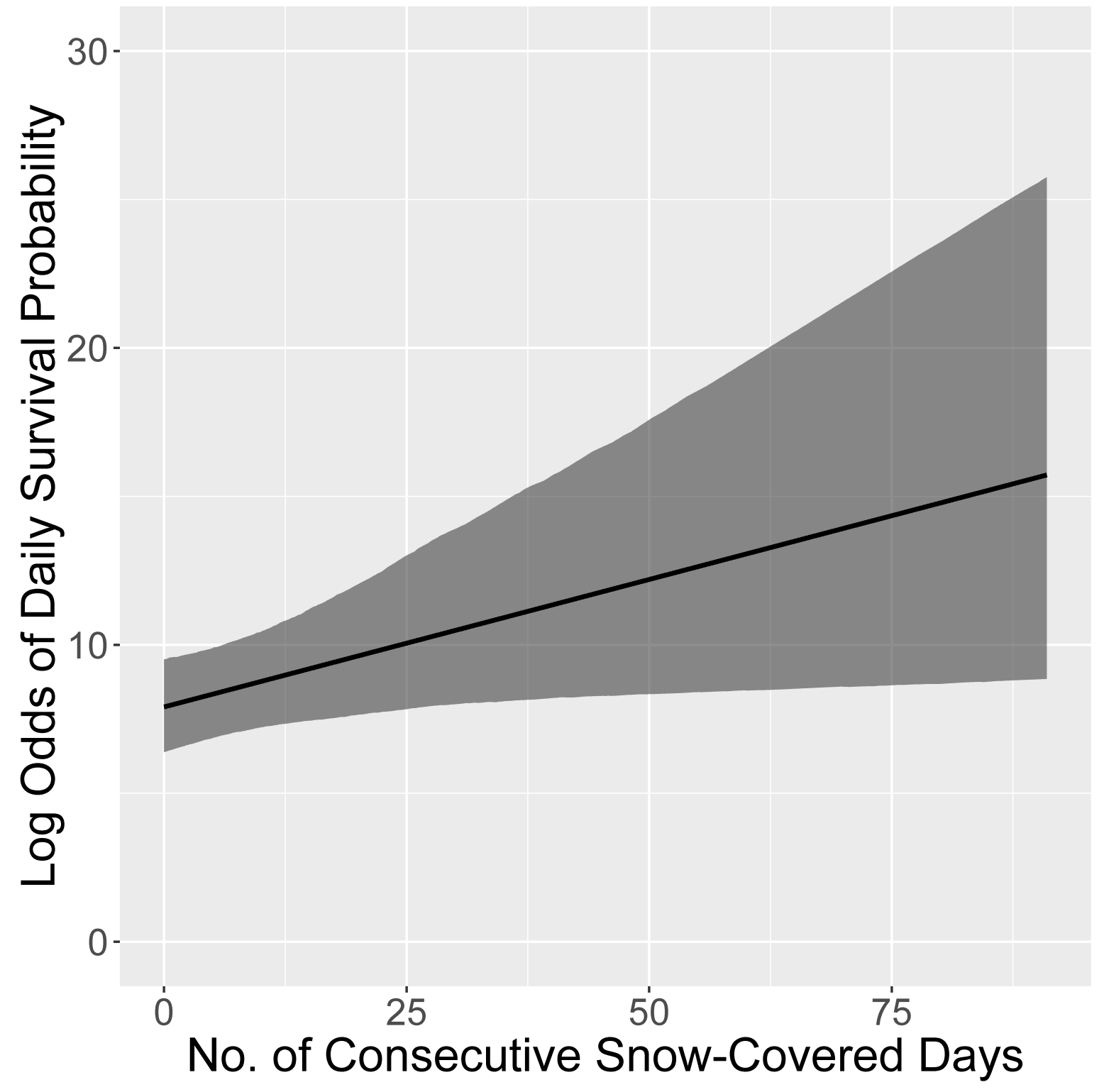

Figure 2.4: Effect, on the log-odds scale, of the number of consecutive snow-covered days on daily survival probability of eastern wild turkey hens from February 2017 to April 2019 in northeastern South Dakota, USA. 

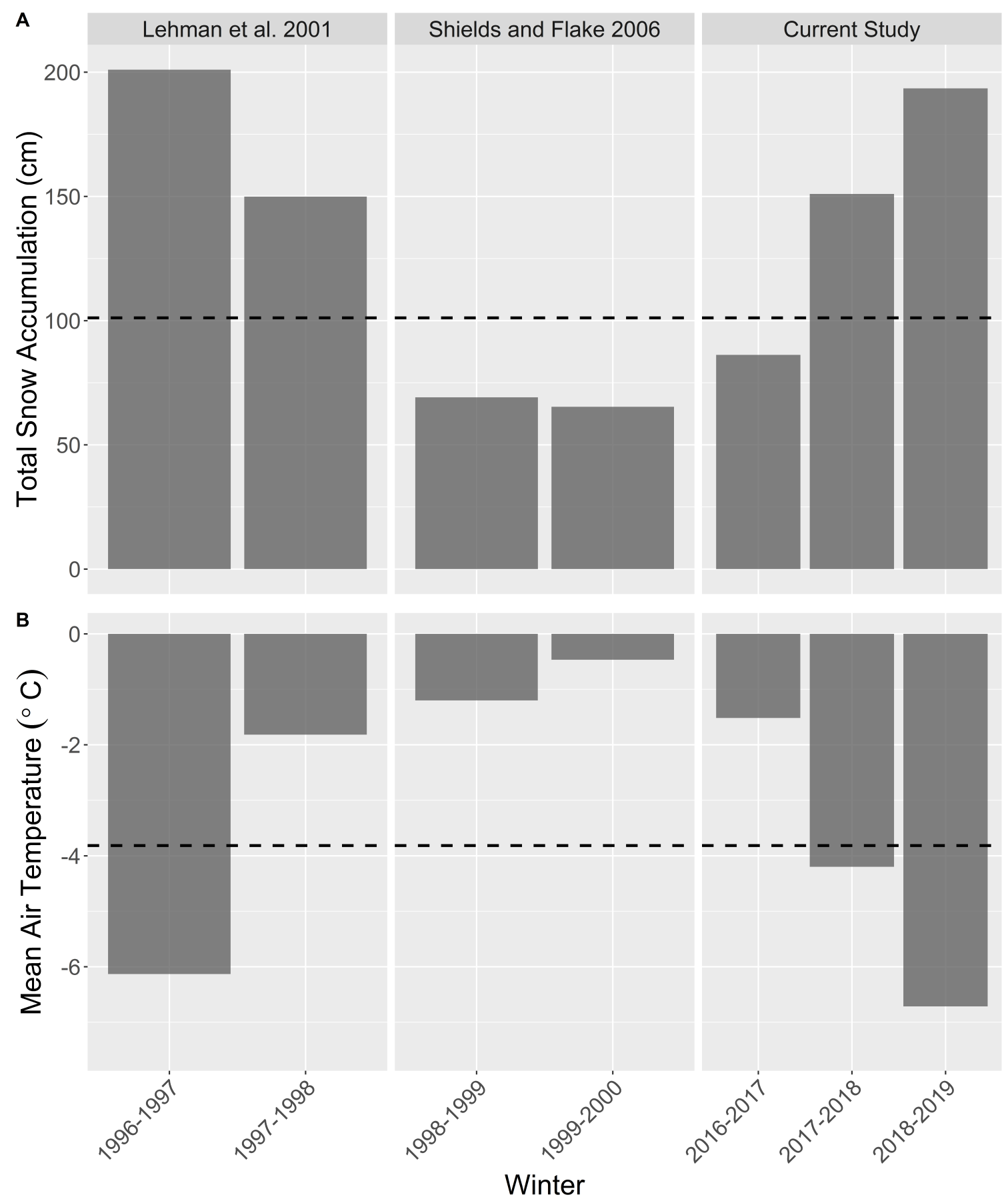

Figure 2.5: Comparison of total snow accumulation $(\mathrm{cm})(\mathrm{A})$ and mean daily air temperature $\left({ }^{\circ} \mathrm{C}\right)$ (B) throughout the winters (1-November through 30-April) observed by Lehman et al. 2001 (19961997, 1997-1998), Shields and Flake 2006 (1998-1999, 1999-2000), and "Current Study" (2016-2017, 2017-2018, 2018-2019) in northeastern South Dakota, USA. The 30-year average (1981-2010) total snow accumulation $(101.1-\mathrm{cm})$ and mean daily air temperature $\left(-3.8^{\circ} \mathrm{C}\right)$ in northeastern South Dakota are illustrated by the horizontal, dashed lines (National Climatic Data Center, 2010). 


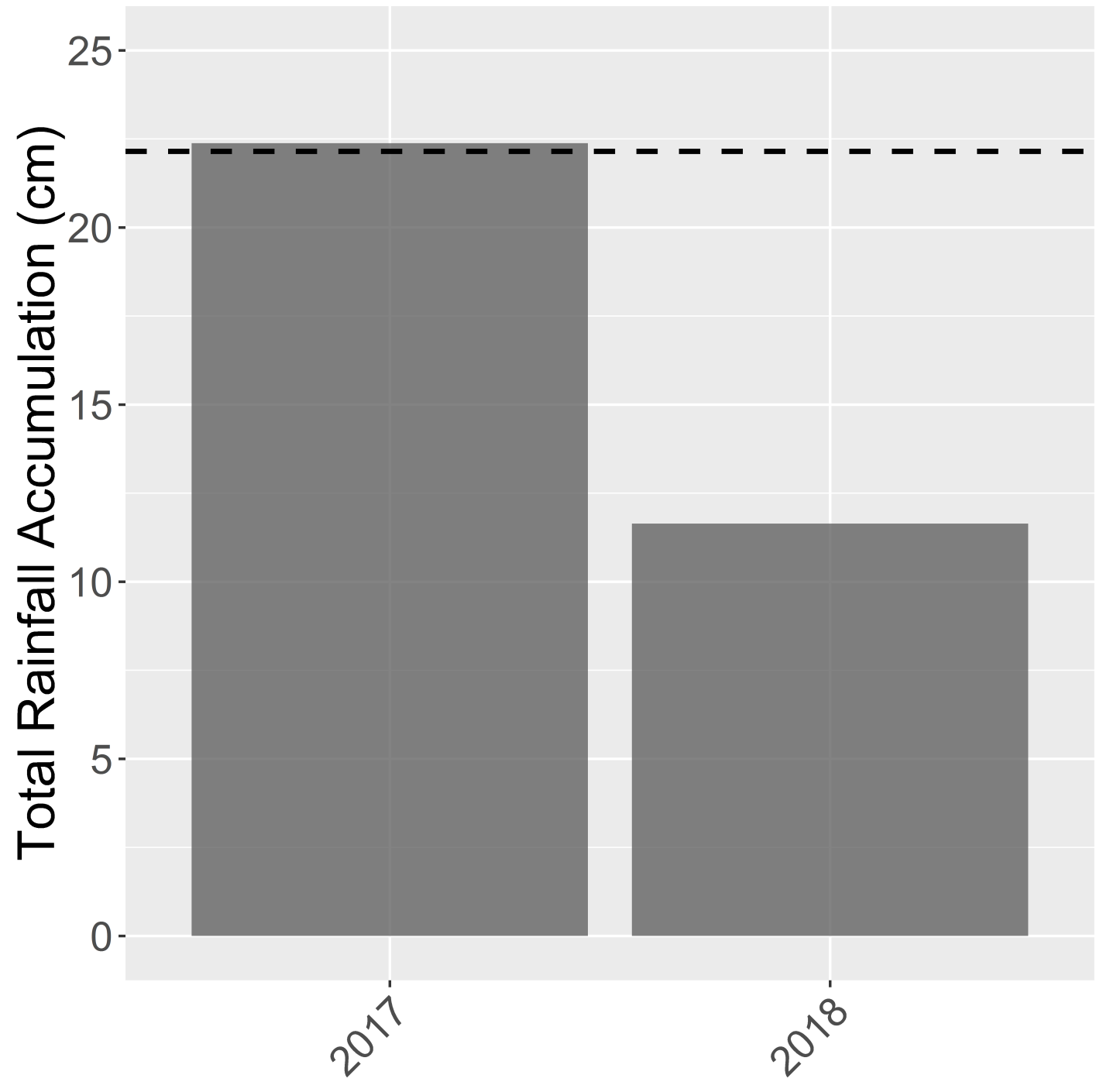

Figure 2.6: Total precipitation (in the form of rainfall) accumulation during the springs (1-April to 30-June) of 2017 and 2018 in northeastern South Dakota, USA. The 30-year average (1981-2010) total precipitation accumulation during spring in Milbank, SD, USA $(22.1-\mathrm{cm})$ is indicated by the dashed line (National Climatic Data Center, 2010). 


\title{
Chapter 3
}

\section{Factors Influencing Productivity of}

\section{Eastern Wild Turkey Hens in}

\section{Northeastern South Dakota}

\begin{abstract}
The population of eastern wild turkeys (Meleagris gallopavo silvestris) in northeastern South Dakota appeared to be expanding soon after reintroduction in the 1990s, however, recent harvest trends suggest declining abundance in the region. Spring turkey hunting expenditures are projected to be around $\$ 6.5$ million in South Dakota, with about $\$ 3$ million of those expenditures occurring within the northeastern prairie region. However, the number of birds harvested during the spring prairie firearm season has been declining since 2010. Due to concerns about a declining population, the autumn hunting season was closed in 2014. The cause of the apparent decline is unclear. Updated information about the factors influencing productivity is needed to assess the status of the population of wild turkeys in northeastern South Dakota and to determine the most effective management strategies for increasing abundance across the region. I captured and radio-marked 80 eastern wild turkey hens (43 adult and 37 yearling) in Grant County, South Dakota during the winter of 2017, and I radio-marked an additional 41 yearling hens during the winter of 2018. I monitored radio-marked hens for productivity during the springs and summers of 2017 and 2018. I used Bayesian methods to model nesting rate, nest survival, re-nesting rate, clutch size, hatchability, and poult survival as a function of covariates. The probability a hen would initiate a nest was $77.1 \%$ and the probability a nest would survive the 28-day incubation period was 49.3\%. Nest survival probability was lower on warm, wet days than on cool, wet days. Adult hens were more likely to re-nest following a failed first nest attempt than yearling hens. The probability an adult
\end{abstract}


hen would re-nest was $59.6 \%$ and the probability a yearling hen would re-nest was $25.1 \%$. The mean clutch size for all nests was 10 eggs and the probability an egg would hatch was $87.1 \%$. The probability a poult survived the 28 -day post-hatch interval was $35.5 \%$ for poults reared by adult hens and $19.7 \%$ for poults reared by yearling hens. Poults that were several weeks old had a greater probability of survival than newly hatched poults. Daily poult survival probability was positively affected by precipitation and was greater during 2017 than in 2018. Management activities should focus on increasing the quality and quantity of herbaceous and early successional habitats to reduce hen risk of mortality while conducting nesting and brood-rearing activities. Additionally, increased availability of suitable nesting habitat on the landscape could mean fewer hens will resort to nesting in alfalfa hayfields, where nest failure is certain and hens are at risk of mortality due to haying. Reducing hen risk of mortality while nesting will allow more hens to be available to re-nest, leading to an overall increase in productivity. Improving eastern wild turkey productivity in northeastern South Dakota should increase abundance of wild turkeys and improve hunting opportunities in the region.

\subsection{Introduction}

Estimates of productivity, and the factors influencing those estimates, can provide insight into the status of a population. They can be combined with estimates of survival into matrix projection models to assess the status of a population (Caswell, 2001). Additionally, perturbation of matrix elements and lowerlevel vital rates, and assessment of the influence of those perturbations on the finite rate of population change $(\lambda)$, can shed light on which demographic parameters have the greatest effect on the ability of a population to grow (Wisdom et al., 2000; Caswell, 2001). For populations of wild turkeys, productivity parameters of interest typically include estimates of nesting rate, nest survival, re-nesting rate, clutch size, hatchability, and poult survival (Pollentier et al., 2014a). These estimates of productivity can be combined to estimate fecundity (i.e., the number of poults of each sex produced per hen) which can, in turn, be combined with estimates of young-of-the-year (i.e., juvenile) survival to provide insight into recruitment of new individuals into the breeding population. Nest and poult survival have a strong influence on the growth rate for populations of eastern wild turkeys in New York (Roberts et al., 1995) and Wisconsin (Pollentier et al., 2014a). Low productivity and recruitment into the breeding population can lead to a population decline (Rolley et al., 1998). Understanding which demographic parameters have the greatest effect on the rate of population change is essential for making scientifically informed decisions about the management of a wildlife population.

Reproductive parameters for eastern wild turkey populations have been studied extensively (Porter et al., 1983; Vander Haegen et al., 1988; Vangilder and Kurzejeski, 1995; Roberts and Porter, 1998a; Hubbard et al., 1999b; Leif, 2001; Paisley et al., 1998; Lehman et al., 2001; Shields and Flake, 2006; 
Switzer and Tucker, 2009; Pollentier et al., 2014b). Nesting rate is the probability an individual hen will initiate a nest attempt during a nesting season, nest survival is the probability a nest will survive the incubation period to successfully hatch at least one poult, re-nesting rate is the probability a hen will initiate a second nest attempt after a failed first nest attempt. Clutch size is the average number of eggs in each nest and hatchability is the proportion of eggs that hatch from the total clutch size. Poult survival is the probability an individual poult will survive the 28-day post-hatch interval. Understanding which environmental, spatial, and intrinsic (i.e., hen age, study year) factors have an effect on reproductive parameters can guide management decisions.

Hen weight at the start of the breeding season can influence whether a hen will attempt a nest during that year as lighter hens (less than $4.3-\mathrm{kg}$ ) are less likely to survive to breed and attempt to nest than heavier hens (Porter et al., 1983). Since reproductive activities (i.e., egg-laying, incubation, and broodrearing) are energetically expensive (Porter et al., 1983), and frequently result in depletion of energy reserves (Breitenbach et al., 1963; Ryder, 1970), hens in better condition (i.e., heavier) at the start of the breeding season are more likely to nest (Porter et al., 1983). Since adult hens are usually heavier than yearling hens (Porter et al., 1983; Vander Haegen et al., 1988), several studies have found that adult hens are more likely to nest than yearling hens (Porter et al., 1983; Vander Haegen et al., 1988; Paisley et al., 1998; Pollentier et al., 2014b). However, other studies did not detect a difference in nesting rate between age-classes (Vangilder and Kurzejeski, 1995; Shields and Flake, 2006). Additionally, Paisley et al. (1998), Leif (2001), Shields and Flake (2006), and Pollentier et al. (2014b) did not detect differences in nesting rates between years, suggesting that the factors influencing nesting rate were relatively similar across years.

After hens initiate and begin incubating a nest, several environmental, spatial, and intrinsic factors influence whether a nest will be successful. Because hen weight is often used as an index of body condition and overall health (Porter et al., 1983; Vander Haegen et al., 1988), and hens in good condition are more likely to be able to complete the energetically expensive task of incubating a nest (Porter et al., 1983), Porter et al. (1983) and Vangilder and Kurzejeski (1995) hypothesized that heavier hens will have greater nest success than lighter hens. While Porter et al. (1983) and Vander Haegen et al. (1988) failed to detect an effect of hen weight at the start of the breeding season on the probability of nest survival, Vangilder and Kurzejeski (1995) found that heavier hens had greater nest success than lighter hens. Porter et al. (1983) found that hen weight was important for determining if a hen would initiate a nest, but that hen weight was not important for predicting if a nest will be successful. Since heavier hens are more likely to initiate a nest than lighter hens, hen weight may become less important for predicting nest survival as all hens that nest will be in relatively good condition.

Because adult hens are, on average, heavier than yearling hens (Porter et al., 1983; Vangilder and Kurzejeski, 1995), it has been hypothesized that adult hens will have greater nest success than yearling 
hens (Vangilder and Kurzejeski, 1995). However, several studies have found that nest success does not differ by the age of the nesting hen (Porter et al., 1983; Paisley et al., 1998; Shields and Flake, 2006). For a population of eastern wild turkeys in Missouri, where adult hens were heavier than yearling hens, Vangilder and Kurzejeski (1995) determined that adult hens had greater nest success than yearling hens. Hen weight may be a better predictor of reproductive potential than hen age (Vangilder and Kurzejeski, 1995).

While Pollentier et al. (2014b) and Lehman et al. (2001) found that nest survival varied between years for eastern wild turkeys in Wisconsin and South Dakota, respectively, other studies found that nest success did not vary by study year (Vangilder and Kurzejeski, 1995; Paisley et al., 1998; Shields and Flake, 2006). The variation in nest success estimates between years found by Lehman et al. (2001) was attributed to greater instances of nest depredation during one year of the study, however, it was unclear if predator abundances, environmental stochasticity, or other factors were influencing the increased nest depredation. Pollentier et al. (2014b) did not speculate about the difference in nest survival found between years.

Precipitation and temperature during the nesting season can influence nest success. Precipitation can be detrimental to nest survival because wet hens are more easily located by mammalian predators that use olfactory cues to locate prey (Storaas, 1988). Roberts and Porter (1998b) and Lehman et al. (2008b) found that precipitation, especially greater-than-normal levels of precipitation, had negative effects on daily nest survival probability. Roberts and Porter (1998b) found that daily nest survival probability increased with colder temperatures and hypothesized that this was due to an interaction between precipitation and temperature. Roberts and Porter (1998b) speculated that if predators use olfactory cues to locate nests (Storaas, 1988), and if bacteria are primarily responsible for the scent emitted by nesting hens (Syrotuck, 2000), that bacterial growth and scent intensity are enhanced by warm, wet conditions and less existent in cool, dry conditions.

Habitat conditions can also influence nest success, although optimal nesting habitat for eastern wild turkeys varies. They nest in habitats ranging from hardwood forests to alfalfa hayfields (Porter, 1992). Leif (2001) found that most eastern wild turkeys in eastern South Dakota placed nest sites within herbaceous vegetation (i.e., grasses and/or legumes) or shrubs. While alfalfa hayfields provide dense nesting cover for wild turkeys, haying of alfalfa fields during the nesting season can cause nest failures and hen mortalities (Vangilder and Kurzejeski 1995, Paisley et al. 1998, Shields and Flake 2006, Chapter 2). The Conservation Reserve Program (hereafter "CRP") provides payments to landowners who are enrolled in the system to take environmentally sensitive land out of agricultural production and instead maintain native grassland, or other vegetation native to the area, that provide benefits such as wildlife habitat, water filtration, and erosion prevention (Stubbs, 2014). Clawson and Rotella (1998) found that nest success was greatest for nests located within CRP grasslands. Vangilder et al. (2001) noted that turkeys 
nesting in more open, agriculturally dominated landscapes in Missouri appeared, on average, to have greater reproductive potential than turkeys nesting in the forested region of eastern Missouri. However, Pollentier et al. (2014b) found that nest survival was slightly higher in forested landscapes than open landscapes in Wisconsin.

While broad scale habitat attributes may influence nest success, microhabitat conditions around the nest are also a strong determinant of nest success. Ideal nest sites for wild turkeys will have some form of lateral cover (i.e, trees, shrubs, herbaceous vegetation, etc.) immediately surrounding the nest to obscure horizontal vision of predators (Lazarus and Porter, 1985; Porter, 1992; Badyaev, 1995). Wild turkey hens often nest where some form of overhanging vegetative cover obscures the nest from overhead predators (Lazarus and Porter, 1985; Wertz and Flake, 1988; Lehman et al., 2002). Leif (2001) noted that wild turkeys sometimes selected nest sites that were adjacent to a guard object, such as a tree trunk. While Lutz and Crawford (1987) and Badyaev (1995) found that nest success was greater in areas of high visual obstruction at the ground level, Rumble and Hodorff (1993) and Lehman et al. (2002) did not find an influence of nest site characteristics on nest success.

Proximity of the nest to human disturbances can influence nest success. Selection of nest sites near roads (i.e., within road ditches) can negatively influence daily nest survival probability in some avian species due to an increased risk of predation (DeGregorio et al., 2014). Selection of nest sites near farmsteads and rural towns may reduce the risk of hen mortality while nesting, and increase nest survival, as a major predator of incubating wild turkey hens - coyote - tend to avoid these areas (Gosselink, 2003).

While it had been hypothesized that variation in nesting chronology (i.e., time of year) may create variation in nest survival probabilities (Vangilder and Kurzejeski, 1995), the literature suggests that nest survival probabilities for eastern wild turkeys in the Midwest are relatively uniform throughout the nesting season. Vangilder and Kurzejeski (1995) expected to find that nest success was lower when nesting was delayed (i.e., increasing date of incubation initiation), however, success was not correlated with nest initiation date. Additionally, two studies have noted that nest success was not different between first nest attempts and re-nest attempts (Paisley et al., 1998; Shields and Flake, 2006).

Hens will often attempt to re-nest if their initial attempt failed. Hen weight at the start of the breeding season can influence whether or not a hen will attempt to re-nest following a failed first nest attempt since Porter et al. (1983) and Vander Haegen et al. (1988) both found that heavier hens were more likely to re-nest than lighter hens. While most studies have found that adult hens re-nest at rates greater than yearling hens (Vander Haegen et al., 1988; Lehman et al., 2001; Shields and Flake, 2006; Pollentier et al., 2014b), Porter et al. (1983) found that for a population of turkeys in Minnesota, yearling hens were more likely to re-nest than adult hens. Vangilder and Kurzejeski (1995) and Paisley et al. (1998) did not detect a difference in re-nesting rate between age-classes. Some studies have found that re-nesting rates varied between years (Vangilder and Kurzejeski, 1995; Paisley et al., 1998); however, 
Pollentier et al. (2014b) found that re-nesting rates were not different between years of the study in Wisconsin.

Hen weight, and therefore overall body condition, may have an effect on clutch size (Ryder, 1970). However, Porter et al. (1983) and Vander Haegen et al. (1988) did not detect an effect of hen weight at the start of the breeding season on clutch size. Since hens that are not in good condition are less likely to nest (Porter et al., 1983), and therefore will not lay a clutch of eggs, estimates of clutch size are biased, as they are calculated from a sample of hens in relatively good condition. Because all clutch-laying hens are likely in relatively good condition, it is difficult to detect an effect of hen weight on clutch size. Several studies indicate that clutch size does not vary between adult and yearling age-classes of eastern wild turkeys (Porter et al., 1983; Vander Haegen et al., 1988; Vangilder and Kurzejeski, 1995; Paisley et al., 1998; Pollentier et al., 2014b). Again, this is probably due to the fact that nesting hens are in relatively good condition, regardless of age, so clutch size is not likely to vary across age-classes. Paisley et al. (1998) found that clutch sizes did not differ between study years in Wisconsin, and Porter et al. (1983), Paisley et al. (1998), and Pollentier et al. (2014b) found that clutch size did not vary between first nest and re-nest attempts, because hen body condition was relatively uniform between years and across nest attempts. Vangilder and Kurzejeski (1995) found that clutch sizes differed between study years and between nest attempts (first nests had larger clutch sizes) in Missouri but did not speculate about the factors influencing these differences.

Additionally, hen weight may have an effect on hatchability, as healthier hens may be able to produce better quality eggs (Ryder, 1970). However, Porter et al. (1983) and Vander Haegen et al. (1988) did not detect an effect of hen weight at the start of the breeding season on hatchability of eggs. Since hens that are not in good condition are less likely to nest (Porter et al., 1983), estimates of hatchability are calculated from a sample of clutches laid by hens that are in relatively good condition, and therefore, it is difficult to detect an effect of hen weight on hatchability. Several studies detected no difference in hatchability between age-classes (Porter et al., 1983; Vander Haegen et al., 1988; Vangilder and Kurzejeski, 1995; Paisley et al., 1998). Again, this is probably due to the fact that nesting hens are in relatively good condition, regardless of age, so the quality of eggs is not likely to differ much across clutches. Both Vangilder and Kurzejeski (1995) and Paisley et al. (1998) determined that hatchability was not different between study years, suggesting conditions that hen body condition was similar between years.

Once poults successfully hatch, survival during the first couple of weeks post-hatch is critical to recruitment into the population as poult survival is lower during the first 2-weeks post-hatch than during the 2-4 week post-hatch interval (Porter et al., 1983; Vander Haegen et al., 1988; Vangilder and Kurzejeski, 1995; Shields and Flake, 2006; Switzer and Tucker, 2009; Pollentier et al., 2014b). Many studies of eastern wild turkey productivity indicate that poult survival increases with poult age because 
older poults are able to better avoid predators and thermo-regulate (Porter et al., 1983; Healy and Nenno, 1985; Vander Haegen et al., 1988; Vangilder and Kurzejeski, 1995; Paisley et al., 1998; Hubbard et al., 1999b; Shields and Flake, 2006; Switzer and Tucker, 2009; Pollentier et al., 2014b). The influence of the age of the brood-rearing hen is less clear, as Porter et al. (1983) found that poults reared by yearling hens had greater survival than poults reared by adult hens, while Shields and Flake (2006) and Vander Haegen et al. (1988) found that the age of the brood-rearing hen did not have an effect on poult survival probability in South Dakota. Again, there are mixed results for variation in poult survival across study years. For a population in Missouri, Vangilder and Kurzejeski (1995) found that poult survival varied between years of the study; however, for populations in South Dakota, poult survival was homogeneous throughout all study years (Leif, 2001; Shields and Flake, 2006). Vangilder and Kurzejeski (1995) speculated that variation in environmental conditions during the brood-rearing season could be responsible for the difference in poult survival between years.

Wet weather can negatively affect poult survival, especially during the first 2-weeks post-hatch (Healy and Nenno, 1985; Healy, 1992). Vangilder and Kurzejeski (1995), Roberts and Porter (1998a), and Lehman et al. (2008a) found that poult survival was negatively affected by greater-than-normal precipitation levels. In the first week or so post-hatch, galliform offspring have poor insulation and thermoregulation capabilities (Schmidt-Nielsen, 1997), making young poults especially vulnerable to hypothermia. Precipitation increases instances of hypothermia leading to increased poult mortality from wet weather conditions (Lehman et al., 2008a). In northern populations, cold weather during the broodrearing season can be detrimental to poult survival and overall reproductive success (Healy and Nenno, 1985; Healy, 1992). Roberts and Porter (1998a) and Lehman et al. (2008a) found that poult survival decreased at cold temperatures due to an increase in the number of hypothermia-induced mortality events (Roberts and Porter, 1998a; Lehman et al., 2008a).

South Dakota lost an estimated $1,837,100$ acres $( \pm 21,100)$ of grassland, and gained approximately 1,439,500 acres $( \pm 15,600)$ of cropland, between 2006 and 2012 (Reitsma et al., 2013). The greatest losses of grassland habitat occurred in the northeast region of South Dakota (Figure 3.1), which lost 16.9\% $( \pm 0.6 \%)$ of grasslands between 2006 and 2012 (Reitsma et al., 2013). Grassland losses may have an impact on the availability and quality of nesting habitat, and therefore, impact productivity of eastern wild turkeys in the northeast region South Dakota.

Establishment of a growing population of eastern wild turkeys in northeastern South Dakota appeared to be successful in the years immediately following reintroduction (Shields, 2001); however, recent harvest trends suggest declining abundance in the region. Harvest of wild turkeys during the spring prairie turkey season declined from a high of 5,809 males in 2010 down to 2,482 males in 2016 (Huxoll, 2016). The cause of the apparent decline in eastern wild turkey abundance in northeastern South Dakota is unclear. Since productivity has a strong influence on population growth (Roberts et al., 1995; Rolley et al., 1998; 
Pollentier et al., 2014a), understanding the factors that influence reproduction is necessary to formulate effective management activities.

Given recent declines in spring hunter harvest success, there is a need to assess the factors influencing productivity of this important game species. The objectives of this study are to: (1) obtain estimates of nesting rate, re-nesting rate, nest survival, clutch size, and hatchability for yearling and adult age-classes of eastern wild turkeys over 2 nesting seasons; (2) obtain estimates of poult survival over the 28-day post-hatch interval; and (3) determine the effects of intrinsic, spatial, and environmental covariates on nest and poult survival for eastern wild turkey hens in northeastern South Dakota.

I hypothesize that nesting rate, clutch size, and hatchability will not differ by age-class of the wild turkey hen. I predict that nest survival will be positively related to hen weight, nest attempt, initiation date, mean daily air temperature, occurrence within CRP, percentage of canopy cover, presence of a guard object, vertical and horizontal nesting cover, and distance to roads. Nest survival will be negatively affected by daily rain accumulation, occurrence within an alfalfa field, occurrence within an agricultural, forested, or pasture-land habitat type, and distance to towns. I predict that age-class and study year will not have an effect on nest survival. I hypothesize that poult survival will be negatively related to daily rain accumulation, and positively related to mean daily temperature. These results will improve understanding of the factors that are influencing eastern wild turkey productivity. The reproductive parameter estimates from this study will ultimately be incorporated into a matrix projection model to estimate the population growth rate, and evaluate how sensitive the growth rate is to variation in demographic rates. The results will guide management of the population of eastern wild turkeys in northeastern South Dakota.

\subsection{Study Area}

The study was conducted in Codington, Deuel, Grant, and Roberts counties in northeastern South Dakota. The study area was split between the Minnesota River-Red River Lowland in the eastern half of the study area and Coteau des Prairies physiographic region in the western half (Flint, 1955; Johnson et al., 1995). The Coteau begins in the northwest and extends in a southeasterly direction across the study area (Miller et al., 1979). On top of the Coteau, the relief is gently undulating to hilly while down in the Lowlands the land is nearly level (Flint, 1955; Miller et al., 1979). Elevations ranged from over $600-\mathrm{m}$ above mean sea level on top of the Coteau to about 300-m above sea level in the Lowland (Miller et al., 1979). Most of the study area consisted of privately owned lands with some state owned (e.g. Game Production Areas) and federally owned (e.g. Waterfowl Production Areas) lands scattered throughout (Figure 3.2). The Lake Traverse Indian Reservation overlaps the western and northern extent of the study area where tribally owned lands are common (Figure 3.2). 
Northeastern South Dakota is in a humid continental climate region, with mean annual precipitation of $61-\mathrm{cm}$ and mean annual temperature of $6.4^{\circ} \mathrm{C}$ across the study area (National Climatic Data Center, 2010). About $60 \%$ of the total annual precipitation occurs during the nesting and brood-rearing seasons (April through August) (National Climatic Data Center, 2010). Early spring snowfall is possible, with about one quarter $(26 \%)$ of the total annual snowfall occurring from March through May (National Climatic Data Center, 2010). Spring and summer temperatures can be highly variable, with average minimum temperatures near $0^{\circ} \mathrm{C}$ in early spring to average maximum temperatures near $28^{\circ} \mathrm{C}$ during peak summer; however, normal mean temperatures for the spring and summer months range from $12-21^{\circ} \mathrm{C}$ (National Climatic Data Center, 2010).

Agriculture dominates the land use in the study area, with most land being used for either cropland, rangeland, or to grow alfalfa or hay for livestock feed (Miller et al., 1979) (Figure 3.3). Most of the grain farming (i.e., corn and soybeans) occurs in the Lowland (Miller et al., 1979). The highlands of the Coteau support native tallgrass prairie which is used primarily for rangeland; however, scattered fields of hay and alfalfa are located in the highlands as well (Miller et al., 1979) (Figure 3.3). Common grasses include warm-season grasses such as big bluestem (Andropogon gerardii), little bluestem (Schizachyrium scoparium), Indiangrass (Sorghastrum nutans), switchgrass (Panicum virgatum), and sideoats grama (Bouteloua curtipendula) (Johnson and Larson, 2007). Common cool-season grasses include smooth brome (Bromus inermis), Kentucky bluegrass (Poa pratensis), western wheatgrass (Pascopyrum smithii), and green needlegrass (Stipa viridula) (Johnson and Larson, 2007). Numerous forbs and patches of western snowberry (Symphoricarpos occidentalis) are scattered throughout the pasture-lands (Johnson and Larson, 2007). Forested areas along the east-facing breaks where the Coteau descends into the Lowlands are dominated by bur oak (Quercus macrocarpa) on the drier slopes (Leatherberry et al., 2000) (Figure 3.3). More mesic areas are dominated by elm-ash (Fraxinus spp.; Ulmus spp.) forests (Leatherberry et al., 2000) that are intermixed with trembling aspen (Populus tremuloides), box elder (Acer negundo), eastern cottonwood (Populus deltoides), and sugar maple (Acer saccharum) (Knupp Moore and Flake, 1994).

Potential wild turkey nest predators within the study area included coyotes (Canis latrans), red fox (Vulpes vulpes), raccoon (Procyon lotor), striped skunk (Mephitis mephitis), and crows (Corvus brachyrhynchos) (Lehman, 1998; Shields, 2001). Potential mammalian predators of wild turkey poults within the study area included weasels (Mustela spp.), mink (Mustela vison), red fox, and coyotes (Hubbard et al., 1999a). Potential avian predators of wild turkey poults within the study area included multiple species of hawks (Buteo spp. and Accipiter spp.), great-horned owls (Bubo virginianus), bald eagles (Haliaeetus leucocephalus), and golden eagles (Aquila chrysaetos) (Hubbard et al., 1999a; South Dakota Department of Game Fish and Parks, 2017). 


\subsection{Methods}

\subsubsection{Capture and Radio-Telemetry}

I located flocks of eastern wild turkeys during the winter (1 Jan-31 Mar) of 2017 and 2018 by searching for signs of turkeys (i.e., scat, feathers, tracks) near forested riparian corridors commonly used for roosting. I scouted for turkey flocks in the morning and evening during peak foraging hours in order to spot flocks out in open habitats (i.e., row-crop agricultural fields). I also communicated with landowners in the area to determine if they had seen flocks of turkeys on their property recently. Once I determined the location of a flock and secured the proper permissions from the landowner, I baited turkeys into capture locations with corn and sunflower seeds spread out over bales of straw. I set up a trail camera at each bait site to determine if wild turkey hens were visiting the bait pile and which times of day the hens were visiting the bait pile. Once hens were regularly visiting the bait pile, I set up capture equipment at the bait site.

I captured wild turkeys using rocket nets (Thompson and Delong, 1967; Wunz, 1984). Following capture, I aged female turkeys as adult ( $>1$ year old) or yearling ( $<1$ year old) based on presence or absence of barring on the 9th and 10th primary feathers (Williams, Jr., 1961) and weighed birds to the nearest $0.1 \mathrm{~kg}$. I secured 80-g very high frequency (VHF) radio telemetry transmitters (Advanced Telemetry Systems, Isanti, MN, USA) using a shock cord harness and backpack-mount. Transmitters were $<3 \%$ of the hens' body weight to reduce the risk of the transmitter interfering with survival and reproduction (Fair et al., 2010). Transmitters were equipped with an activity signal, short-term nonmoving signal, and mortality signal set to activate after 8 hours of inactivity. I used R-1000 telemetry receivers (Communications Specialists, Orange, CA, USA) to listen to the signals from radio-marked wild turkeys. I monitored turkeys 6 days per week during the spring and summer (1 Apr-31 Jul); however, turkeys that were incubating nests were monitored daily. All handling, marking, and monitoring procedures were approved by the Animal Care and Use Committee (Permit No. 1606003205; South Dakota State Permit 37).

\subsubsection{Nest Marking and Monitoring}

I monitored nesting activity of hens and nest predation events on nests from 1-April to 6-August, 20172018. I identified female turkeys as attempting a nest at the onset of incubation. The date of incubation initiation was determined when a non-moving signal was received from a transmitter. When it was determined that a hen was incubating a nest, I located and marked the nest. I marked the nest area with $\sim 4$ flags at distances of 20-40-m from the nest bowl depending on cover height and density of vegetation while attempting to minimize disturbance. I ascertained the location of the nest bowl in relation to each flag using a hand-held H-type or Yagi antenna to determine the direction of the incubating radio-marked 
hen in relation to each flag. I recorded the coordinates of each flag with a Global Positioning System (GPS) in case any of the flags were removed to ensure I would be able to locate the nest when it is no longer being tended by the radio-marked hen.

On subsequent visits to the nest, investigators stayed $>100$-m away while monitoring to determine if the nest was successful or failed. If a non-moving signal was observed, I determined that the hen was still tending the nest. If a moving signal was observed, I determined that the hen was no longer tending the nest. If a mortality signal was observed, I determined that the hen died while tending the nest, and I would locate the transmitter and assess the cause-of-death. When I determined that the hen was no longer tending to the nest, I would locate the nest bowl, record the coordinates of the nest bowl using a GPS, and determine nest fate. Nests were classified as successful by the presence of hatched eggshells, or as failed if nest contents were depredated, destroyed, or abandoned (Lehman et al., 2001). If the nest was successful, I would determine the number of eggs that hatched from the total clutch size by counting eggshell fragments and membranes (Lehman et al., 2001). I counted the number of eggs in failed nests to determine clutch size if the eggs were relatively intact and undisturbed (Lehman et al., 2001). If the clutch size of failed nests could not be accurately determined, I did not include that nest in my clutch size analysis.

\subsubsection{Poult Monitoring}

The initial number of poults that hatched was determined at each successful nest site based on egg shell and membrane remains (Lehman et al., 2001). The number of poults in each brood were counted at 1 , 2, and 4-weeks post-hatch by observing broods feeding in open areas (Lehman et al., 2008a); however, if dense vegetation interfered with observations, broods were flushed to count poults. Broods often formed crèches (multiple hens with a group of commingled poults) after poults reached 2-weeks of age, and crèches were very common when broods reached 4-weeks of age, making it very difficult to differentiate individual broods during the day. Therefore, I counted these broods at night while they were in the roost with the hen in order to obtain an accurate count of poults.

\subsubsection{Environmental and Spatial Covariate Estimation}

I estimated nest-site characteristics on the nest fate date (i.e., the day a nest successfully hatches or fails) (Lehman et al., 2008b). I quantified nest-site metrics using transects centered at the nest bowl and I averaged data collected along transects for each variable of interest (i.e., visual obstruction, total cover). I estimated over story canopy cover at the nest bowl using a spherical densiometer (Forestry Suppliers, Jackson, MS, USA). The spherical densiometer was placed 1-m above the nest bowl, and the proportion of the mirrored surface that was covered by vegetation, or another obstructing object, was recorded. I measured understory visual obstruction readings (VOR) of vegetation by placing a Robel pole with 
2.54-cm increments in the nest bowl and at 1-m from the nest in the 4 cardinal directions (Robel et al., 1970; Benkobi et al., 2000). I recorded the lowest visible increment on the pole from a distance of 4-m while kneeling to a height of 1-m (Robel et al., 1970). I measured VOR from the 4 cardinal directions at the nest bowl; however, at the peripheral 1-m from the nest measurements, I estimated VOR from only 3 cardinal directions, ignoring the 4 th direction back across the nest bowl so as not to duplicate visual obstruction readings across the nest bowl (Lehman et al., 2008b). I measured the height (in centimeters) of living vegetation at the nest bowl and at $1-\mathrm{m}$ from the nest in the 4 cardinal directions. I estimated total cover of grass, forbs, shrubs, and other cover using a $0.1-\mathrm{m}^{2}$ quadrat at the nest bowl and at 5 , 1-m intervals in the cardinal directions (Daubenmire, 1959). I determined if the nest bowl had a guard object (i.e., tree trunk, rock, etc.) that provided complete visual obstruction in a particular direction. I qualitatively categorized the habitat surrounding the nest bowl as either grassland, pasture, row-crop agriculture, or forest based on the dominant land-use where the nest was located.

I used ArcMap version 10.6.1 (Environmental Systems Research Institute) and information from the State of South Dakota's GIS database (State of South Dakota, 2018) to determine if a nest was located within an active CRP land parcel or not, and to calculate the distance (meters) from each nest to the nearest road (i.e., interstate, federal highway, state highway, local paved road, local unpaved road) and each nest to the nearest town boundary. Towns were designated by areas where roads and building development were organized into dense city blocks and did not include any expansion of development into the surrounding rural area (See "City Boundary" in Figure 3.2). If a nest was contained within the boundary of a town, the covariate value of distance to town would be zero.

I placed 10 rainfall and temperature monitoring stations throughout the study area before the onset of nesting and retrieved the monitoring stations after all broods were $>4$-weeks old. Monitoring stations consisted of a rain gauge and a HOBO Pendant Temperature Data Logger (Onset Computer Corporation, Bourne, MA, USA) that recorded 4-6 temperature readings at evenly spaced intervals each day. Monitoring stations were placed systematically throughout the study area to cover the extent of all radio-marked hen locations. Rain gauges were checked after every rainfall event and the amount of rain was recorded to the nearest tenth of an inch. I calculated total daily rainfall accumulation (mm) and mean daily temperature $\left({ }^{\circ} \mathrm{C}\right)$ for each monitoring station for each day of the study. I assigned precipitation and temperature covariates to each individual nest and each individual brood (for nest and poult survival analyses, respectively) by assuming precipitation and temperature conditions at the location of each nest and at the location of each brood was equal to the precipitation and temperature conditions observed at the closest monitoring station. 


\subsubsection{Modeling Reproductive Parameters}

\section{Nesting Rate}

I modeled nesting rate as the probability an individual hen, that was alive on 1-April, would attempt to nest that year. I assumed whether hen $i$ would attempt to nest was a Bernoulli random variable:

$$
y_{i} \sim \operatorname{Bernoulli}\left(p_{i}\right)
$$

where $y_{i}=1$ if an individual hen $i$ attempted a nest and $y_{i}=0$ if an individual hen $i$ did not attempt a nest. I further assumed a logit-linear model for nesting rate which I model as a function of age-class of each hen (adult or yearling), year of the study (2017 or 2018), and weight of each hen (kg). I assumed a uniform $(-20,20)$ prior distribution for the intercept coefficient and logistic $(0,1)$ prior distributions for all other slope coefficients.

\section{Nest Survival}

I assumed survival of nest $i$ during day $t$ was a Bernoulli random variable:

$$
y_{i t} \sim \operatorname{Bernoulli}\left(y_{i(t-1)} p_{i t}\right)
$$

where $y_{i t}=1$ if a nest $i$ survived day $t, y_{i t}=0$ if an individual $i$ died during day $t$, and where $p_{i t}$ represented daily survival probability (Royle and Dorazio, 2008). I further assumed a logit-linear model for daily survival probability which I model as a function of age-class of the nesting hen (adult or yearling), weight of the nesting hen $(\mathrm{kg})$, year of the study (2017 or 2018), nest attempt (first attempt or re-nest attempt), initiation date (the first day the hen began incubating the nest), daily rain accumulation (hereafter "precipitation") (mm), daily mean temperature (hereafter "temperature") $\left({ }^{\circ} \mathrm{C}\right)$, habitat type (agriculture, forest, grassland or pasture), nesting within alfalfa or not, nesting within CRP or not, percent canopy cover, guard object present or absent, mean VOR, variation in VOR, minimum VOR, mean total cover, minimum total cover, distance to the nearest road $(\mathrm{m})$, and distance to the nearest town $(\mathrm{m})$. I modeled a quadratic effect of temperature and modeled the interaction between temperature and precipitation.

Thirteen nests were missing observations for mean VOR, variation in VOR, minimum VOR, mean total cover, and minimum total cover because the cause of failure was haying of vegetation surrounding the nest and, therefore, I was not able to accurately measure VOR and total cover in the field. Rather than discard those nests, I imputed missing values, accounting for uncertainty in unmeasured variables (Gelman et al., 2013). I assumed missing observations were Gaussian random variables, and I assumed prior mean and variance equal to observed mean and variance of nests within similar habitats at nest 
fate. Prior mean and variance for 10 nests with missing data that were located within alfalfa hayfields were calculated from 2 nests within alfalfa hayfields that were not lost due to haying, and therefore, had vegetation measured at the fate date. Prior mean and variance for 3 nests with missing data that were located within grasslands were calculated from 59 nests within grasslands that had vegetation measured at the fate date.

I start capture days for all nests at time $t=0$ and began modeling survival probability at 1 day postcapture at time $t=1$. I accounted for repeated observations on individual nests by fitting a random coefficients model (Hobbs and Hooten, 2015). I assumed each coefficient $\beta_{j i}$ was a Gaussian random variable:

$$
\beta_{j i} \sim \operatorname{Gaussian}\left(\mu_{j}, \tau_{j}\right)
$$

where $\mu_{j}$ and $\tau_{j}$ represented the population-level mean and variance, respectively, of the model coefficients for each nest $i$. I assumed logistic $(0,1)$ prior distributions for the population-level means of all slope coefficients. I selected inverse gamma $(1,1)$ prior distributions for precision parameters $\tau_{j}$, which provided little prior information.

\section{Re-nesting Rate}

I modeled re-nesting rate as the probability an individual hen would attempt a second nest, conditional upon failure of the first nest. I considered a hen unavailable for re-nesting if she was killed while tending to the first nest. I assumed whether individual hen $i$ would attempt a second nest was a Bernoulli random variable:

$$
y_{i} \sim \operatorname{Bernoulli}\left(p_{i}\right)
$$

where $y_{i}=1$ if an individual hen $i$ attempted a second nest and $y_{i}=0$ if an individual hen $i$ did not attempt a second nest. I further assumed a logit-linear model for re-nesting rate which I model as a function of age-class of each hen (adult or yearling), year of the study (2017 or 2018), and weight of each hen $(\mathrm{kg})$. I assumed a uniform $(-20,20)$ prior distribution for the intercept coefficient and logistic $(0,1)$ prior distributions for all other slope coefficients.

\section{Clutch Size}

I modeled mean clutch size based on the number of eggs laid in each individual nest $i$. I assumed the number of eggs laid in nest $i$ was a Poisson random variable:

$$
y_{i} \sim \operatorname{Poisson}\left(p_{i}\right)
$$


where $y_{i}$ was the number of eggs counted in each individual nest $i$ and $p$ was the mean number of eggs across all nests included in the analysis. I further assumed a log linear model for clutch size which I model as a function of age-class of the nesting hen (adult or yearling), year of the study (2017 or 2018), weight of the nesting hen $(\mathrm{kg})$, and nest attempt (first or second). I assumed a uniform $(-20,20)$ prior distribution for the intercept coefficient and Gaussian $(0,1)$ prior distributions for all other slope coefficients.

\section{Hatchability}

I modeled hatchability as the proportion of eggs that hatched from each individual nest $i$ based on the total number of eggs laid in each individual nest $i$. I assumed the number of eggs that hatched from nest $i$ was a Binomial random variable:

$$
y_{i} \sim \operatorname{Binomial}\left(p_{i}, c_{i}\right)
$$

where $y_{i}$ was the number of eggs that hatched from each individual nest $i, c_{i}$ was the total number of eggs laid in each individual nest $i$, and $p$ was the proportion of eggs that hatched from the total number of eggs included in the analysis. I further assumed a logit linear model for hatchability which I model as a function of age-class of the nesting hen (adult or yearling), year of the study (2017 or 2018), and weight of the nesting hen $(\mathrm{kg})$. I assumed a uniform $(-20,20)$ prior distribution for the intercept coefficient and logistic $(0,1)$ prior distributions for all other slope coefficients.

\section{Poult Survival}

I modeled daily survival of individual poults using a Bayesian variation of the methods outlined in the 'Young Survival from Marked Adults' model developed in Lukacs et al. (2004). I assumed that broods were independent from one another and individual poults within each brood were exchangeable (i.e., the identity of the individual poult did not matter); however, this model differed from the Lukacs et al. (2004) method, in that the survival of poults was allowed to vary across broods at a given age and time interval. I assumed $100 \%$ mortality for a brood if the brood-rearing hen died during the 28-day post-hatch interval. I assumed the number of observed poults in each brood $i$ at each day post-hatch $t$ was a Binomial random variable:

$$
N_{i t} \sim \operatorname{Binomial}\left(\phi_{i t}, N_{i(t-1)}\right)
$$

where $N_{i t}$ at time $t=1$ was equal to the initial number of poults in each brood $i, N_{i t}$ at each time interval from $t=2-29$ (1-28-days post-hatch) was a latent random variable equal to the number of poults alive in each brood $i$, and $\phi_{i t}$ represented daily survival probability of each poult in brood $i$ between time $t$ and time $t+1$. I modeled the number of poults counted $C$ in each brood $i$ at each monitoring event $k$ 
as a Binomial random variable:

$$
C_{i k} \sim \operatorname{Binomial}\left(p, N_{i t}\right)
$$

where $C_{i k}$ was the number of poults counted in each brood $i$ at monitoring event $k, p$ was the probability of detecting each poult, and $N_{i t}$ was a latent variable indicating the number of poults from brood $i$ alive at time $t$. I modeled 3 total poult monitoring events $k$ for each brood $i$ at 7, 14, and 28 days post-hatch $(t=8,15,29)$.

I further assumed a logit-linear model for daily survival probability which I model as a function of brood age (1-28 days post-hatch), age of the brood-rearing hen (adult or yearling), year of the study (2017 or 2018), daily rain accumulation (hereafter "precipitation") (mm), and daily mean temperature (hereafter "temperature") $\left({ }^{\circ} \mathrm{C}\right)$. I modeled the interaction between precipitation and temperature. I assumed logistic $(0,1)$ prior distributions for all slope coefficients, and I assumed a uniform $(0,1)$ prior distribution for the probability of detection $p$.

I fit all of the models using Bayesian methods to maintain a consistent analytical approach as I would ultimately combine all parameters into a matrix projection model. I fit each model with JAGS version 4.3.0 (Plummer, 2003) via the jagsUI version 1.4.9 interface (Kellner, 2018) in program $\mathrm{R}$ version 3.5.1 (R Core Team, 2018). I ran 3 chains for each model using trace plots to determine an adequate burn-in period and subsequently ran models until I achieved reasonable convergence $(\hat{R} \leq 1.1$; Gelman et al. (2013)). While interpreting output of the reproductive parameter models, if the $95 \%$ credible interval (CI) for the log-odds ratio (LOR) of the slope coefficient of a model covariate or interaction did not overlap 0 , I concluded that the covariate or interaction had an effect on the reproductive parameter.

\subsection{Results}

I captured 43 adult and 37 yearling wild turkey hens during the winter of 2017, and I captured an additional 42 yearling wild turkey hens during the winter of 2018 to replace birds lost during the first year of the study. Eight yearling hens captured during the first year of the study transitioned to the adult age-class for the second year of the study.

Nesting rate probabilities were estimated from a total of 155 hens that were alive on 1-April and available to nest during 2017 and 2018. The probability adult hens would attempt at least one nest was $0.801(95 \% \mathrm{CI}=0.681,0.894)$ while the probability yearling hens would attempt at least one nest was $0.740(95 \% \mathrm{CI}=0.601,0.854)$ (Figure 3.4). Hen body weight $(\mathrm{kg})$ at the time of capture had a positive effect on nesting rate (Table 3.1; Figure 3.5). The age-class of the hen and the year of the study did not have an effect on nesting rate (Table 3.1).

I observed a total of 147 nest attempts during this study. Sixty-five nest attempts occurred during 2017 and 82 occurred during 2018. Five nests were censored due to investigator interference causing the 
hen to abandon the nest (Table 3.2). Five additional nests were censored because I was unable to visit the nest site due to lack of landowner permissions ("Unknown"; Table 3.2). Therefore, nest survival probabilities were estimated from a total of 137 nests and were comprised of 471 daily intervals from April 23, 2017 through August 6, 2018 for a total of 2,412 days where an individual nest was at risk of failure. Over a 28-day average incubation period, probability of survival for nests laid by adult hens was $0.521(95 \% \mathrm{CI}=0.420,0.624)$ while the probability of survival for nests laid by yearling hens was $0.464(95 \% \mathrm{CI}=0.334,0.603)$ (Figure 3.6). Fifty-six of 147 nest attempts were successful, while 91 were failures. Predation of eggs was the leading cause of nest failure, accounting for over half of all failed nest attempts (Table 3.2). Haying of the vegetation surrounding the nest and death of the incubating hen were also major sources of nest failure, accounting for $14 \%$ and $11 \%$ of all failed nest attempts, respectively (Table 3.2 ).

Grassland habitat was the most frequently selected nesting habitat type (Table 3.3). Twenty-two of the nests placed within the grassland habitat type were placed within a CRP grassland, specifically, while 37 were placed within a non-CRP grassland (Table 3.3). The fewest number of nests were placed within the agriculture habitat type (Table 3.3). Most of the nests placed within agriculture were placed in alfalfa hayfields, specifically, while the others were placed within or adjacent to row-crop agriculture (Table 3.3). None of the nests placed in alfalfa hayfields were successful (Table 3.3).

Precipitation and temperature had an interactive effect on daily nest survival probability (Table 3.1). On days without precipitation, daily nest survival probability was lowest when the mean daily temperature was $19.2^{\circ} \mathrm{C}$ (Figure 3.7 ). On days with precipitation, daily nest survival probability was lowest when the mean daily temperature was $24.8^{\circ} \mathrm{C}$ (Figure 3.7 ). Daily nest survival probability was lower on warm, wet days than on cool, wet days (Figure 3.7). Distance from the nearest road had a positive effect on daily nest survival probability (Table 3.1; Figure 3.8).

None of the variables measuring microhabitat conditions around the nest bowl (i.e., mean VOR, VOR variation, minimum VOR, mean total cover, minimum total cover, percent canopy cover, and the presence of a guard object) affected daily nest survival probability (Table 3.1). Daily nest survival probability did not differ between habitat types (i.e., agriculture, forest, grassland, and pasture), and daily nest survival probability was not affected by the nest being within an alfalfa hayfield or within a CRP grassland (Table 3.1). Distance from the nearest town did not affect daily nest survival probability (Table 3.1). Daily nest survival probability was not affected by the age-classes of the nesting hen, hen body weight $(\mathrm{kg})$ at the time of capture, year of the study, nest attempt (i.e., first nest or re-nest), or nest initiation date (Table 3.1).

Re-nesting rate probabilities were estimated from a total of 60 hens that were available to re-nest after a failed first nest attempt during 2017 and 2018. The probability adult hens would re-nest was 0.5961 $(95 \% \mathrm{CI}=0.398,0.779)$ while the probability yearling hens would re-nest was $0.251(95 \% \mathrm{CI}=0.090$, 
0.470) (Figure 3.4). Adult hens were more likely to re-nest than yearling hens (Table 3.1; Figure 3.4). The year of the study and hen body weight $(\mathrm{kg})$ at the time of capture did not affect re-nesting rate (Table 3.1).

Clutch size was estimated from a sample size of 104 nests laid during 2017 and 2018. Nests were excluded from the analysis if an accurate count of eggs could not be obtained (i.e., the nest was depredated and only some egg fragments were found). During the first nest attempt, the mean clutch size laid by adult hens was $10.4(95 \% \mathrm{CI}=9.3,11.6)$ while the mean clutch size laid by yearling hens was $9.8(95 \%$ $\mathrm{CI}=8.7,11.0)$ (Figure 3.9). During a re-nest attempt, the mean clutch size laid by adult hens was $10.4(95 \% \mathrm{CI}=9.0,11.8)$ while the mean clutch size laid by yearling hens was $9.8(95 \% \mathrm{CI}=8.2,11.6)$ (Figure 3.9). The age-class of the hen, year of the study, hen body weight (kg) at the time of capture, and nest attempt did not affect clutch size (Table 3.1).

Hatchability was estimated from a sample size of 54 nests that successfully hatched during 2017 and 2018. One nest was censored from the analysis because it was suspected to be a dump-nest (i.e., multiple hens had laid eggs into one nest bowl) so the clutch size was inflated and the quality of eggs could have differed between the hens that laid them. Hatchability of clutches laid by adult hens was $0.875(95 \%$ $\mathrm{CI}=0.822,0.916)$ while the hatchability of clutches laid by yearling hens was $0.867(95 \% \mathrm{CI}=0.802$, 0.921) (Figure 3.10). The age-class of the hen, year of the study, and hen body weight $(\mathrm{kg})$ at the time of capture did not affect hatchability (Table 3.1).

Poult survival probabilities were estimated from a total of 55 broods over a 28-day post-hatch interval. Over the 28-day post-hatch interval, probability of survival for poults reared by adult hens was 0.355 $(95 \% \mathrm{CI}=0.352,0.367)$ while the probability of survival for poults reared by yearling hens was 0.197 $(95 \% \mathrm{CI}=0.195,0.208)$ (Figure 3.11). The age of brood, the age of the brood-rearing hen, the year of the study, and precipitation all had an effect on daily poult survival probability (Table 3.1; Figure 3.12). Temperature did not affect daily poult survival probability (Table 3.1).

\subsection{Discussion}

Nesting rates and poult survival probabilities appear to be lower than previously published estimates. Nesting rate for both age-classes of eastern wild turkey hens in northeastern South Dakota is lower than previous estimates of nesting rate from expanding populations in South Dakota (Leif, 2001; Lehman et al., 2001; Shields and Flake, 2006) and Minnesota (Porter et al., 1983), and lower than an established population in Missouri (Vangilder and Kurzejeski, 1995) (Table 3.4). Poult survival probabilities for broods reared by both adult and yearling age-classes are lower than estimates from established populations in Missouri (Vangilder and Kurzejeski, 1995), Iowa (Hubbard et al., 1999b), and Wisconsin (Paisley et al., 1998), as well as an expanding population in South Dakota (Lehman et al., 2001) (Table 3.4). In 
Chapter 4, I determined that the population growth rate is influenced by adult hen reproductive contribution (i.e., recruitment of offspring from adult hens into the population). Specifically, adult hen nesting rate, and the clutch size and nest survival of nests laid by adult hens are the lower-level reproductive parameters that have the greatest effect on the rate of population change (see results from Chapter 4). These lower-than-normal estimates of nesting rate and poult survival probability could be contributing to lower productivity of adult hens in northeastern South Dakota. If the population is not reproducing well enough to replace individuals throughout the year, this low recruitment could be contributing to the suspected population decline.

Estimates of nest survival, re-nesting rate, clutch size, and hatchability for wild turkeys in northeastern South Dakota are similar to, or even greater than, previously published estimates from field studies of eastern wild turkeys in the Midwest (Porter et al., 1983; Vangilder et al., 1987; Vangilder and Kurzejeski, 1995; Hubbard et al., 1999b; Paisley et al., 1998; Leif, 2001; Lehman et al., 2001; Shields and Flake, 2006; Switzer and Tucker, 2009; Pollentier et al., 2014b) (Table 3.4). As expected, nesting rate increased as hen body weight increased (Figure 3.5), as heavier birds are better able to complete the energetically expensive task of incubating a clutch (Porter et al., 1983). Similar to an established population of turkeys in Missouri (Vangilder and Kurzejeski, 1995) and a previous study conducted in northeastern South Dakota (Shields and Flake, 2006), I found that nesting rate did not differ by age-class (Figure 3.4; Table 3.4). Since nesting rate is strongly influenced by hen body weight, and the mean body weights of adult $(4.6-\mathrm{kg} ; 95 \% \mathrm{CI}=3.5,6.0)$ and yearling $(4.1-\mathrm{kg} ; 95 \% \mathrm{CI}=3.4,4.8)$ hens that nested were not different, it is not surprising that nesting rate did not differ between age-classes. Hen body condition, not hen age, appears to be a better indicator for whether or not a hen will initiate a nest in northeastern South Dakota.

I found that precipitation and temperature affected nest survival probability. While increases in daily precipitation had a positive effect on nest survival probability on cool days (Figure 3.7, C), increases in daily precipitation did not have an effect on nest survival probability on warm days (Figure 3.7, D). On warm days, nest survival probability was relatively low (compared to cool days), regardless of the amount of precipitation that accumulated that day (Figure 3.7, D). Additionally, on days with precipitation, survival probability decreased as the mean daily temperature increased (Figure 3.7, B). This contradicts previously published literature that suggests precipitation, especially greater-than-normal levels of precipitation, have deleterious effects on daily nest survival probability (Roberts and Porter, 1998b; Lehman et al., 2008b). However, during this study, the total precipitation accumulation during the spring was, on average, lower-than-normal (Figure 3.13). Because spring appeared to be, on average, drier-than-normal during this study, I did not observe the deleterious effect of precipitation on nest survival. In addition, nest survival probability was lower on warm, wet days than it was on cool, wet days (Figure 3.7). Syrotuck (2000) hypothesized that warm, wet conditions enhance growth of scent-causing 
bacteria. If mammalian predators use olfactory cues to locate incubating hens (Storaas, 1988), and incubating hens are more easily detectable on warm, wet days due to increased bacterial growth (Syrotuck, 2000), decreased nest survival during these conditions is expected.

As expected, nest survival decreased when nests were placed close to roads due to increased incidences of nest predation (DeGregorio et al., 2014). I expected that distance from the nearest town to have a negative effect on nest survival. Nesting within more "urban" areas, such as rural towns, can reduce the risk of hen mortality while nesting since the main predator of wild turkeys in this study area - coyotetend to avoid these areas (Gosselink, 2003). However, I failed to detect an effect of distance from the nearest town on nest survival probability.

While I did not detect an effect of VOR or total cover on nest survival, Lutz and Crawford (1987) and Badyaev (1995) suggested that nests with greater amounts of lateral cover immediately surrounding the nest bowl had a better chance of surviving the incubation period. Leif (2001) found that hens often nested next to a guard object to provide additional lateral cover from predators; and Lazarus and Porter (1985), Wertz and Flake (1988), and Lehman et al. (2002) found that wild turkey hens often nested where there was some form of overhanging vegetative cover to obscure the nest from overhead predators. However, I did not detect an effect of the presence of a guard object or percent canopy cover (i.e., overhead visual obstruction) on nest survival probability.

Since none of the nests placed within alfalfa were successful (Table 3.3), I expected to see a negative effect of nesting within alfalfa on nest survival probability. However, I was unable to detect a direct effect of nesting within alfalfa on nest survival. It is likely that the sample of nests within alfalfa $(\mathrm{n}=12 ; 8 \%$ of all nest attempts), was not large enough to detect an effect on nest survival probability. Additionally, while I expected to see a positive effect of nesting within CRP grasslands on nest survival probability, I failed to detect an effect. This could be attributed to the fact that only 23 nest attempts occurred within CRP (16\%) and less than half of the nests laid within CRP were successful (48\%). I also failed to detect any difference in nest survival probability between habitat types (i.e., grassland, forest, pasture, agriculture).

Similar to previous findings from Minnesota (Porter et al., 1983), Missouri (Vangilder and Kurzejeski, 1995), Wisconsin (Paisley et al., 1998), and northeastern South Dakota (Shields and Flake, 2006), I did not find an effect of hen age on nest survival. Porter et al. (1983) determined that a hen weighing 4.3-kg or more has greater potential for reproductive success than a hen weighing less than 4.3-kg. Since mean body weight did not differ by age-class, and the mean body weight of all hens that nested during this study was above the threshold defined by Porter et al. (1983) $(4.4-\mathrm{kg} ; 95 \% \mathrm{CI}=3.4,5.8)$, it is not surprising that nest survival was not affected by hen age or weight.

I found that nest survival was not different between first nest attempts or re-nest attempts, similar to populations in Wisconsin (Paisley et al., 1998) and northeastern South Dakota (Shields and Flake, 
2006). Since nest survival does not differ by attempt, all nesting attempts will have the same relative contribution to productivity. Similar to Vangilder and Kurzejeski (1995), I found that nest survival did not vary based on the date of incubation initiation, meaning that nest survival probabilities are consistent throughout the nesting season (i.e., nests laid early in the season have the same survival probability as nests laid later in the season).

While I did not detect an effect of hen weight on the probability of re-nesting, I did find that adult hens were more likely to re-nest than yearling hens. This result is similar to previous studies of eastern wild turkeys in northeastern South Dakota (Lehman et al., 2001; Shields and Flake, 2006) and for a growing population in Wisconsin (Pollentier et al., 2014b) (Table 3.4). The probability of re-nesting may be influenced by hen age more than hen weight.

The re-nesting rate for adults was greater than, or similar to, estimates from previous field studies of eastern wild turkeys (Table 3.4). However, previous estimates of re-nesting rate for yearling hens are more variable, and the re-nesting rate found during this study was greater than some, and less than other, previously published rates (Table 3.4). Notably, the re-nesting rate for yearling hens during this study was greater than the re-nesting rate for yearling hens for a growing population of eastern wild turkeys in Wisconsin, where yearling hens did not attempt to re-nest at all (Pollentier et al., 2014b). Renesting improves overall productivity regardless of age (Porter et al., 1983); however, for this population of eastern wild turkeys I found that adult hen re-nesting rate has a greater influence on population growth than yearling hen re-nesting rate (see results from Chapter 4). Since re-nesting rates for adult hens are greater than, or similar to, re-nesting rates from other populations of eastern wild turkeys in the Midwest, the re-nesting rate of adult hens is likely having a positive influence on the reproductive contribution of turkeys in northeastern South Dakota. These high re-nesting rates could potentially be offsetting the negative impacts of lower-than-average nesting rates in this study area.

Similar to Porter et al. (1983) and Vander Haegen et al. (1988), I did not detect an effect of hen weight on clutch size or hatchability. I also did not detect a difference between clutch sizes and hatchability of eggs laid by adult or yearling hens. Porter et al. (1983), Vander Haegen et al. (1988), Vangilder and Kurzejeski (1995), Paisley et al. (1998), and Pollentier et al. (2014b) also determined that clutch size and hatchability did not vary by age-class. While Vangilder and Kurzejeski (1995) found that first nest clutch sizes were larger than re-nest clutch sizes in Missouri; Porter et al. (1983), Paisley et al. (1998), Pollentier et al. (2014b), and I determined that clutch size did not vary by nest attempt. The estimates of clutch size and hatchability were similar to other estimates for eastern wild turkeys (Table 3.4). Since clutch size of first nest attempts laid by adult hens has a relatively large impact on the population growth rate compared to other lower-level reproductive rates (see results from Chapter 4), clutch size could be contributing to the suspected population decline.

Greater-than-normal levels of precipitation, combined with cold temperatures, can be detrimental to 
daily poult survival probability (Healy and Nenno, 1985; Healy, 1992; Roberts and Porter, 1998a; Lehman et al., 2008a) by causing hypothermia-induced mortality while poults are young (Schmidt-Nielsen, 1997). However, I observed that precipitation had a positive effect, and temperature did not have an effect, on poult survival (Figure 3.12). Lehman et al. (2008a) attributed 11 poult mortality events to hypothermia induced by wet, cold weather conditions. Temperatures leading up to the hypothermia-caused poult mortality events detected by Lehman et al. (2008a) were much colder (mean minimum daily temperature $=1.5^{\circ} \mathrm{C}$ ) than the temperatures poults were exposed to during the 28-day post hatch interval during this study period (minimum mean daily temperature $=11.0^{\circ} \mathrm{C}$ ). It is possible that temperatures within the brood-rearing seasons captured by this study were not cold enough (mean daily temperature $=22.5^{\circ} \mathrm{C}$, $95 \% \mathrm{CI}=15.3,29.6)$ for precipitation events to cause hypothermia-induced poult mortality.

Similar to other studies, I found that poult survival probability increased with the age of the poult (number of days post-hatch) (Porter et al., 1983; Vander Haegen et al., 1988; Vangilder and Kurzejeski, 1995; Paisley et al., 1998; Hubbard et al., 1999b; Lehman et al., 2001; Shields and Flake, 2006; Switzer and Tucker, 2009; Pollentier et al., 2014b) (Figure 3.12). Poult age has a positive effect on poult survival because once poults reach approximately 2 weeks of age, they are able to escape ground predators by retreating into trees and roosting in trees at night (Spears et al., 2007). Additionally, older poults are better able to thermo-regulate (Healy and Nenno, 1985; Schmidt-Nielsen, 1997), and are therefore less susceptible to hypothermia (Roberts and Porter, 1998a; Lehman et al., 2008a). Poults reared by adult hens had a greater probability of survival than poults reared by yearling hens, which is unlike previous estimates of eastern wild turkey poult survival in northeastern South Dakota (Shields and Flake, 2006), but is similar to estimates of Merriam's wild turkey poult survival in the Black Hills Region of South Dakota (Lehman et al., 2008a). Adult hens may be better at protecting their young from environmental conditions and predators than yearling hens, leading to increased survival probability of poults reared by adult hens.

Poult survival was higher during 2017 than during 2018 (Figure 3.12). Annual variation in poult survival could be contributed to environmental stochasticity between brood-rearing seasons and fluctuations in predator abundance, and therefore predation risk, between years (Roberts and Porter, 1998a). The estimates of poult survival until 28-days post-hatch for broods reared by adult and yearling hens were lower than many previously published estimates (Table 3.4). However, in Chapter 4, I determined that poult survival did not have a strong effect on the population growth rate. Therefore, even though the estimates of poult survival during this study are lower-than-average, it is unlikely that low poult survival is driving the suspected population decline. 


\subsection{Management Implications}

While I did not observe a direct effect of nesting in grasslands, including CRP grasslands, versus nesting in non-grassland habitat on nest survival probability, it is possible that loss of grasslands across the landscape is having indirect effects on nest survival and overall productivity. Haying of alfalfa during the nesting season was a major source of nest and hen mortality during this study. Twelve nests $(8.2 \%$ of all attempts) were located within alfalfa fields and $0 \%$ of these nests were successful (Table 3.3). In addition, during most of the events where a nest was lost due to haying, the hen was killed as well (58.3\%). This resulted in 7 hens being killed by haying equipment (11\% of all hen mortality events; Chapter 2) that were subsequently unavailable to re-nest. Based on the onset of incubation, in 2017, $75 \%$ of all nests would have hatched by July 3rd, and in 2018, $75 \%$ of all nests would have hatched by July 9th. Delaying the cutting of alfalfa until the after the first week of July, could reduce the risk of hen mortality due to haying equipment since the majority of hens will be done incubating by this time. If hay must be cut before this time, installing a flushing bar on the cutting equipment can increase hen survival by pushing hens off of their nests and allowing them to escape the haying equipment (Klonglan et al., 1959). Klonglan et al. (1959) found that for pheasant populations in Iowa, the use of flushing bars on haying equipment reduced hen mortality by $38 \%$.

Additionally, 2 bearded hens were harvested during the 2017 spring bearded-only hunting season. While one hen was harvested in early April, and was likely not yet engaging in nesting activities, the other hen was harvested in late April when several hens $(\sim 6)$ had already began laying nests. Even though harvest only accounted for $3 \%$ of the total hen mortality over the study period, harvest of hens prior to the nesting and brood-rearing season could lead to declines in population growth by decreasing the number of individuals that are able to make reproductive contributions that year. If concerns of a declining population persist, designating a "male-only" season would eliminate legal harvest of hens altogether. Reducing human-caused sources of mortality for wild turkey hens, whether by harvest of individuals or by accidental killing due to haying, will improve overall reproductive probability. Improvements to productivity and recruitment could potentially stabilize, or lead to growth of, the population of eastern wild turkeys in northeastern South Dakota. 
Table 3.1: Population-level mean log-odds ratio (LOR), lower 95\% credible interval (CI) level, and upper 95\% CI level for each covariate and interaction used to model nesting rate, nest survival, re-nesting rate, clutch size, hatchability, and poult survival during 2017 and 2018 for the population of eastern wild turkeys in northeastern South Dakota, USA.

\begin{tabular}{|c|c|c|c|c|}
\hline Parameter & Covariate & LOR & Lower CI Level & Upper CI Level \\
\hline \multirow[t]{4}{*}{ Nesting Rate } & $(\text { Intercept })^{1}$ & 0.910 & 0.252 & 1.566 \\
\hline & Hen Age: Adult & 0.353 & -0.453 & 1.190 \\
\hline & Study Year: 2018 & 0.165 & -0.534 & 0.897 \\
\hline & Hen Weight & 0.517 & 0.002 & 1.030 \\
\hline \multirow[t]{25}{*}{ Nest Survival } & $(\text { Intercept })^{1}$ & 3.309 & 1.787 & 4.960 \\
\hline & Hen Age: Adult & 0.785 & -0.609 & 2.328 \\
\hline & Study Year: 2018 & 0.745 & -0.655 & 2.225 \\
\hline & Hen Weight & 0.386 & -0.390 & 1.208 \\
\hline & Nest Attempt: Re-Nest & -0.090 & -1.992 & 1.799 \\
\hline & Initiation Date & 0.101 & -0.876 & 0.996 \\
\hline & Precipitation & 1.444 & 0.413 & 3.031 \\
\hline & Temperature & 0.043 & -0.523 & 0.643 \\
\hline & Temperature $^{2}$ & 0.655 & 0.176 & 1.229 \\
\hline & Precipitation * Temperature & -1.409 & -2.558 & -0.439 \\
\hline & Precipitation $^{*}$ Temperature ${ }^{2}$ & 0.203 & -0.747 & 1.394 \\
\hline & Habitat Type: Agriculture & -0.326 & -2.456 & 1.682 \\
\hline & Habitat Type: Forest & 0.569 & -1.435 & 2.659 \\
\hline & Habitat Type: Pasture & 1.149 & -0.476 & 2.896 \\
\hline & Within Alfalfa Hayfield & -1.146 & -4.229 & 1.474 \\
\hline & Within CRP Grassland & 0.888 & -0.895 & 2.743 \\
\hline & \% Canopy Cover & -0.107 & -1.131 & 0.865 \\
\hline & Guard Object Present & 0.729 & -1.019 & 2.582 \\
\hline & Mean VOR & 1.251 & -0.203 & 2.739 \\
\hline & VOR Variation & 0.236 & -0.850 & 1.333 \\
\hline & Minimum VOR & 0.674 & -1.020 & 2.275 \\
\hline & Mean Total Cover & -0.797 & -1.729 & 0.093 \\
\hline & Minimum Total Cover & 0.412 & -0.560 & 1.426 \\
\hline & Distance to Road & 0.682 & 0.008 & 1.412 \\
\hline & Distance to Town & -0.758 & -1.737 & 0.108 \\
\hline \multirow[t]{4}{*}{ Re-nesting Rate } & $(\text { Intercept })^{1}$ & -1.778 & -3.045 & -0.658 \\
\hline & Hen Age: Adult & 1.574 & 0.377 & 2.824 \\
\hline & Study Year: 2018 & 0.609 & -0.487 & 1.746 \\
\hline & Hen Weight & -0.165 & -0.785 & 0.435 \\
\hline \multirow[t]{5}{*}{ Clutch Size } & $(\text { Intercept })^{1}$ & 2.322 & 2.198 & 2.441 \\
\hline & Hen Age: Adult & 0.060 & -0.075 & 0.200 \\
\hline & Study Year: 2018 & -0.042 & -0.164 & 0.079 \\
\hline & Hen Weight & 0.023 & -0.044 & 0.090 \\
\hline & Nest Attempt: Re-Nest & -0.003 & -0.151 & 0.138 \\
\hline \multirow[t]{4}{*}{ Hatchability } & $(\text { Intercept })^{1}$ & 2.077 & 1.510 & 2.673 \\
\hline & Hen Age: Adult & 0.059 & -0.598 & 0.703 \\
\hline & Study Year: 2018 & -0.176 & -0.707 & 0.342 \\
\hline & Hen Weight & -0.006 & -0.304 & 0.317 \\
\hline \multirow[t]{7}{*}{ Poult Survival } & $(\text { Intercept })^{1}$ & 3.887 & 3.365 & 4.536 \\
\hline & Poult Age & 1.267 & 1.064 & 1.488 \\
\hline & Hen Age: Adult & 0.446 & 0.193 & 0.703 \\
\hline & Study Year: 2018 & -0.253 & -0.497 & -0.010 \\
\hline & Precipitation & 1.637 & 0.112 & 3.669 \\
\hline & Temperature & -0.416 & -0.957 & 0.122 \\
\hline & Precipitation $*$ Temperature & -1.202 & -3.061 & 0.824 \\
\hline
\end{tabular}

${ }^{1}$ References for Hen Age: Yearling, Study Year: 2017, Nest Attempt: First Nest, and Habitat Type: Grassland are contained within the model intercept. 
Table 3.2: Causes of nest failure for nests laid by eastern wild turkey hens during 2017 and 2018 in northeastern South Dakota, USA.

\begin{tabular}{lcc}
\hline Cause of Death & Count & Percentage \\
\hline Abandoned & 7 & $8 \%$ \\
Death of Incubating Hen ${ }^{1}$ & 10 & $11 \%$ \\
Haying & 13 & $14 \%$ \\
Investigator Interference & 5 & $5 \%$ \\
Predation of Eggs & 47 & $52 \%$ \\
Trampled by Livestock & 4 & $4 \%$ \\
Unknown & 5 & $5 \%$ \\
\hline Total & 91 \\
\hline${ }^{1} 9$ events caused by predation; 1 1 event caused \\
\multicolumn{2}{l}{ by a vehicle collision }
\end{tabular}


Table 3.3: Habitat types and sub-habitat types of nest sites selected by eastern wild turkey hens during 2017 and 2018 in northeastern South Dakota, USA.

\begin{tabular}{llcc}
\hline Habitat Type & Sub-Habitat Type & No. of Nests & No. of Successful Nests \\
\hline Agriculture & & 21 & 2 \\
& Row-Crop Agriculture $^{1}$ & 9 & 2 \\
Forest & Alfalfa Hayfield & 12 & 0 \\
Grassland & & 31 & 11 \\
& & 59 & 28 \\
& CRP Grassland & 11 \\
Pasture & Other Grassland & 22 & 17 \\
\hline Total & & 37 & 15 \\
\hline
\end{tabular}

${ }^{1}$ One nest was located within a field of barley (Hordeum vulgare); 8 others were located adjacent to a row-crop field

${ }^{2}$ A grassland enrolled in the Conservation Reserve Program 
Table 3.4: Estimates of nesting rate, re-nesting rate, nest success, clutch size, hatchability, and poult survival from a population of eastern wild turkeys in northeastern South Dakota (current study) compared to published estimates from field studies of eastern wild turkeys. If two estimates are presented for a given study, the first estimate indicates the value of that parameter for yearling hens and the second estimate indicates the value of that parameter for adult hens. Ranges of estimates represent variation in a parameter within a sample of both yearling and adult hens.

\begin{tabular}{|c|c|c|c|c|c|c|c|}
\hline State & $\begin{array}{l}\text { Nesting } \\
\text { Rate }\end{array}$ & $\begin{array}{c}\text { Re- } \\
\text { nesting } \\
\text { Rate }\end{array}$ & $\begin{array}{c}\text { Nest } \\
\text { Success }\end{array}$ & $\begin{array}{l}\text { Clutch } \\
\text { Size }\end{array}$ & Hatchability & $\begin{array}{l}\text { Poult } \\
\text { Survival }\end{array}$ & Source \\
\hline South Dakota & $74 \%, 80 \%$ & $25 \%, 60 \%$ & $46 \%, 52 \%$ & $9.8,10.4$ & $87 \%, 88 \%$ & $20 \%, 36 \%$ & $\begin{array}{l}\text { (Current } \\
\text { Study) }\end{array}$ \\
\hline Minnesota & $88 \%, 96 \%$ & $70 \%, 57 \%$ & $61 \%, 64 \%$ & $11.1,12.8$ & $83 \%, 76 \%$ & $39 \%, 32 \%$ & $\begin{array}{l}\text { Porter et al. } \\
1983\end{array}$ \\
\hline Massachusetts & $\begin{array}{l}81 \% \\
100 \%\end{array}$ & $33 \%, 57 \%$ & $33 \%, 68 \%$ & $11.7,12.8$ & $83 \%, 86 \%$ & $31 \%, 39 \%$ & $\begin{array}{l}\text { Vander } \\
\text { Haegen } \\
\text { et al. } 1988\end{array}$ \\
\hline Missouri & $\begin{array}{l}91.5- \\
100 \%\end{array}$ & $\begin{array}{l}46.1 \% \\
38.8 \%\end{array}$ & $\begin{array}{l}20.4 \% \\
34.8 \%\end{array}$ & 10.38 & $89.8 \%$ & $45.6 \%$ & $\begin{array}{l}\text { Vangilder } \\
\text { and } \\
\text { Kurzejeski } \\
1995\end{array}$ \\
\hline Iowa & & & & & & $40-52 \%$ & $\begin{array}{l}\text { Hubbard } \\
\text { et al. } 1999 b\end{array}$ \\
\hline Wisconsin & $\begin{array}{l}78.6 \% \\
97.6 \%\end{array}$ & $\begin{array}{l}42.1 \% \\
59.6 \%\end{array}$ & $\begin{array}{l}4.7 \% \\
16.0 \%\end{array}$ & $10.3,11.2$ & $87.1 \%$ & $47.3 \%$ & $\begin{array}{l}\text { Paisley et al. } \\
1998\end{array}$ \\
\hline South Dakota & $91 \%$ & $26 \%$ & $41 \%$ & 10.4 & $92.7 \%$ & & Leif 2001 \\
\hline South Dakota & $86 \%$ & $59 \%$ & $70 \%$ & 10.5 & & $51 \%$ & $\begin{array}{l}\text { Lehman } \\
\text { et al. } 2001\end{array}$ \\
\hline South Dakota & $\begin{array}{l}90.5 \% \\
94.3 \%\end{array}$ & $\begin{array}{l}22.2 \% \\
51.4 \%\end{array}$ & $\begin{array}{l}47.6 \% \\
50.6 \%\end{array}$ & & & $36.4 \%$ & $\begin{array}{l}\text { Shields and } \\
\text { Flake } 2006\end{array}$ \\
\hline South Dakota & $72-87 \%$ & & $34.4 \%$ & $9.0-10.2$ & $88 \%$ & & $\begin{array}{l}\text { Switzer and } \\
\text { Tucker } 2009\end{array}$ \\
\hline Wisconsin & $\begin{array}{l}34.4 \% \\
90.1 \%\end{array}$ & $\begin{array}{l}0.0 \% \\
41.2 \%\end{array}$ & $\begin{array}{l}3.1 \% \\
33.0 \%\end{array}$ & 10.67 & $92 \%$ & $36.6 \%$ & $\begin{array}{l}\text { Pollentier } \\
\text { et al. } 2014 b\end{array}$ \\
\hline
\end{tabular}




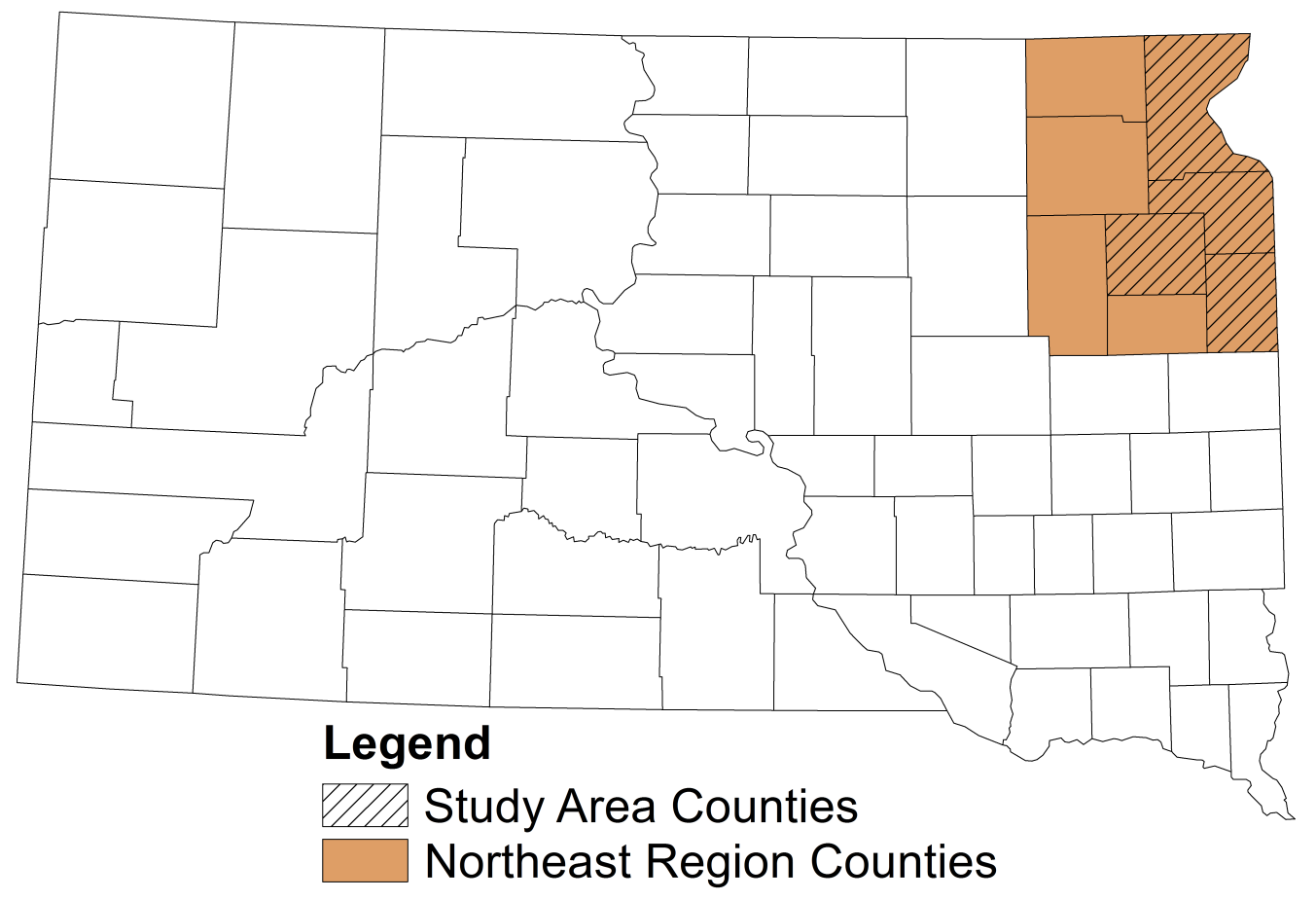

Figure 3.1: Map of the counties included in the Northeast Region of South Dakota, USA (Marshall, Roberts, Day, Grant, Clark, Codington, Deuel, and Hamlin Counties) and the counties included within the study area extent. 


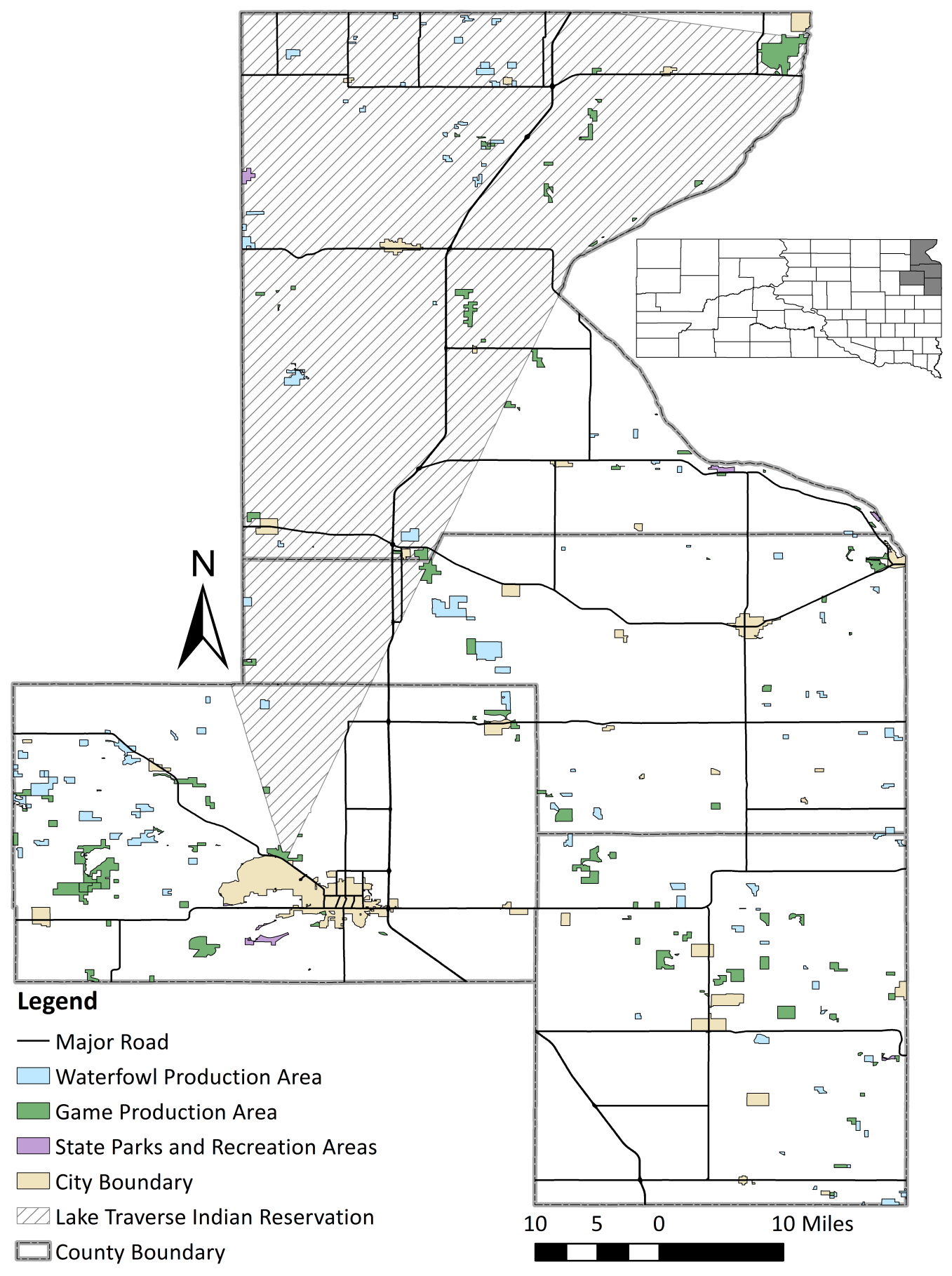

Figure 3.2: Map of land ownership across Codington, Deuel, Grant, and Roberts Counties in northeastern South Dakota, USA. White areas within county boundaries indicate privately owned lands. 


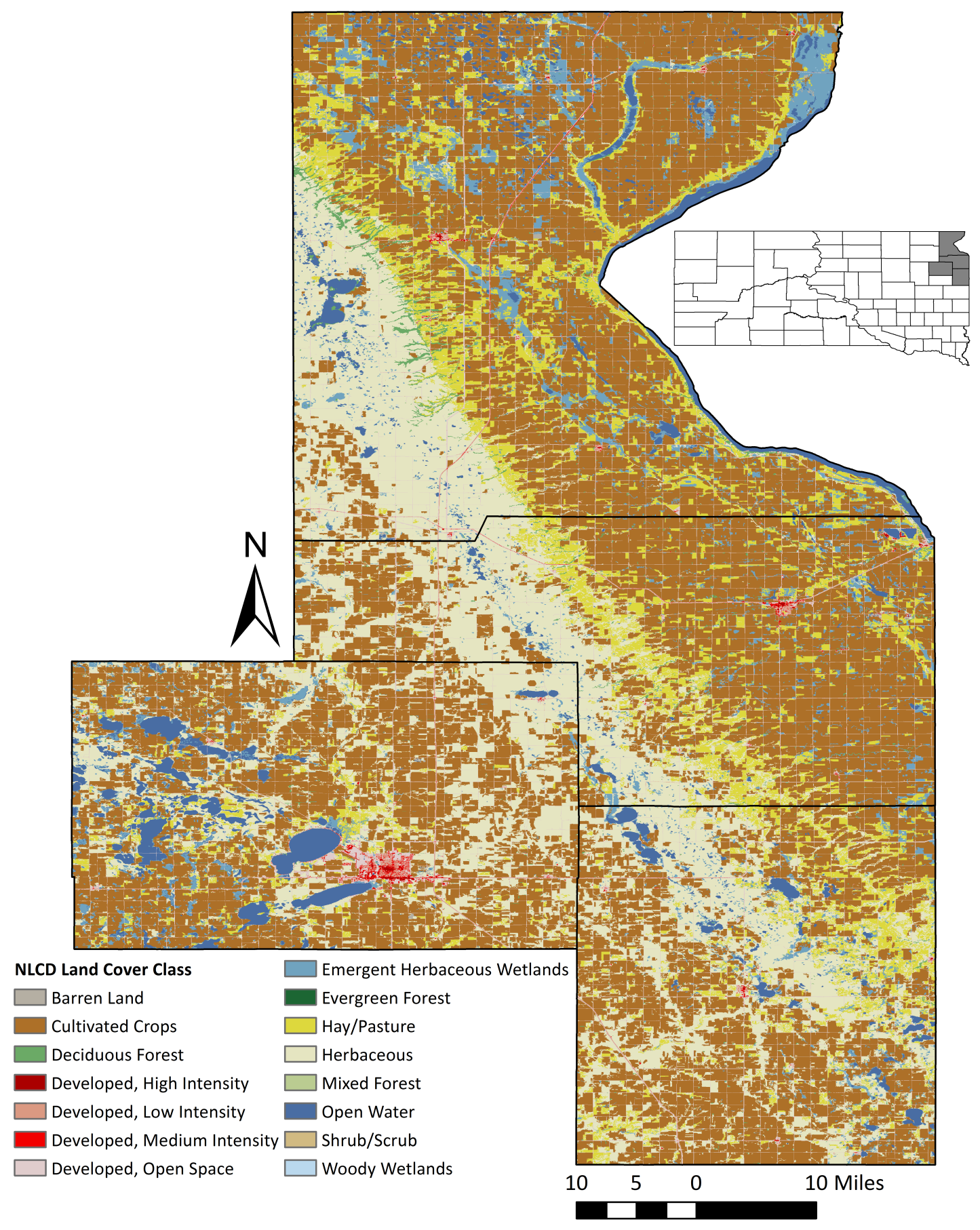

Figure 3.3: National Land Cover Database (2016) land cover classes for Codington, Deuel, Grant, and Roberts Counties in northeastern South Dakota, USA. 

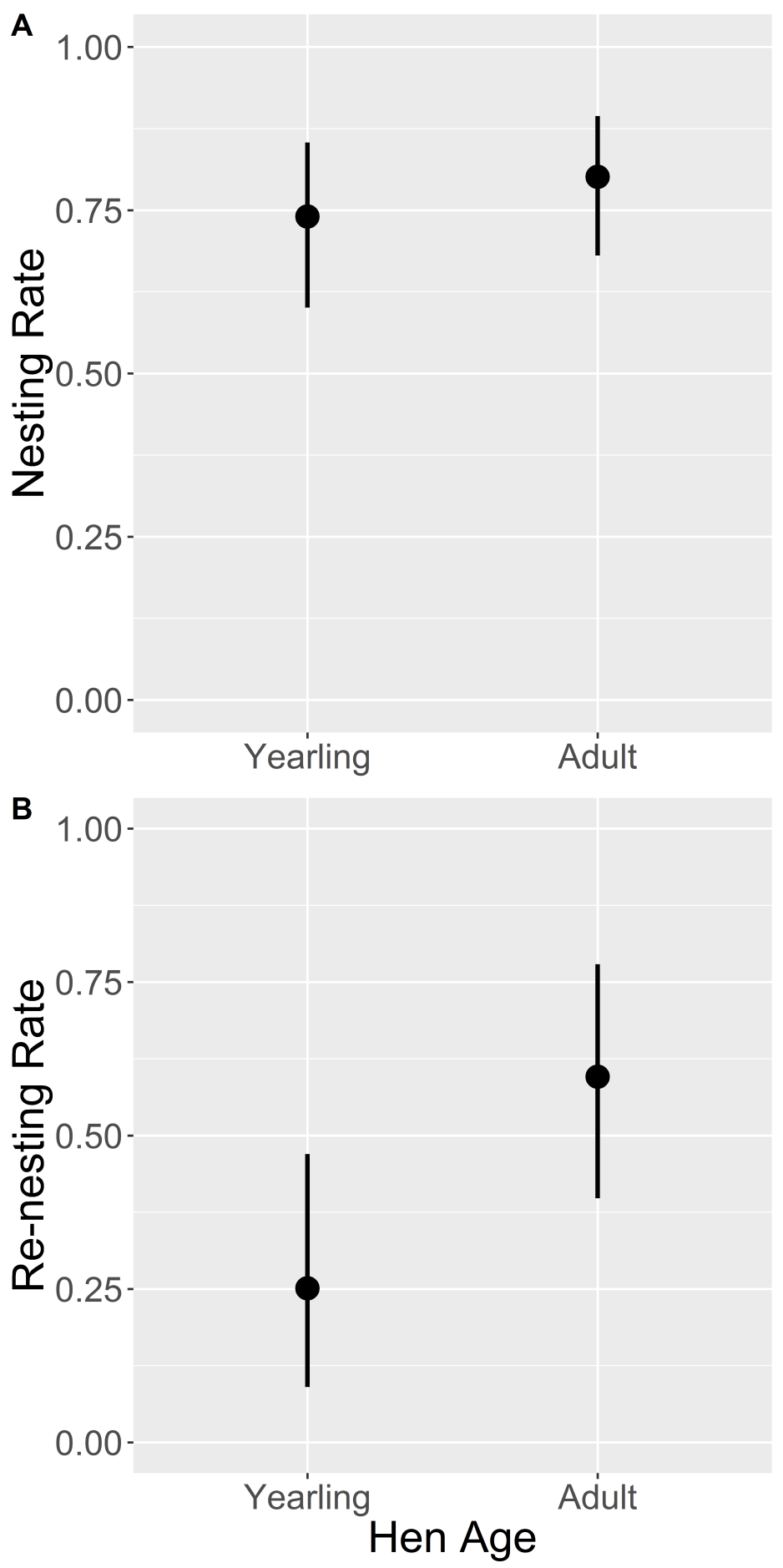

Figure 3.4: Probability of nesting (A) and re-nesting (B) for yearling and adult eastern wild turkey hens during 2017 and 2018 in northeastern South Dakota, USA. 

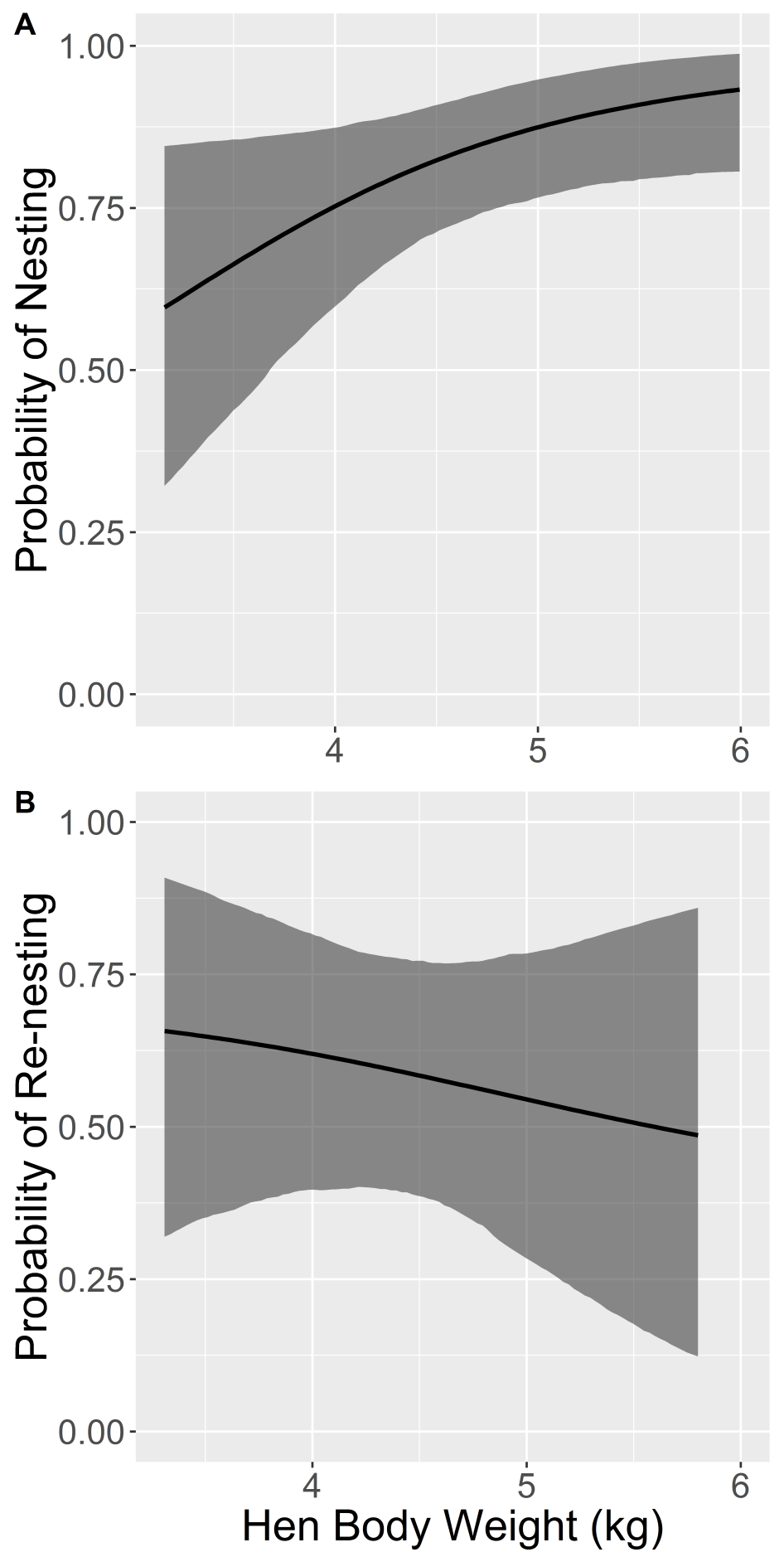

Figure 3.5: Effect of hen weight $(\mathrm{kg})$ on the probability of nesting (A) and re-nesting (B) for yearling and adult eastern wild turkey hens during 2017 and 2018 in northeastern South Dakota, USA. 
1.00

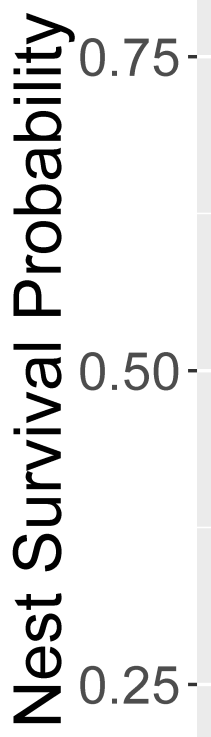

0.00

\section{Yearling}

Hen Age

Figure 3.6: Probability of survival over a 28-day incubation period for nests laid by yearling and adult eastern wild turkey hens during 2017 and 2018 in northeastern South Dakota, USA. 

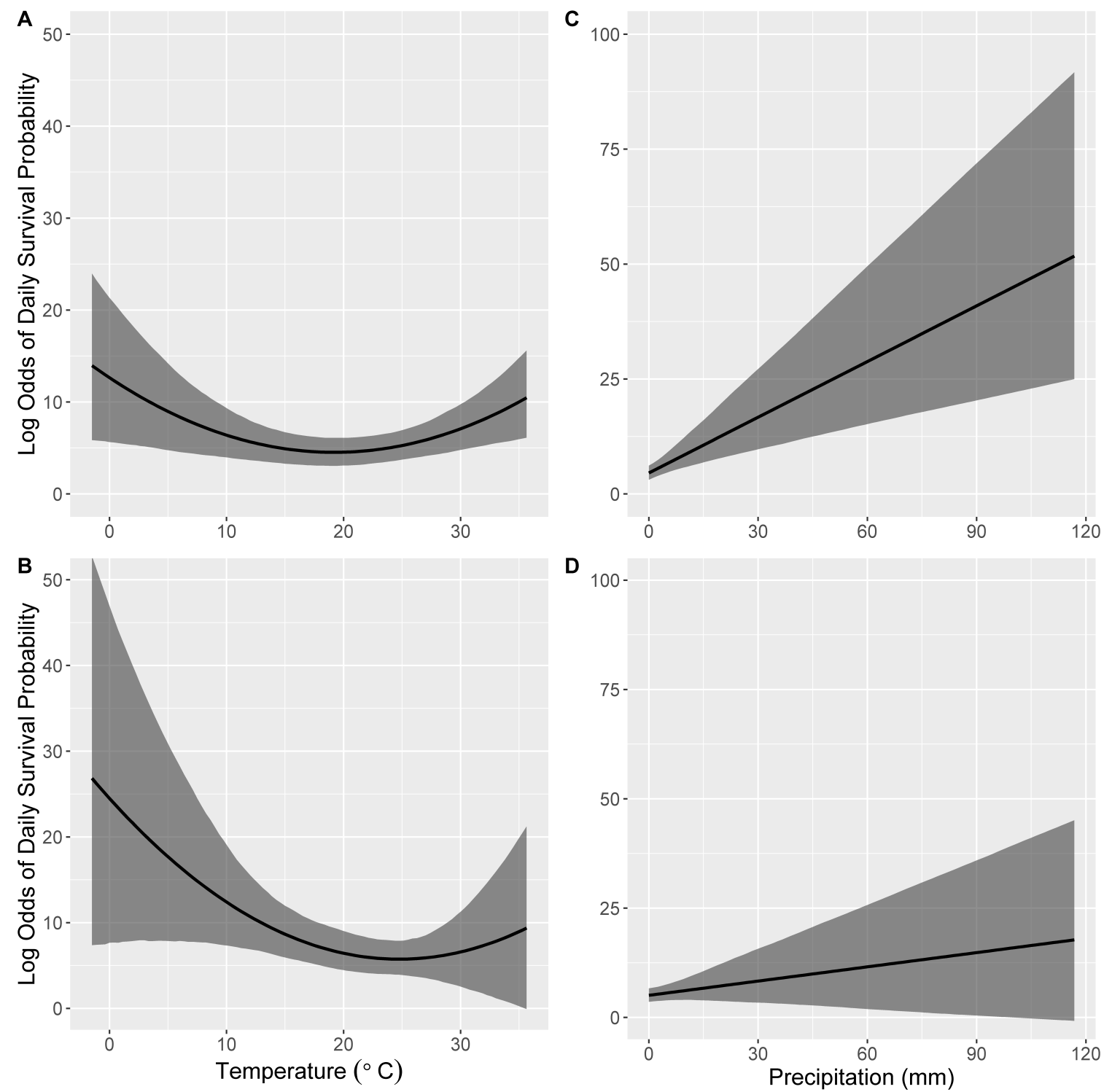

Figure 3.7: Effect, on the log-odds scale, of temperature $\left({ }^{\circ} \mathrm{C}\right)$ on days without precipitation (A) temperature on days with precipitation $(\mathrm{B})$ precipitation $(\mathrm{mm})$ on cool days $(\mathrm{C})$ and precipitation on warm days (D) on daily nest survival probability for nests laid by eastern wild turkey hens during 2017 and 2018 in northeastern South Dakota, USA. Daily nest survival probability was lowest when the mean daily temperature was $19.2^{\circ} \mathrm{C}$ on days without precipitation $(\mathrm{A})$ and $24.8^{\circ} \mathrm{C}$ on days with precipitation (B). 


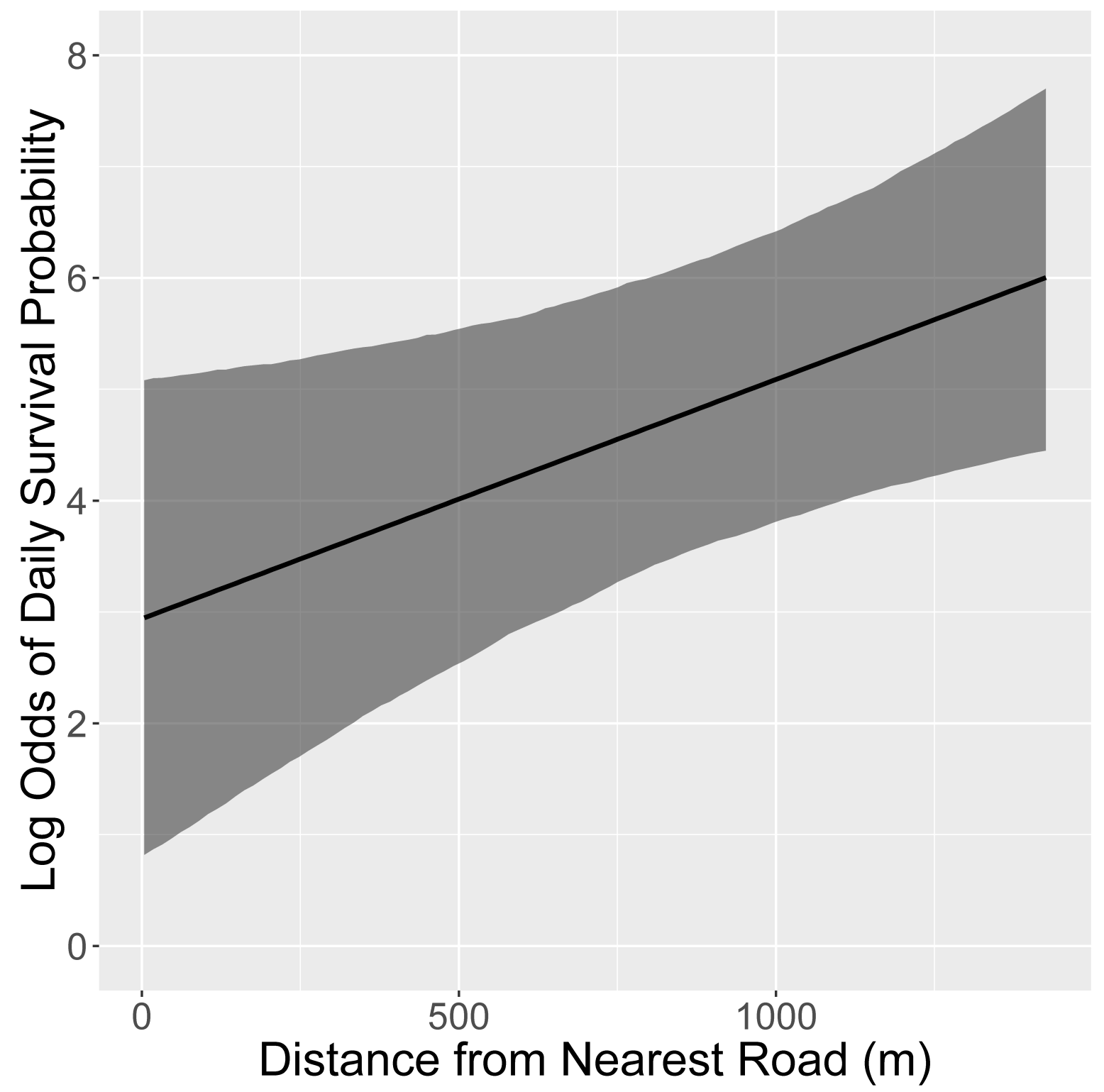

Figure 3.8: Effect, on the log-odds scale, of distance from the nearest road $(\mathrm{m})$ on daily nest survival probability for nests laid by eastern wild turkey hens during 2017 and 2018 in northeastern South Dakota, USA. 


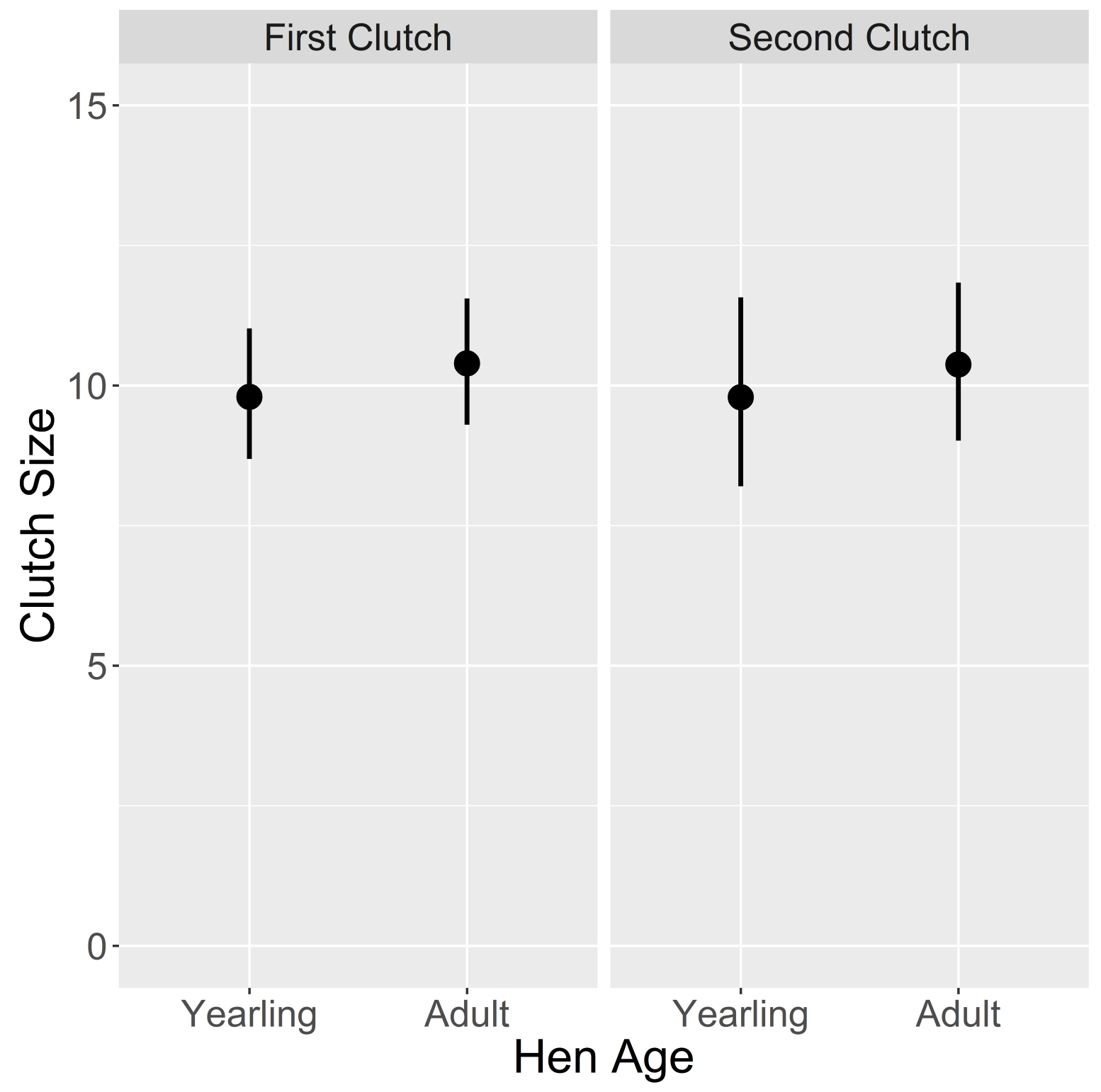

Figure 3.9: Mean clutch size for first and second nest attempts made by yearling and adult eastern wild turkey hens during 2017 and 2018 in northeastern South Dakota, USA. 


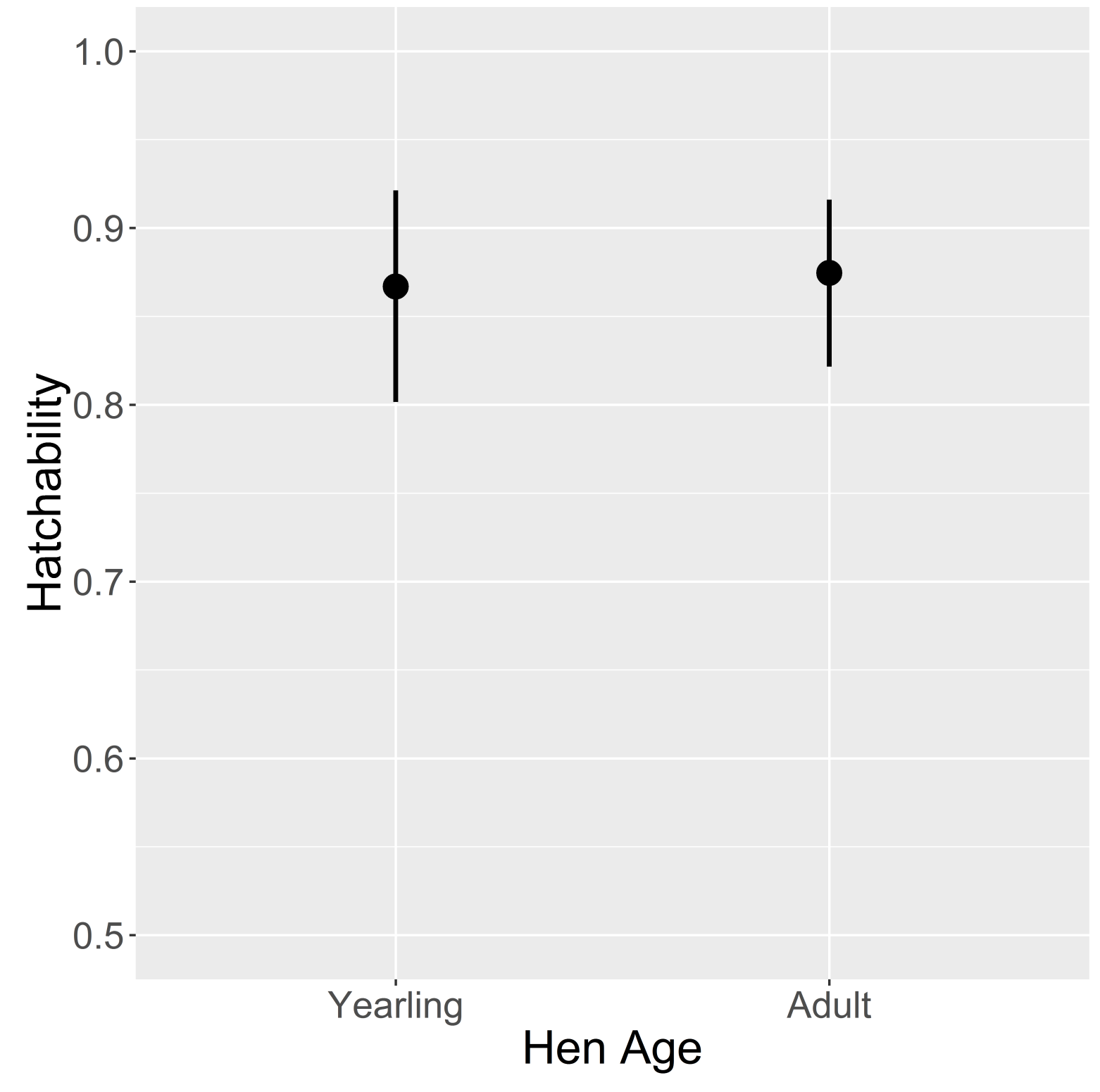

Figure 3.10: Hatchability of eggs for all successful nest attempts made by yearling and adult eastern wild turkey hens during 2017 and 2018 in northeastern South Dakota, USA. 


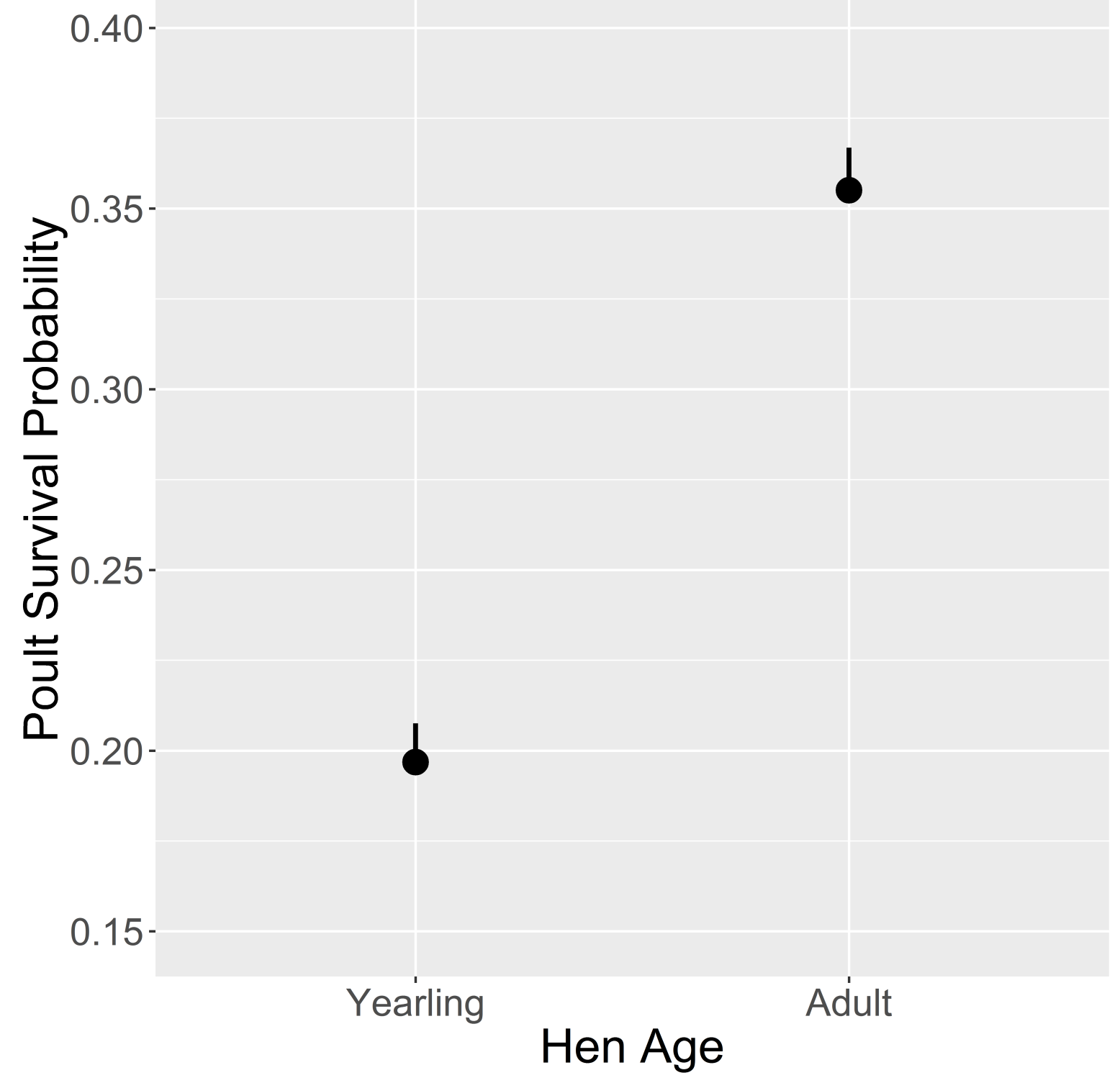

Figure 3.11: Probability of survival for poults over the 28-day post-hatch interval for broods reared by yearling and adult eastern wild turkey hens during 2017 and 2018 in northeastern South Dakota, USA. 

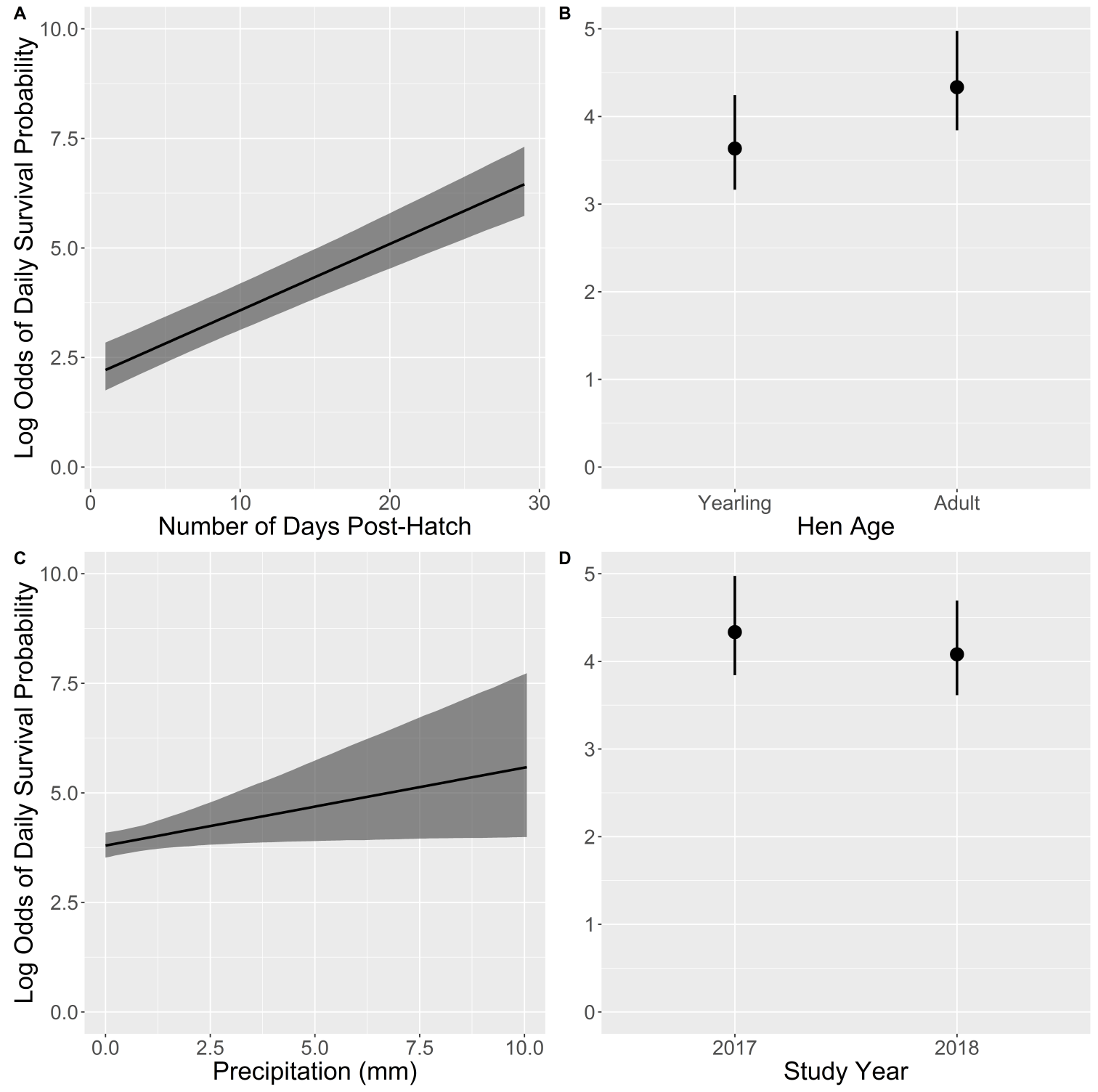

Figure 3.12: Effect, on the log-odds scale, of brood age (number of days post-hatch) (A), age of the brood-rearing hen $(\mathrm{B})$, daily rainfall accumulation $(\mathrm{mm})(\mathrm{C})$, and year of the study (D) on daily survival probability of eastern wild turkey poults during 2017 and 2018 in northeastern South Dakota, USA. 


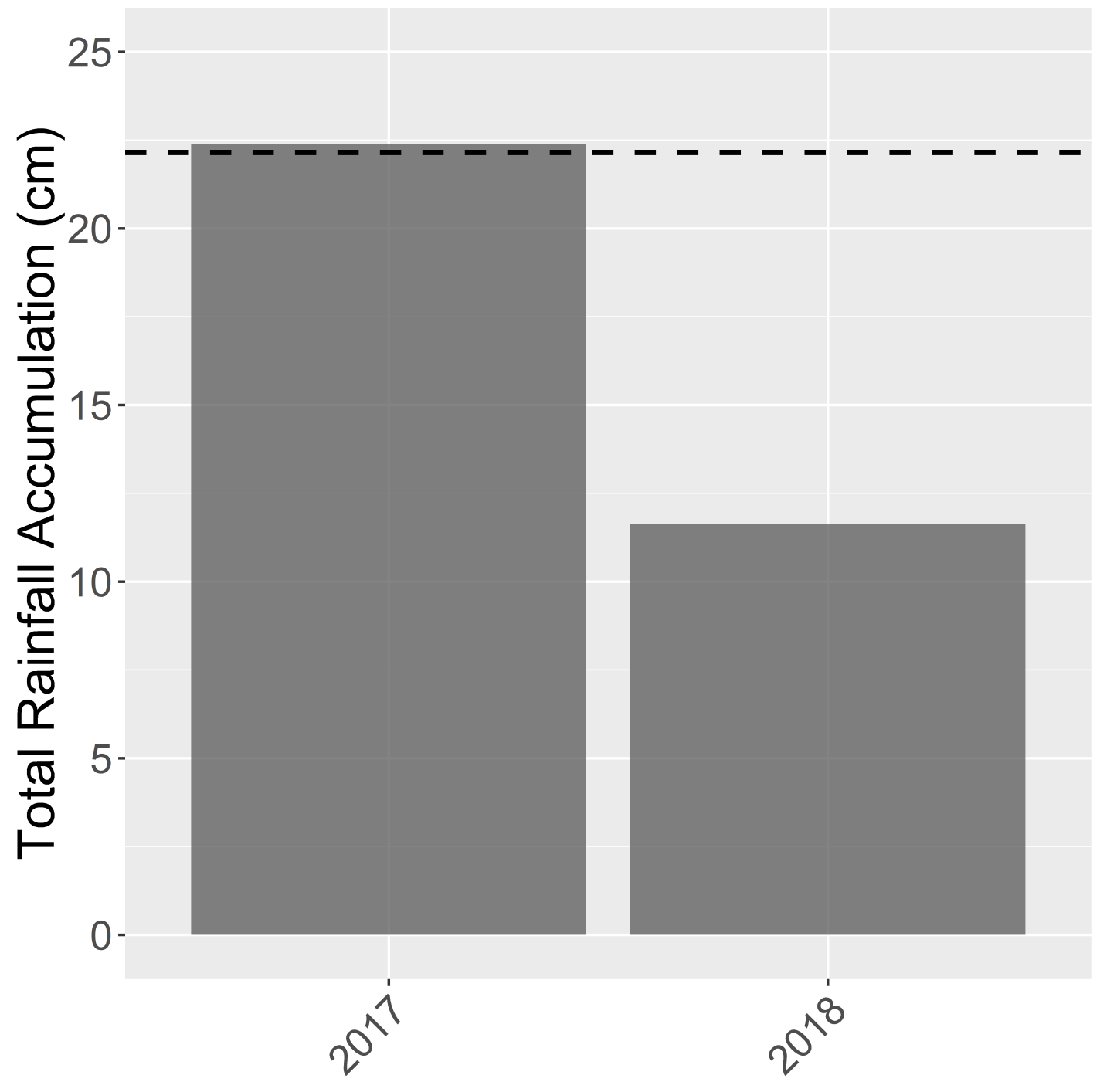

Figure 3.13: Total precipitation accumulation during the springs (1-April to 30-June) of 2017 and 2018 in northeastern South Dakota, USA. The 30-year average (1981-2010) total precipitation accumulation during spring in Milbank, SD, USA $(22.1-\mathrm{cm})$ is indicated by the dashed line (National Climatic Data Center, 2010). 


\title{
Chapter 4
}

\section{Factors Influencing Eastern Wild}

\section{Turkey Population Growth in}

\section{northeastern South Dakota}

\begin{abstract}
The population of eastern wild turkeys (Meleagris gallopavo silvestris) in northeastern South Dakota appeared to be expanding soon after reintroduction in the 1990s, however, recent harvest trends suggest declining abundance in the region. Annual spring turkey hunting expenditures are projected to be around $\$ 6.5$ million in South Dakota, with about $\$ 3$ million of those expenditures occurring within the northeastern prairie region. However, the number of birds harvested during the spring prairie firearm season has been declining since 2010. Due to concerns about a declining population, the autumn hunting season was closed in 2014. The cause of the apparent decline is unclear. An updated estimate of the population growth rate, and the factors limiting population growth, is needed to assess the status of the population of wild turkeys in northeastern South Dakota and to determine the most effective management strategies for increasing abundance across the region. I incorporated estimates of hen survival and productivity into a matrix model to project the population growth rate. Additionally, I performed perturbation analyses and conducted a life-stage simulation analysis (LSA) to assess the impact of each demographic parameter on population growth. The population of eastern wild turkeys is currently stable-to-growing $(\lambda=1.107 ; 95 \% \mathrm{CI}=0.943,1.275)$, and population growth is most greatly affected by changes in hen survival. Management activities should focus on improving hen survival by reducing the top two sources of mortality - mammalian predation and haying by agricultural equipment. Enhancing the quality of herbaceous and early successional habitats could reduce hen risk of mortality
\end{abstract}


while conducting nesting and brood-rearing activities. Additionally, increased availability of suitable nesting habitat on the landscape could mean fewer hens will resort to nesting in alfalfa hayfields, where nest failure is certain and hens are at risk of mortality due to haying. Improving eastern wild turkey hen survival in northeastern South Dakota should increase abundance of wild turkeys and improve hunting opportunities in the region.

\subsection{Introduction}

Understanding which demographic parameters have the greatest effect on the rate of population change $(\lambda)$ is essential for making scientifically informed decisions about the management of a wildlife population. Estimates of survival and productivity can be combined into matrix projection models, that are based on the life-history strategy of the wildlife population of interest, to assess the status of a population (Caswell, 2001). Additionally, perturbation of matrix elements and lower-level vital rates, and assessment of the influence of those perturbations on the finite rate of population change $(\lambda)$, can shed light on which demographic parameters have the greatest effect on the ability of a population to grow (Wisdom et al., 2000; Caswell, 2001). This can inform managers of which demographic parameters management activities should focus on in order to have the greatest impact on population growth.

For example, Crouse et al. (1987) designed a stage-based projection model from the life-history of loggerhead sea turtles (Caretta caretta) to examine which demographic parameter estimates had the greatest impact on population growth and how the population would respond to various management activities. While previous management of loggerhead sea turtles concentrated on improving survival of eggs on nesting-beaches, Crouse et al. (1987) determined that this would have little impact on population growth. Since population growth was most greatly affected by changes in juvenile loggerhead survival, Crouse et al. (1987) determined that improving survival of juvenile loggerhead turtles would most greatly impact population growth. Therefore, management activities began to focus on reducing a major source of mortality of juvenile loggerhead turtles - capture and subsequent drowning in trawl nets.

For populations of wild turkeys, reproductive parameters of interest typically include estimates of nesting rate, nest survival, re-nesting rate, clutch size, hatchability, and poult survival (Pollentier et al., 2014a). These estimates of productivity can be combined to estimate fecundity (i.e., the number of poults of each sex produced per hen) which can, in turn, be combined with estimates of young-of-the-year (i.e., juvenile) survival to provide insight into recruitment of new individuals into the breeding population. Low annual survival rates, working in combination with low productivity, can lead to population declines. If annual survival of a population is low, reproductive contributions must be high enough to replace individuals lost from the population throughout the year to maintain population stability.

Managers have used populations models embedded with demographic parameters to assess the status 
of eastern wild turkeys for several decades (Suchy et al., 1983; Roberts et al., 1995; Vangilder and Kurzejeski, 1995; Rolley et al., 1998; McGhee and Berkson, 2007; Alpizar-Jara et al., 2001; Pollentier et al., 2014a). Many of the previous efforts to model eastern wild turkey population dynamics assessed the effects of female harvest on these populations (Suchy et al., 1983; Vangilder and Kurzejeski, 1995; Rolley et al., 1998; Alpizar-Jara et al., 2001; McGhee et al., 2008; Pollentier et al., 2014a). For populations in Iowa (Suchy et al., 1983), Missouri (Vangilder and Kurzejeski, 1995), southwestern Wisconsin (Rolley et al., 1998), and Virginia and West Virginia (Alpizar-Jara et al., 2001), where autumn either-sex hunting seasons are implemented, female mortality during the autumn had a large impact on population growth. Since female survival, especially in the autumn, is important for maintaining a stable population of wild turkeys, conservative harvest during the either-sex autumn season has been recommended when concerned about potential population declines (Suchy et al., 1983; Vangilder and Kurzejeski, 1995; Rolley et al., 1998; Alpizar-Jara et al., 2001; McGhee et al., 2008). Rolley et al. (1998) suggested that along with hen survival, recruitment into the breeding population has great potential to influence population dynamics in Wisconsin, and reduced autumn and winter mortality of young-of-the-year juvenile hens would lead to increased numbers of individuals in the breeding population the following spring.

For established populations of eastern wild turkeys in New York (Roberts et al., 1995) and Wisconsin (Pollentier et al., 2014a), nest and poult survival had the greatest influence on population growth. Roberts et al. (1995) suggested that because winter survival of wild turkeys in New York was high, and therefore not limiting population growth, management efforts should concentrate on making improvements to nesting and brood-rearing habitats. Similarly, Pollentier et al. (2014a) contended that continued restoration and maintenance of quality herbaceous and early successional habitats has the greatest potential to positively influence population growth by improving nest and poult survival. Pollentier et al. (2014a) noted that improvements to nesting and brood-rearing habitats have the potential to also improve hen survival by reducing female risk to mortality while incubating nests and raising poults. Specifically in Midwestern systems, previous research has determined that nest and poult survival (Vangilder and Kurzejeski, 1995; Pollentier et al., 2014a) and hen survival (Vangilder and Kurzejeski, 1995; Rolley et al., 1998) are both strong determinants of eastern wild turkey population growth.

Since their reintroduction in the 1990s, eastern wild turkeys have become a culturally and economically important game species in northeastern South Dakota. Establishment of a growing population of eastern wild turkeys appeared to be successful in the years immediately following reintroduction (Shields, 2001); however, recent harvest trends suggest declining abundance in the region. Harvest of wild turkeys during the spring prairie turkey season declined from a high of 5,809 males in 2010 down to 2,482 males in 2016 (Huxoll, 2016). The cause of the apparent decline in eastern wild turkey abundance in northeastern South Dakota is unclear.

Given recent declines in spring hunter harvest success, there is a need to assess the demographic 
performance of this important game species using current vital rate estimates. A matrix projection model, constructed with updated estimates of survival and productivity, will provide insight in the status of the population (i.e., whether or not it is in decline). Performing perturbation analyses to assess which matrix elements and lower-level vital rates have the greatest effect on the finite rate of population change, can identify which management activities have the greatest potential to improve eastern wild turkey population growth in South Dakota.

The objectives of this study are to: (1) incorporate vital rate estimates into a female-only, stage-based deterministic matrix projection model; (2) project the population growth rate $(\lambda)$ to determine if the population is growing, declining, or stable; and (3) perform perturbation analyses to determine which demographic parameters have the greatest effect on the finite rate of population change. Given recent harvest trends, I predict that the population of eastern wild turkeys in northeastern South Dakota will be in decline $(\lambda<1)$. I hypothesize that adult hen survival and nest survival will have the greatest effect on the finite rate of population change. These results will inform management actions and harvest regulations for wild turkeys in northeastern South Dakota.

\subsection{Study Area}

The study was conducted in Codington, Deuel, Grant, and Roberts counties in northeastern South Dakota. The study area was split between the Minnesota River-Red River Lowland in the eastern half of the study area and Coteau des Prairies physiographic region in the western half (Flint, 1955; Johnson et al., 1995). The Coteau begins in the northwest and extends in a southeasterly direction across the study area (Miller et al., 1979). On top of the Coteau, the relief is gently undulating to hilly while down in the Lowlands the land is nearly level (Flint, 1955; Miller et al., 1979). Elevations ranged from over 600-m above mean sea level on top of the Coteau to about 300-m above sea level in the Lowland (Miller et al., 1979). Most of the study area consisted of privately owned lands with some state owned (e.g. Game Production Areas) and federally owned (e.g. Waterfowl Production Areas) lands scattered throughout (Figure 4.1). The Lake Traverse Indian Reservation overlaps the western and northern extent of the study area where tribally owned lands are common (Figure 4.1).

Northeastern South Dakota is in a humid continental climate region, with mean annual precipitation of $61-\mathrm{cm}$ and mean annual temperature of $6.4^{\circ} \mathrm{C}$ across the study area (National Climatic Data Center, 2010). Average seasonal snowfall for the region is 101-cm, and, on average, there are 17 days of at least 5 -in. $(\sim 13-\mathrm{cm})$ of snow on the ground, but the number of snow-covered days varies greatly from year to year (National Climatic Data Center, 2010). Snow can accumulate up to half a meter in depth during the winter months; however, snow depth is often variable across the study area as wind creates deep snow-drifts as well as wind-swept areas (Miller et al., 1979). About $60 \%$ of the total annual precipitation 
occurs during the nesting and brood-rearing seasons (April through August) (National Climatic Data Center, 2010). Early spring snowfall is possible, with about one quarter (26\%) of the total annual snowfall occurring from March through May (National Climatic Data Center, 2010). Spring and summer temperatures can be highly variable, with average minimum temperatures near $0^{\circ} \mathrm{C}$ in early spring to average maximum temperatures near $28^{\circ} \mathrm{C}$ during peak summer; however, normal average temperatures for the spring and summer months range from $12-21^{\circ} \mathrm{C}$ (National Climatic Data Center, 2010).

Agriculture dominates the land use in the study area, with most land being used for either cropland, rangeland, or to grow alfalfa or hay for livestock feed (Miller et al., 1979) (Figure 4.2). Most of the grain farming (i.e., corn and soybeans) occurs in the Lowland (Miller et al., 1979). The highlands of the Coteau support native tallgrass prairie which is used primarily for rangeland; however, scattered fields of hay and alfalfa are located in the highlands as well (Miller et al., 1979) (Figure 4.2). Common grasses include warm-season grasses such as big bluestem (Andropogon gerardii), little bluestem (Schizachyrium scoparium), Indiangrass (Sorghastrum nutans), switchgrass (Panicum virgatum), and sideoats grama (Bouteloua curtipendula) (Johnson and Larson, 2007). Common cool-season grasses include smooth brome (Bromus inermis), Kentucky bluegrass (Poa pratensis), western wheatgrass (Pascopyrum smithii), and green needlegrass (Stipa viridula) (Johnson and Larson, 2007). Numerous forbs and patches of western snowberry (Symphoricarpos occidentalis) are scattered throughout the pasture-lands (Johnson and Larson, 2007). Forested areas along the east-facing breaks where the Coteau descends into the Lowlands are dominated by bur oak (Quercus macrocarpa) on the drier slopes (Leatherberry et al., 2000) (Figure 4.2). More mesic areas are dominated by elm-ash (Fraxinus spp.; Ulmus spp.) forests (Leatherberry et al., 2000) that are intermixed with trembling aspen (Populus tremuloides), box elder (Acer negundo), eastern cottonwood (Populus deltoides), and sugar maple (Acer saccharum) (Knupp Moore and Flake, 1994).

Potential predators of wild turkey hens within the study area included mammalian species - coyotes (Canis latrans) and red fox (Vulpes vulpes) - as well as avian species-bald eagles (Haliaeetus leucocephalus), golden eagles (Aquila chrysaetos), and great-horned owls (Bubo virginianus) (Lehman, 1998; Rumble et al., 2003; Flake et al., 2006; Lehman et al., 2007). Potential wild turkey nest predators within the study area included coyotes (Canis latrans), red fox (Vulpes vulpes), raccoon (Procyon lotor), striped skunk (Mephitis mephitis), and crows (Corvus brachyrhynchos) (Lehman, 1998; Shields, 2001). Potential mammalian predators of wild turkey poults within the study area included weasels (Mustela spp.), mink (Mustela vison), red fox, and coyotes (Hubbard et al., 1999a). Potential avian predators of wild turkey poults within the study area included multiple species of hawks (Buteo spp. and Accipiter spp.), great-horned owls (Bubo virginianus), bald eagles (Haliaeetus leucocephalus), and golden eagles (Aquila chrysaetos) (Hubbard et al., 1999a; South Dakota Department of Game Fish and Parks, 2017). 


\subsection{Methods}

\subsubsection{Vital Rate Parameter Estimates}

I estimated population growth rates using estimates of 8 demographic parameters for eastern wild turkey hens in northeastern South Dakota from data collected during 2017 to 2018 that I incorporated into my population model based on the methods outlined in Chapter 2 and Chapter 3. I calculated the probability of nesting (NEST) as the proportion of hens, alive on 1-April, that attempted at least 1 nest that year. I calculated probability of re-nesting (RENEST) as the probability a hen would initiate a second nest, conditional on a failed first nest attempt. I estimated nest survival (NSURV) as the proportion of nests that successfully hatched at least 1 poult. I estimated clutch size $(C L U T C H)$ as the mean number of eggs laid in each nest, and I estimated hatchability $(H A T C H)$ as the proportion of eggs that hatched from the total number of eggs laid in successful nests. I estimated poult survival (POULT) as the proportion of poults that survived to 28-days post-hatch from the initial number of poults in each brood.

I estimated fecundity $\left(F_{i}\right)$, or the number of female poults produced per hen assuming a constant 1:1 sex ratio at hatch, as:

$$
\begin{aligned}
F_{i}= & {\left[\left(N E S T \times C L U T C H_{1} \times N S U R V\right)+(1-N S U R V) \times\left(R E N E S T \times C L U T C H_{2} \times N S U R V\right)\right] } \\
& \times(H A T C H \times P O U L T \times 0.5)
\end{aligned}
$$

where subscript $i$ denotes age-class (yearling or adult) and subscripts 1 and 2 indicate parameter estimates associated with nesting and re-nesting attempts, respectively.

I estimated survival of radio-marked yearling ( $S_{y}$, approx. 9-21 months old) and adult $\left(S_{a}, \geq 21\right.$ months old) hens as the probability of surviving from 1-April through 31-March the following year (Pollentier et al., 2014b). I estimated young-of-the-year juvenile survival $\left(S_{j}\right.$, 28-days old to approx. 9 months old) as the probability of surviving the 242-day interval from 1-August through 31-March (Pollentier et al., 2014b). Since I did not directly collect survival data on juvenile hens, I approximated $S_{j}$ as the survival of yearling hens during the same time period (Roberts et al., 1995; Rolley et al., 1998). Juvenile hens transition to the yearling age-class and yearling hens transition to the adult age-class on 1-April each year (Lehman et al., 2001). All vital rates were estimated using Bayesian methods.

\subsubsection{Population Model and Perturbation Analyses}

I developed a 2-stage matrix projection model to summarize the age-structured variation in demographic rates for eastern wild turkeys in northeastern South Dakota. The model was entirely based on female demographics under the assumption that there were sufficient males available to breed with females 
(Roberts et al., 1995; Pollentier et al., 2014a). During field data collection, I captured turkeys prior to the spring dispersal and breeding season. Therefore, I constructed my deterministic matrix model $A$ as a female-only, pre-breeding birth-pulse model following the form of Caswell (2001):

$$
\mathbf{A}=\left(\begin{array}{cc}
F_{y} S_{j} & F_{a} S_{j} \\
S_{y} & S_{a}
\end{array}\right)
$$

where $S_{j}, S_{y}$, and $S_{a}$ represent survival probabilities of juvenile, yearling, and adult hens, respectively; and $F_{y}$ and $F_{a}$ represent fecundity of yearling and adult hens, respectively. Matrix elements were comprised of lower-level vital rates. I used the POPBIO package version 2.4.4 in Program $\mathrm{R}$ version 3.5.1 to estimate asymptotic population growth rates, denoted $\lambda$, and to estimate the elasticity $(E)$ of $\lambda$ to proportional changes in each lower-level vital rate (Stubben and Milligan, 2007; R Core Team, 2018).

I accounted for uncertainty in $\lambda$ and $E$ by obtaining random realizations of lower-level vital rates. I obtained 3,000 posterior draws of estimated survival rates and reproductive rates from the methods described in Chapter 2 and Chapter 3, respectively. For each random draw, I calculated age-specific survival and fecundity estimates and constructed a unique projection matrix $A$, from which I calculated $\lambda$ and $E$. I did not consider the finite rate of change significantly different from a stable population if the 95\% CI around $\lambda$ included 1 (Rota et al., 2014; Lehman et al., 2018).

I conducted a life-stage simulation analysis (LSA) (Wisdom et al., 2000) to correlate changes in $\lambda$ with associated changes in corresponding survival probability, reproductive rates, and fecundity. I used coefficients of determination to calculate the amounts of variation in $\lambda$ that could be explained by variation in each parameter. Parameters with high $R^{2}$ values had a greater effect on the population growth rate than parameters with low $R^{2}$ values.

\subsection{Results}

The mean deterministic matrix $\bar{A}$, calculated from the mean values of each lower-level vital rate, was as follows:

$$
\bar{A}=\left(\begin{array}{ll}
0.246 & 0.663 \\
0.620 & 0.629
\end{array}\right)
$$

The mean finite rate of population change $(\lambda)$ was $1.107(95 \% \mathrm{CI}=0.943,1.275)$ (Figure 4.3$)$. The elasticities of each lower-level vital rate indicate that $\lambda$ was most greatly affected by proportional changes in adult hen survival, and that adult fecundity had a greater effect on $\lambda$ than yearling hen fecundity (Table 4.2). Juvenile hen survival $\left(S_{j}\right)$, yearling hen survival, hatchability of eggs laid by adult hens, and survival of poults reared by adult hens had a relatively large proportional effect on $\lambda$ (Table 4.2). 
The LSA determined that variation in $\lambda$ was most greatly explained by variation in yearling and juvenile hen survival (Table 4.2, Figure 4.4). Adult hen survival also explained substantial variation in $\lambda$ (Table 4.2, Figure 4.4). Variation in adult fecundity explained variation in $\lambda$ better than yearling hen fecundity (Table 4.2; Figure 4.5). Adult hen nest survival explained the greatest amount of variation in $\lambda$ out of all lower-level measurements of reproductive contribution (Figure 4.6). Poult survival explained very little variation in $\lambda$ (Figure 4.7).

\subsection{Discussion}

While there were concerns that the population of eastern wild turkeys in northeastern South Dakota is in decline, the estimated population growth rate $(\lambda)$ indicates that the population is stable-to-increasing $(1.107,95 \% \mathrm{CI}=0.943,1.275)$. However, this estimate contains considerable uncertainty, as it is the product of survival and productivity parameters estimated from information gathered over only 2 years.

Survival of hens of all ages had the greatest effect on the population growth rate, as indicated by both the elasticity analysis and LSA (Figure 4.4). Several previous studies identified hen survival as an important factor influencing population growth (Suchy et al., 1983; Vangilder and Kurzejeski, 1995; Rolley et al., 1998; Alpizar-Jara et al., 2001). Annual survival of hens during this study ( 60.5\%) was lower than previously published estimates of hen survival from expanding populations of eastern wild turkeys in South Dakota (77.7\%, Leif 2001; 72.1\%, Lehman et al. 2001; 69.7\%, Shields and Flake 2006). The relatively low survival probability, in conjunction with the large effect hen survival has on population growth, likely means that the population decline was driven by low hen survival.

Adult hen fecundity also had a relatively large impact on population growth according to both the elasticity analysis and LSA (Figure 4.5). Because adult hen fecundity and juvenile hen survival were both shown to have a large influence on the population growth rate, recruitment of new individuals into the breeding population is critical for population growth. This result is consistent with other population demographic studies of eastern wild turkeys in the Midwest (Vangilder and Kurzejeski, 1995; Rolley et al., 1998; Pollentier et al., 2014a) where recruitment was an important driver of population growth. South Dakota lost an estimated $1,837,100$ acres $( \pm 21,100)$ of grassland, and gained approximately $1,439,500$ acres $( \pm 15,600)$ of cropland, between 2006 and 2012 (Reitsma et al., 2013). The greatest losses of grassland occurred in the northeast region of South Dakota with an estimated loss of $16.9 \%( \pm 0.6 \%)$ between 2006 and 2012 (Reitsma et al., 2013). The loss of Conservation Reserve Program (CRP) grasslands across the landscape reduces availability of quality nesting habitat, forcing hens to nest in suboptimal habitat. This could potentially have indirect effects on hen and nest survival, and therefore, overall productivity. Haying of alfalfa during the nesting season was a major source of nest and hen mortality during this study. Twelve nests ( $8.2 \%$ of all attempts) were located within alfalfa fields and $0 \%$ of these 
nests were successful. In addition, during most of the events where a nest was lost due to haying, the hen was killed as well (58.3\%). This resulted in 7 hens being killed by haying equipment (11\% of all hen mortality events) that were subsequently unavailable to re-nest. Reducing human-caused sources of mortality for wild turkey hens, whether by harvest of individuals or by accidental killing due to haying, will improve fecundity and positively impact population growth.

While the finite rate of population change from this analysis suggests that the population of eastern wild turkeys in northeastern South Dakota is not currently experiencing a decline, reduced harvest success between 2010 and 2016 suggests a decline in abundance during this time (Figure 4.8). Harvest of hens in northeastern South Dakota peaked in 2007 and 2008 when 479 and 475 hens, respectively, were harvested during the autumn, either-sex season (Huxoll, 2007, 2008). Harvest of over 150 hens during the autumn hunting season continued through 2012 (Huxoll, 2012). Little and Kienzler (1990) estimated adult and subadult survival rates before and after an autumn, either-sex hunting season was implemented in Iowa and concluded that autumn harvest mortality of eastern wild turkey hens in the open, agriculturally dominated landscape was likely additive. The high levels of hen harvest from 2007 through 2012 could have contributed to low annual survival of hens during those years.

Closing the autumn hunting season in northeastern South Dakota in 2014 reduced annual harvest of hens from several hundred to $<10$ per year. Subsequently, harvest of males during the spring season increased substantially between 2016 and 2017 (2,482 in 2016; 3,323 in 2017), and while harvest went down slightly between 2017 and 2018 (2,724 in 2018), the number of males harvested in 2018 was still greater than in 2016 (Figure 4.8; Huxoll 2016). I hypothesize that substantial reduction in potentially additive harvest mortality of hens had a positive influence on both hen survival and population growth, leading to the stable population growth rate observed during this study. More consistent population-level surveys, like this, are important for maintaining an accurate estimate of population trends through time.

\subsection{Management Implications}

The population of eastern wild turkeys in northeastern South Dakota does not appear to be currently experiencing a decline in abundance $(\lambda=1.107)$, however, considering the uncertainty around the estimate $(95 \% \mathrm{CI}=0.943,1.275)$, and the large influence of hen survival on the population growth rate (Table 4.2, Figure 4.4), management activities should aim to not create any added mortality for hens to ensure that the population does not end up in decline. Therefore, to maintain a stable population, the autumn, either-sex hunting season should not be re-opened, as an additional source of mortality for hens could lead to a population decline.

Increasing annual survival of hens, by reducing human-caused sources of mortality, could potentially lead to a growing population. Even though harvest of beardless hens was not allowed during this study, 
two bearded adult hens were legally harvested during the bearded-only hunting season in spring of 2017 . While harvest only accounted for $3 \%$ of the total hen mortality over the study period, harvest of hens prior to the nesting and brood-rearing season could lead to declines in population growth by decreasing the number of individuals that are able to make reproductive contributions that year. Designating "maleonly" seasons in the spring and autumn would eliminate legal harvest of hens altogether, by making harvest of bearded hens illegal.

Haying of alfalfa during the nesting season was the second-greatest cause of mortality. Focusing on reducing human-caused hen mortality due to haying will have a strong positive impact on population growth, since it will contribute to increases in both hen survival and fecundity. Based on the onset of incubation, in $2017,75 \%$ of all nests would have hatched by July 3rd, and in 2018, $75 \%$ of all nests would have hatched by July 9th. Delaying the cutting of alfalfa until the after the first week of July, could reduce the risk of hen mortality due to haying equipment since the majority of hens will be done incubating by this time. If hay must be cut before this time, installing a flushing bar on the cutting equipment can increase hen survival by pushing hens off of their nests and allowing them to escape the haying equipment (Klonglan et al., 1959). Klonglan et al. (1959) found that for pheasant populations in Iowa, the use of flushing bars on haying equipment reduced hen mortality by $38 \%$.

The most significant portion of hen mortality during this study was attributed to predation, specifically by mammalian predators. The majority of those predation events occurred during the spring months when hens are spending extensive amounts of time on the ground conducting nesting and broodrearing activities. (Pollentier et al., 2014b) contended that improvements to the quantity and quality of herbaceous nesting and brood-rearing habitats (i.e., CRP grasslands) could reduce hen risk to mortality while simultaneously increasing reproductive success. Additionally, the presence of more suitable nesting habitat on the landscape could mean fewer hens will resort to nesting in alfalfa hayfields where probability of nest failure was $100 \%$ and where hens are at risk of mortality due to haying. Increasing hen survival probability and fecundity rates would ensure stability of, and could lead to a stronger growth rate for, the population of eastern wild turkeys in northeastern South Dakota. 
Table 4.1: Minimum and maximum values of the 3,000 demographic parameter estimates used in the eastern wild turkey hen population model for northeastern South Dakota, USA. Estimates were calculated from data collected from February 2017 to April 2019.

\begin{tabular}{|c|c|c|c|c|c|c|}
\hline \multirow[b]{2}{*}{ Parameter $^{1}$} & \multicolumn{3}{|c|}{ Yearling } & \multicolumn{3}{|c|}{ Adult } \\
\hline & Mean & Minimum & Maximum & Mean & Minimum & Maximum \\
\hline$N E S T$ & 0.740 & 0.493 & 0.914 & 0.801 & 0.526 & 0.946 \\
\hline$R E N E S T$ & 0.251 & 0.037 & 0.629 & 0.596 & 0.231 & 0.851 \\
\hline$N S U R V$ & 0.459 & 0.227 & 0.740 & 0.519 & 0.322 & 0.693 \\
\hline$C L U T C H_{1}$ & 9.798 & 7.845 & 12.046 & 10.396 & 8.516 & 12.507 \\
\hline$C L U T C H_{2}$ & 9.790 & 7.102 & 13.188 & 10.377 & 8.202 & 13.170 \\
\hline$H A T C H$ & 0.867 & 0.734 & 0.951 & 0.875 & 0.788 & 0.939 \\
\hline POULT & 0.197 & 0.195 & 0.226 & 0.355 & 0.352 & 0.391 \\
\hline$F$ & 0.338 & 0.134 & 0.582 & 0.911 & 0.544 & 1.350 \\
\hline$S_{j}$ & 0.726 & 0.530 & 0.909 & & & \\
\hline$S$ & 0.617 & 0.384 & 0.866 & 0.625 & 0.390 & 0.858 \\
\hline
\end{tabular}

${ }^{1} N E S T$ is nesting rate; RENEST is re-nesting rate; $N S U R V$ is nest survival probability; $C L U T C H_{1}$ is clutch size of first nests; $C L U T C H_{2}$ is clutch size of re-nests; $H A T C H$ is hatchability; POULT is poult survival probability to 28-days post-hatch; $F$ is the fecundity rate; $S_{j}$ is the probability a juvenile hen will survive to recruit into the breeding population; and $S$ is annual hen survival probability. 
Table 4.2: Elasticities $(E)$ and coefficients of determination $\left(R^{2}\right)$ for lower-level reproductive rates, fecundity rates, and survival rates for eastern wild turkey hens from February 2017 to April 2019 in northeastern South Dakota, USA.

\begin{tabular}{lcccc}
\hline & Yearling & Adult & Yearling & Adult \\
\cline { 2 - 5 } Parameter $^{1}$ & $E$ & $E$ & $R^{2}$ & $R^{2}$ \\
\hline NEST & 0.068 & 0.204 & 0.009 & 0.031 \\
RENEST & 0.012 & 0.072 & 0.009 & 0.024 \\
NSURV & 0.069 & 0.197 & 0.016 & 0.079 \\
CLUTCH & 0.068 & 0.204 & 0.004 & 0.030 \\
CLUTCH & 0.012 & 0.072 & 0.000 & 0.011 \\
HATCH & 0.080 & 0.276 & 0.006 & 0.009 \\
POULT & 0.080 & 0.276 & 0.001 & 0.000 \\
F & 0.080 & 0.276 & 0.043 & 0.174 \\
$S_{j}$ & 0.356 & & 0.530 & \\
$S$ & 0.276 & 0.368 & 0.530 & 0.258 \\
\hline
\end{tabular}

${ }^{1} N E S T$ is nesting rate; RENEST is re-nesting rate; $N S U R V$ is nest survival probability; $\mathrm{CLUTCH}_{1}$ is clutch size of first nests; $\mathrm{CLUTCH} \mathrm{H}_{2}$ is clutch size of re-nests; $H A T C H$ is hatchability; $P O U L T$ is poult survival probability to 28 -days post-hatch; $F$ is the fecundity rate; $S_{j}$ is the probability a juvenile hen will survive to recruit into the breeding population; and $S$ is annual hen survival probability. 


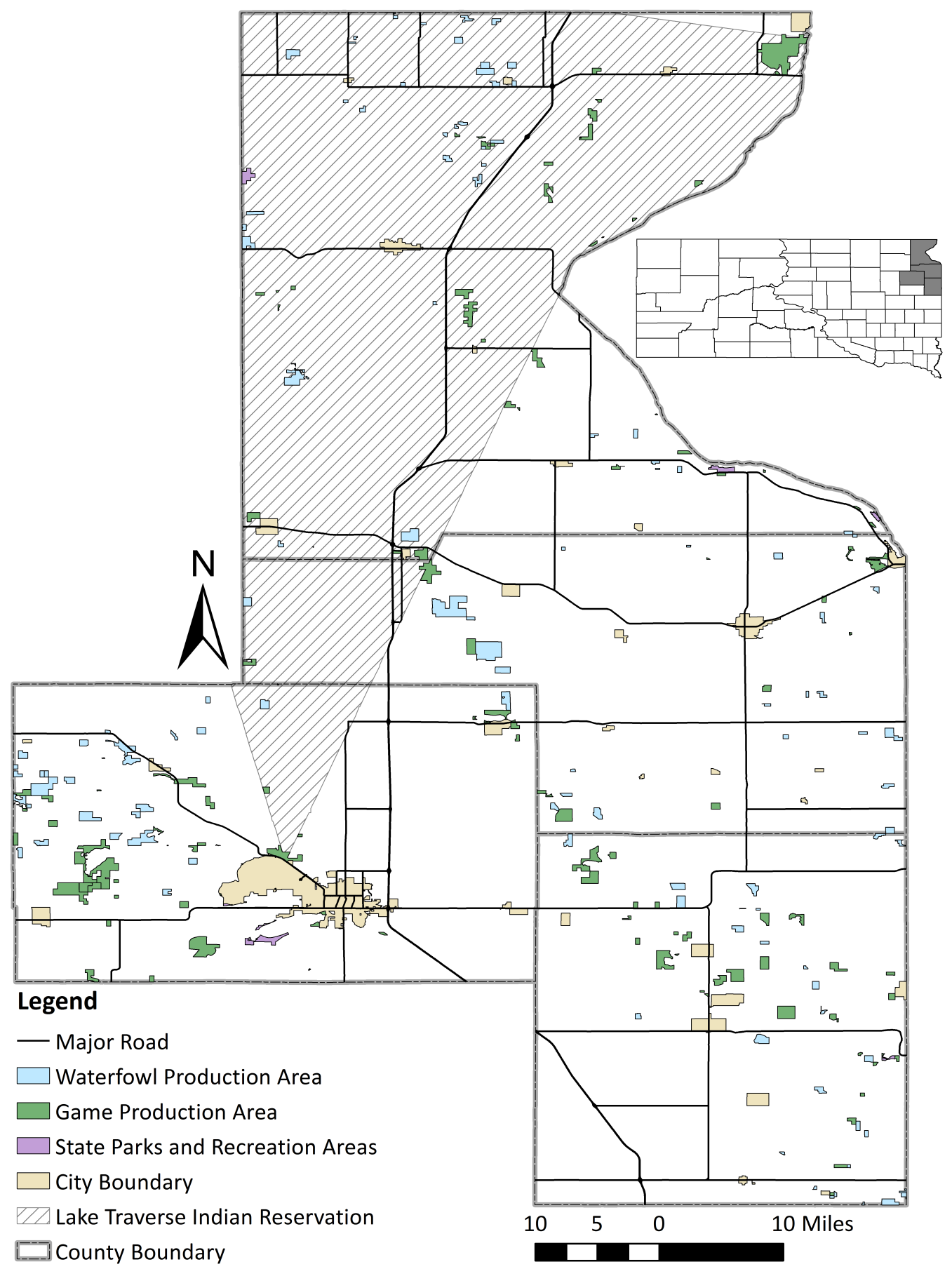

Figure 4.1: Map of land ownership across Codington, Deuel, Grant, and Roberts Counties in northeastern South Dakota, USA. White areas within county boundaries indicate privately owned lands. 


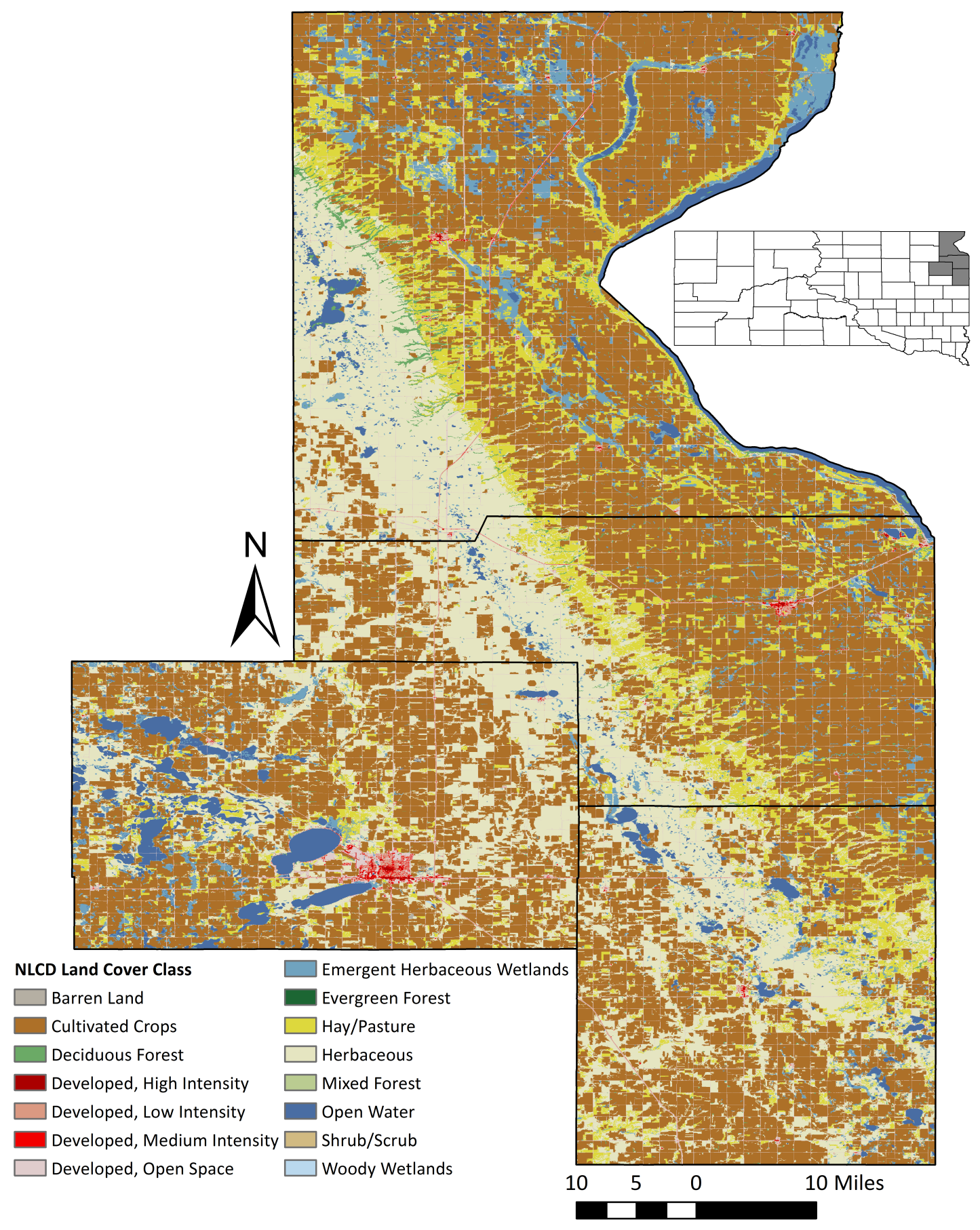

Figure 4.2: National Land Cover Database (2016) land cover classes for Codington, Deuel, Grant, and Roberts Counties in northeastern South Dakota, USA. 


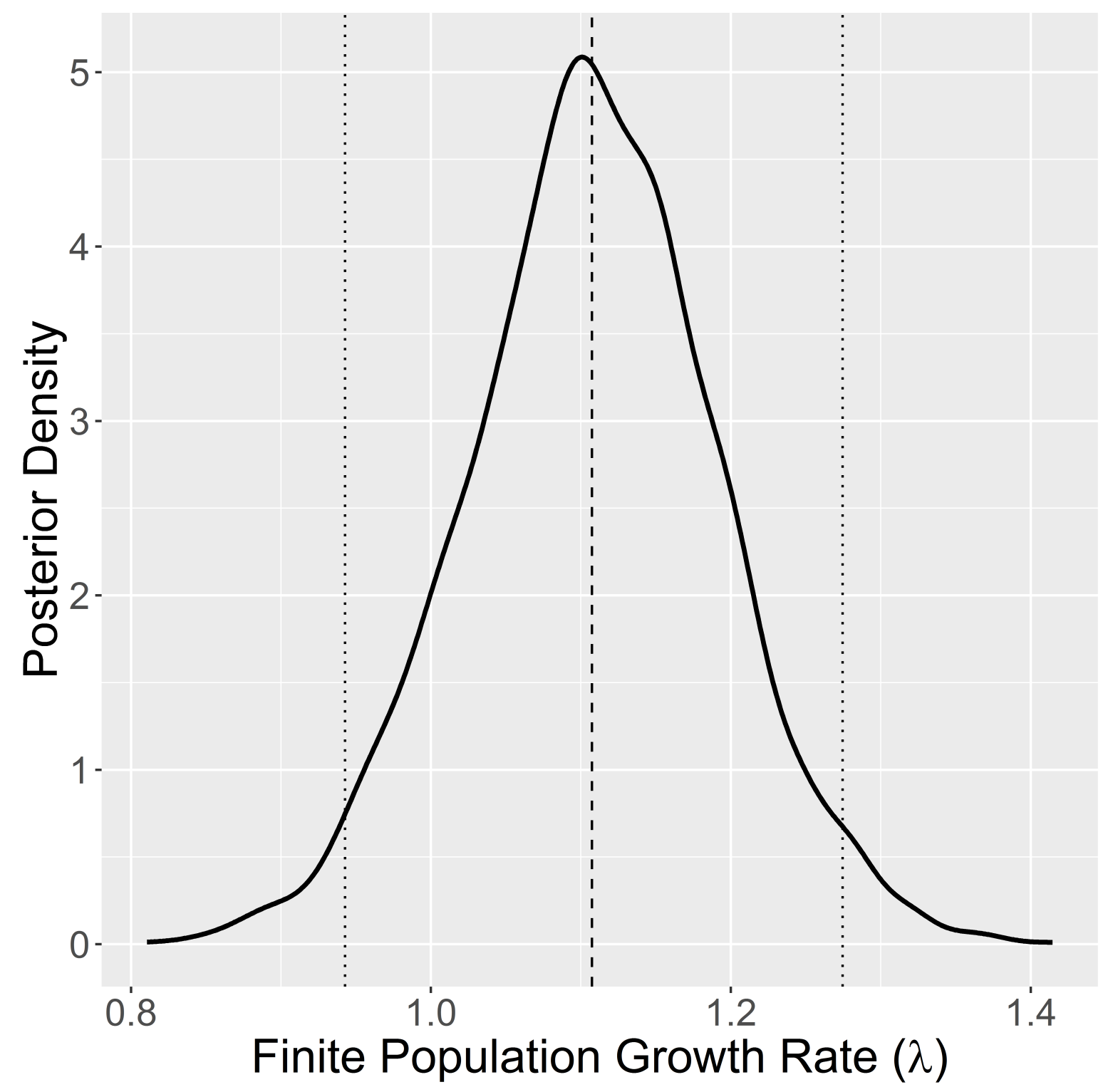

Figure 4.3: Posterior density of asymptotic population growth rates $(\lambda)$ for the population of eastern wild turkey hens in northeastern South Dakota, USA from February 2017 to April 2019. The vertical, dashed line indicates the mean value of $\lambda( \pm 95 \%$ credible interval). Values $<1$ indicate declining abundance, whereas values $>1$ indicate increasing abundance. 

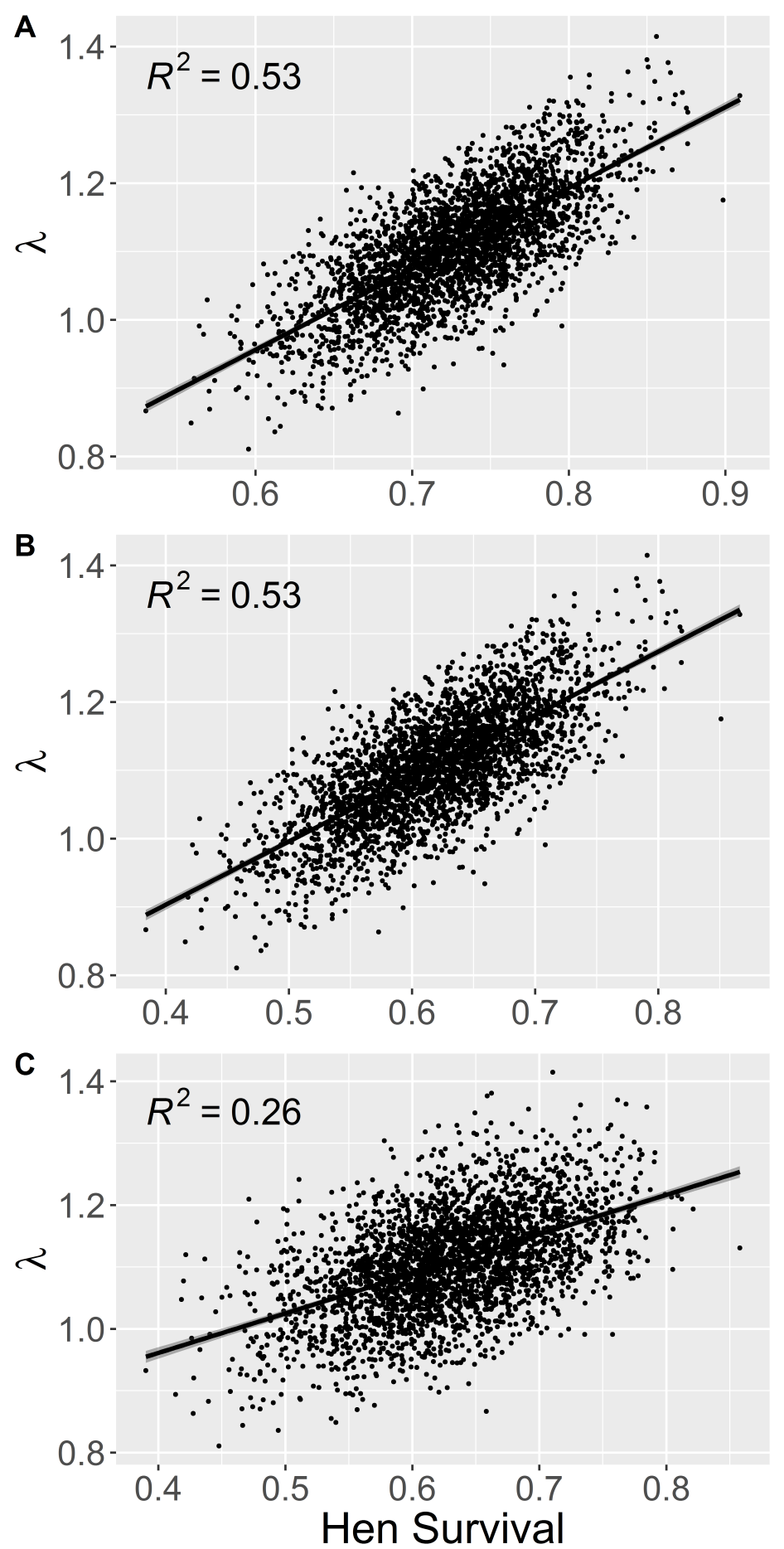

Figure 4.4: Realizations of estimated asymptotic population growth rates $(\lambda)$ of eastern wild turkey hens as a function of survival rates of juvenile (A), yearling (B), and adult (C) hens from February 2017 to April 2019 in northeastern South Dakota, USA. Scatter plots are based on 3,000 random realizations of estimated vital rates. 

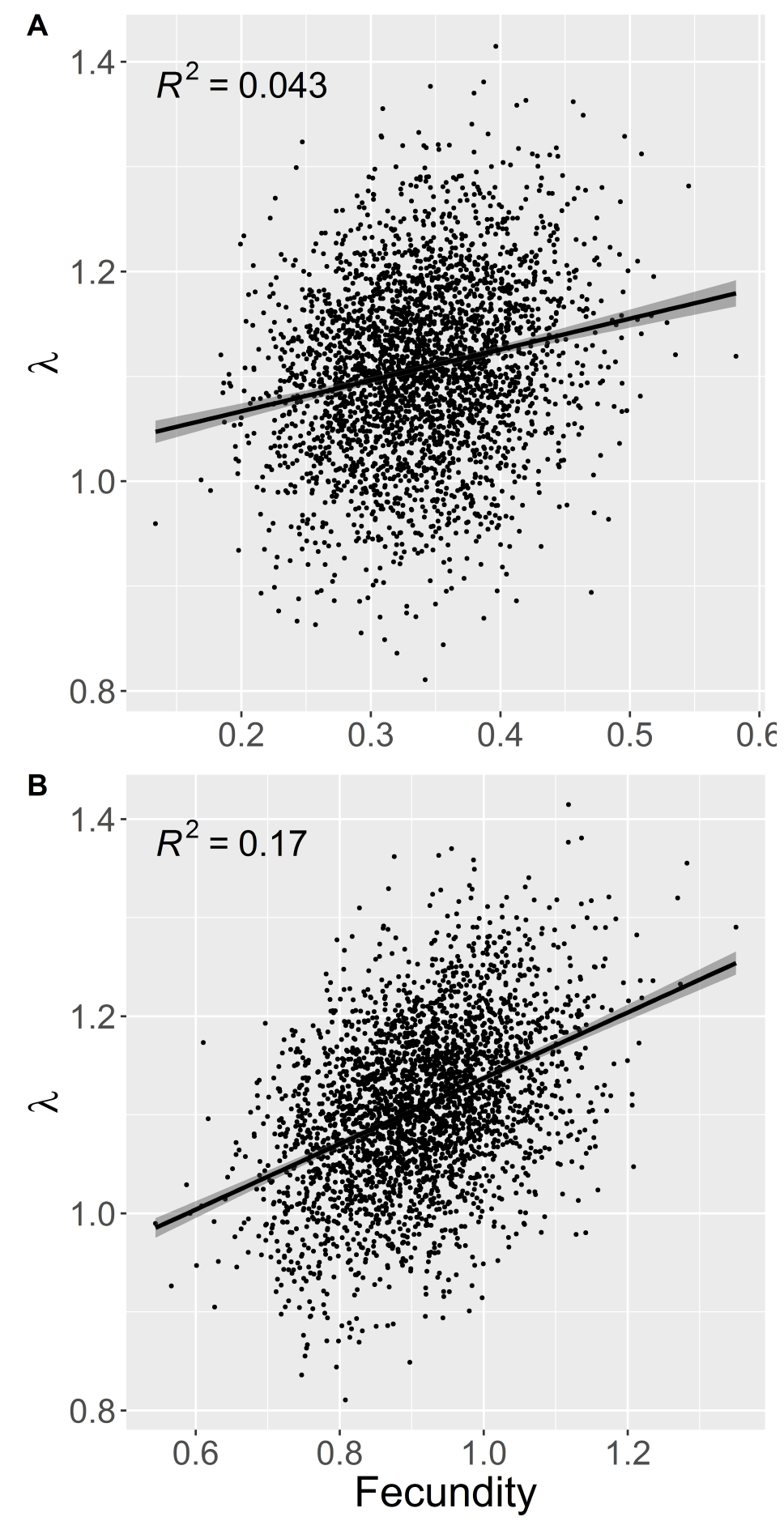

Figure 4.5: Realizations of estimated asymptotic population growth rates $(\lambda)$ of eastern wild turkey hens as a function of fecundity rates of yearling (A) and adult (B) hens from February 2017 to April 2019 in northeastern South Dakota, USA. Scatter plots are based on 3,000 random realizations of estimated vital rates. 

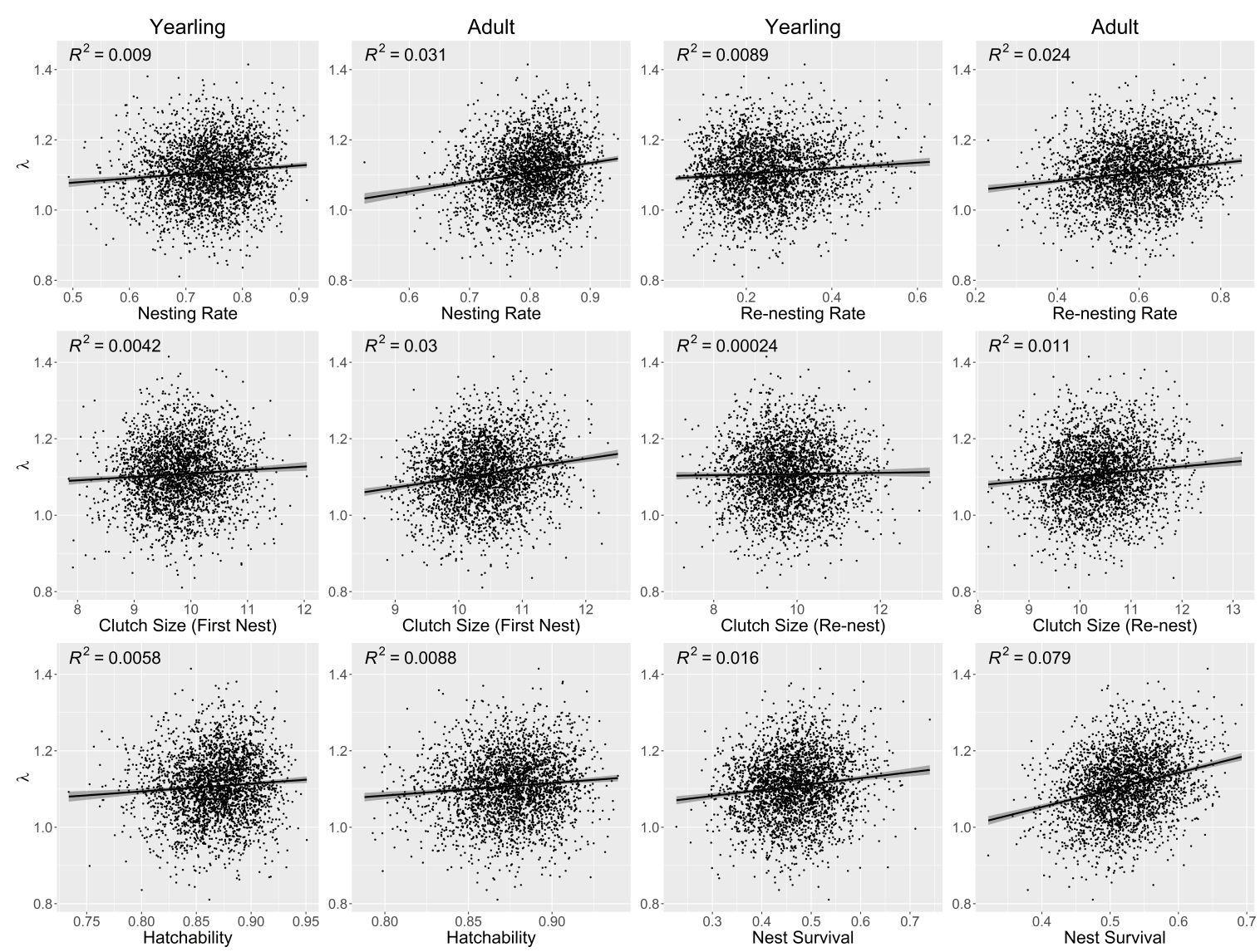

Figure 4.6: Realizations of estimated asymptotic population growth rates $(\lambda)$ of eastern wild turkey hens as a function of lower-level reproductive parameters of yearling and adult hens during the nesting seasons of 2017 and 2018 in northeastern South Dakota, USA. Scatter plots are based on 3,000 random realizations of estimated vital rates. 

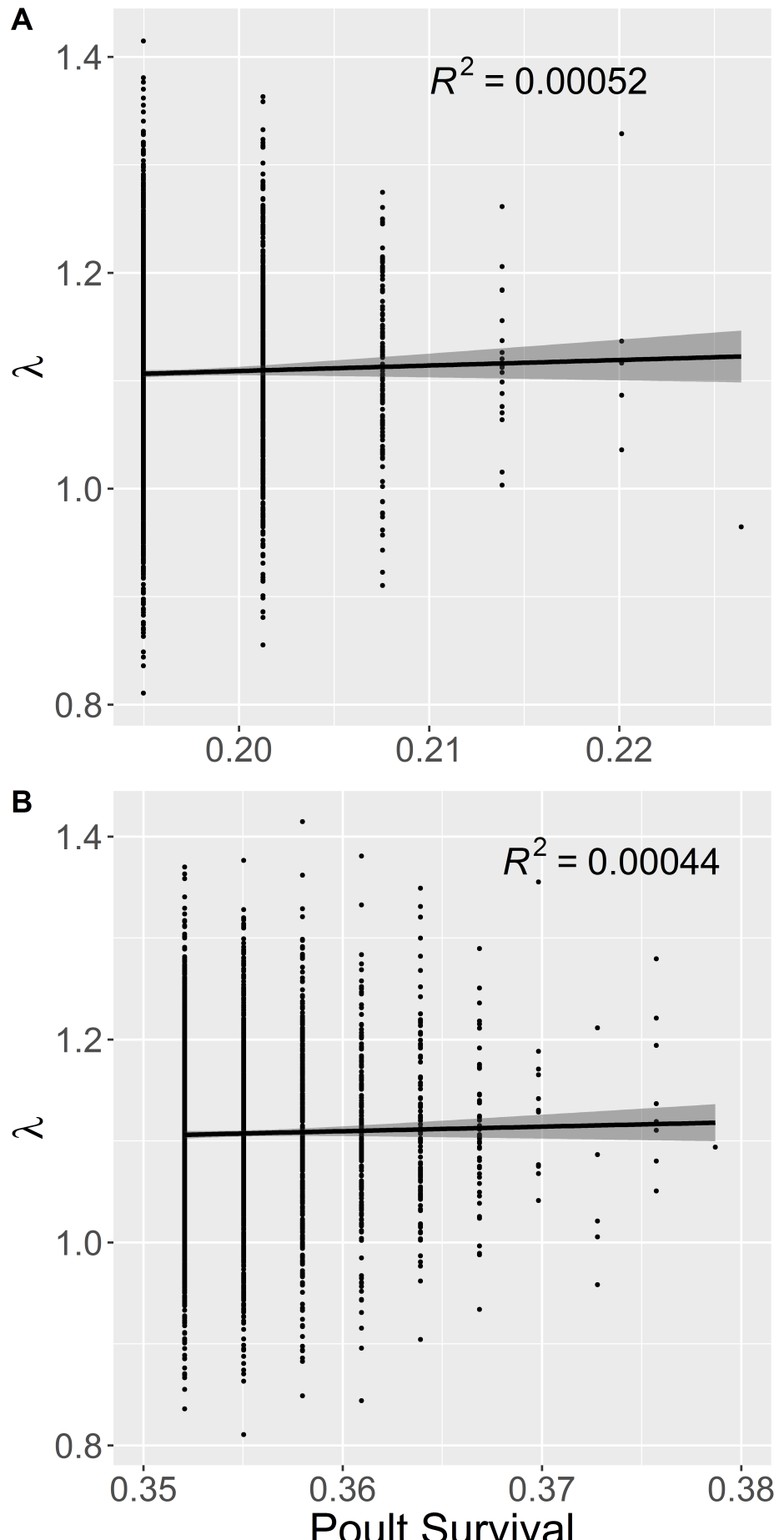

Figure 4.7: Realizations of estimated asymptotic population growth rates $(\lambda)$ of eastern wild turkey hens as a function of the survival of poults in broods reared by yearling (A) and adult (B) hens during the brood-rearing seasons of 2017 and 2018 in northeastern South Dakota, USA. Scatter plots are based on 3,000 random realizations of estimated vital rates. 


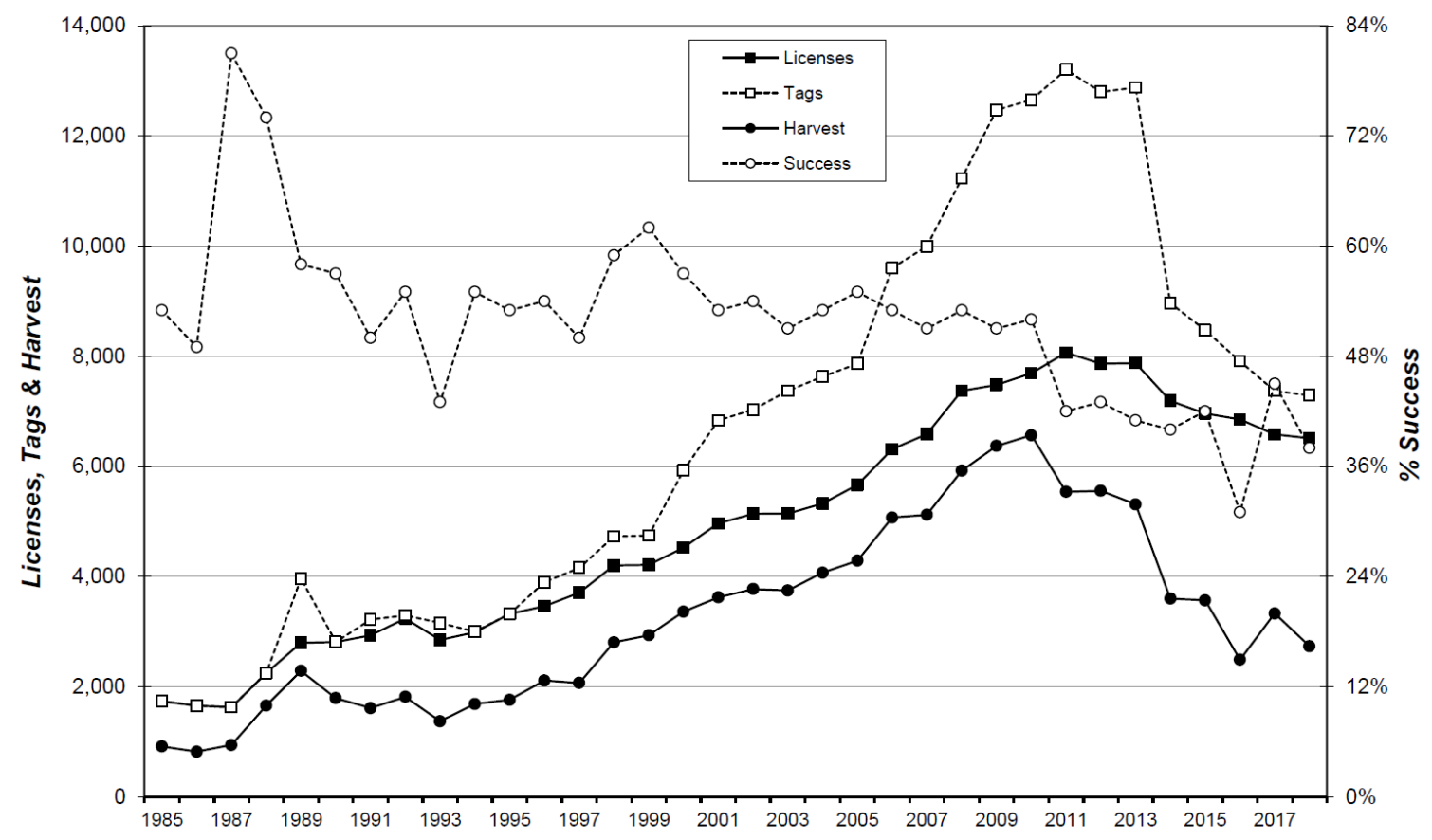

Figure 4.8: Number of hunting licenses sold, number of wild turkey hunting tags sold, number of wild turkeys harvested, and apparent hunter harvest success (\%) during the Spring Prairie Turkey Firearm seasons from 1985-2016 in South Dakota, USA. Figure is adapted from Huxoll 2016). 


\section{Literature Cited}

Alpizar-Jara, R., E. N. Brooks, K. H. Pollock, D. E. Steffen, J. C. Pack, and G. W. Norman. 2001. An Eastern Wild Turkey Population Dynamics Model for Virginia and West Virginia. The Journal of Wildlife Management 65:415-424.

Austin, D. E., and L. W. DeGraff, 1975. Winter Survival of Wild Turkeys in the Southern Adirondack. Pages 55-60 in L. K. Halls, editor. Proceedings of the Third National Wild Turkey Symposium. The Texas Chapter of the Wildlife Society, Austin, Texas, USA.

Badyaev, A. V. 1995. Nesting Habitat and Nesting Success of Eastern Wild Turkeys in the Arkansas Ozark Highlands. The Condor 97:221-232.

Bekoff, M., and M. C. Wells. 1980. The Social Ecology of Coyotes. Scientific American 242:130-148.

Benkobi, L., D. W. Uresk, G. Schenbeck, and R. M. King. 2000. Protocol for Monitoring Standing Crop in Grasslands Using Visual Obstruction. Journal of Range Management 53:627-633.

Breitenbach, R. P., C. L. Nagra, and R. K. Meyer. 1963. Effect of Limited Food Intake on Cyclic Annual Changes in Ring-Necked Pheasant Hens. The Journal of Wildlife Management 27:24-36.

Caswell, H. 2001. Matrix Population Models. Sinauer Associates, Inc. Publishers, Sunderland, Massachusetts, USA.

Clawson, M. R., and J. J. Rotella. 1998. Success of Artificial Nests in CRP Fields, Native Vegetation, and Field Borders in Southwestern Montana. Journal of Field Ornithology 69:180-191.

Crête, M., and S. Larivière. 2003. Estimating the Costs of Locomotion in Snow for Coyotes. Canadian Journal of Zoology 81:1808-1814.

Crouse, D. T., L. B. Crowder, and H. L. Caswell. 1987. A Stage-Based Population Model for Loggerhead Sea Turtles and Implications for Conservation. Ecology 68:1412-1423.

Daubenmire, R. F. 1959. Canopy Coverage Method of Vegetation Analysis. Northwest Science 33:43-64. 
Deelen, T. R. V., and T. E. Gosselink. 2006. Coyote Survival in a Row-Crop Agricultural Landscape. Canadian Journal of Zoology 84:1630-1636.

DeGregorio, B. A., P. J. Weatherhead, and J. H. Sperry. 2014. Power Lines, Roads, and Avian Nest Survival: Effects on Predator Identity and Predation Intensity. Ecology and Evolution 4:1589-1600.

Delahunt, K. S., 2011. Nesting Ecology, Survival, and Home Range of Wild Turkeys in an Agricultural Landscape. Ph.D. thesis, Southern Illinois University Carbondale.

Fair, J. M., E. Paul, and J. Jones, editors. 2010. Guidelines to the Use of Wild Birds in Research. Third edition. The Ornithological Council, Washington, D.C., USA.

Flake, L. D., C. P. Lehman, A. P. Leif, and M. A. Rumble. 2006. The Wild Turkey in South Dakota. South Dakota Department of Game, Fish and Parks, Pierre, and South Dakota Agricultural Experiment Station, Brookings, South Dakota.

Flint, R. F., 1955. Pleistocene Geology of Eastern South Dakota. Geological Survey Professional Paper 262 Technical report, U.S. Government Printing Office, Washington, D.C., USA.

Gelman, A., H. S. Stern, J. B. Carlin, D. B. Dunson, A. Vehtari, and D. B. Rubin. 2013. Bayesian Data Analysis. Third edition. Chapman and Hall/CRC Press, Boca Raton, Florida, USA.

Gese, E. M., R. L. Ruff, and R. L. Crabtree. 1996. Foraging Ecology of Coyotes (Canis latrans): The Influence of Extrinsic Factors and a Dominance Hierarchy. Canadian Journal of Zoology 74:769-783.

Gosselink, T. E. 2003. Temporal Habitat Partitioning and Spatial Use of Coyotes and Red Foxes in East-Central Illinois. The Journal of Wildlife Management 67:90-103.

Haroldson, K. J., M. L. Svihel, R. O. Kimmel, and M. R. Riggs. 1998. Effect of Winter Temperature on Wild Turkey Metabolism. The Journal of Wildlife Management 62:299-305.

Healy, W. M., 1992. Population Influences: Environment. Pages 129-143 in J. G. Dickson, editor. The Wild Turkey: Biology and Management. Stackpole Books, Harrisburg, Pennsylvania, USA.

Healy, W. M., and E. S. Nenno. 1985. Effect of Weather on Wild Turkey Poult Survival. Proceedings of the National Wild Turkey Symposium 5:91-101.

Hobbs, N. T., and M. B. Hooten. 2015. Bayesian Models: A Statistical Primer for Ecologists. Princeton University Press, Princeton, New Jersey, USA.

Hubbard, M. W., D. L. Garner, and E. E. Klaas. 1999a. Factors Influencing Wild Turkey Hen Survival in Southcentral Iowa. The Journal of Wildlife Management 63:731-738. 
Hubbard, M. W., D. L. Garner, and E. E. Klaas. 1999b. Wild Turkey Poult Survival in Southcentral Iowa. The Journal of Wildlife Management 63:199-203.

Humberg, L. A., T. L. Devault, and O. E. Rhodes, Jr. 2009. Survival and Cause-Specific Mortality of Wild Turkeys in Northern Indiana. American Midland Naturalist 161:313-322.

Huxoll, C., 2007. South Dakota Game Report No. 2008-03 - 2007 Annual Report - Big Game Harvest Projections. South Dakota Department of Game, Fish and Parks Technical report, Pierre, South Dakota, USA.

Huxoll, C., 2008. South Dakota Game Report No. 2009-03 - 2008 Annual Report - Big Game Harvest Projections. South Dakota Department of Game, Fish and Parks Technical report, Pierre, South Dakota, USA.

Huxoll, C., 2012. South Dakota Game Report No. 2013-05 - 2012 Annual Report - Big Game Harvest Projections. South Dakota Department of Game, Fish and Parks Technical report, Pierre, South Dakota, USA.

Huxoll, C., 2016. South Dakota Game Report No. 2017-06 - 2016 Annual Report - Big Game Harvest

Projections. South Dakota Department of Game, Fish and Parks Technical report, Pierre, South Dakota, USA.

Johnson, J. R., and G. E. Larson. 2007. Grassland Plants of South Dakota and the Northern Great Plains. South Dakota State University College of Agriculture \& Biological Sciences South Dakota Agricultural Experiment Station, Brookings, South Dakota.

Johnson, M. L., and M. S. Gaines. 1990. Evolution of Dispersal: Theoretical Models and Empirical Tests Using Birds and Mammals. Annual Review of Ecology and Systematics 21:449-480.

Johnson, R. R., K. F. Higgins, and D. E. Hubbard. 1995. Using Soils to Delineate South Dakota Physiographic Regions. Great Plains Research 5:309-322.

Kane, D. F., R. O. Kimmel, and W. E. Faber. 2007. Winter Survival of Wild Turkey Females in Central Minnesota. The Journal of Wildlife Management 71:1800-1807.

Kellner, K., 2018. jagsUI: A Wrapper Around rjags to Streamline JAGS Analyses.

Klonglan, E. D., R. L. Robbins, and B. L. Ridley. 1959. Evaluation of Effectiveness of Pheasant Flushing Bars in Iowa Hayfields. Proceedings of the Iowa Academy of Science 66:534-552.

Knupp, P. M., 1990. Relationship of Forest Characteristics and Landscape Patterns to Wild Turkey Populations in Eastern and Central South Dakota. Electronic theses and dissertations, South Dakota State University. 
Knupp Moore, P. M., and L. D. Flake. 1994. Forest Characteristics in Eastern and Central South Dakota. Proceedings of the South Dakota Academy of Science 73:163-174.

Kurzejeski, E. W., L. D. Vangilder, and J. B. Lewis. 1987. Survival of Wild Turkey Hens in North Missouri. The Journal of Wildlife Management 51:188-193.

Lazarus, J. E., and W. F. Porter. 1985. Nest Habitat Selection by Wild Turkeys in Minnesota. Proceedings of the National Wild Turkey Symposium 5:67-81.

Leatherberry, E. C., R. J. Piva, and G. J. Josten, 2000. South Dakota's Forest Resources Outside he Black Hills National Forest, 1996. North Central Research Station, Forest Service, United States Department of Agriculture Technical report, St. Paul, Minnesota.

Lehman, C. P., 1998. A Comparison of Eastern Wild Turkeys and Rio Grande Turkeys in Northeastern South Dakota. Thesis, South Dakota State University.

Lehman, C. P., L. D. Flake, A. P. Leif, and R. D. Shields. 2001. Comparative Survival and Reproduction of Sympatric Eastern and Rio Grande Wild Turkey Females in Northeastern South Dakota. Proceedings of the National Wild Turkey Symposium 8:123-125.

Lehman, C. P., L. D. Flake, and M. A. Rumble. 2007. Survival And Cause-Specific Mortality Of Merriam's Turkeys In The Southern Black Hills. Proceedings of the National Wild Turkey Symposium 9:295-301.

Lehman, C. P., L. D. Flake, M. A. Rumble, and D. J. Thompson. 2008a. Merriam's Turkey Poult Survival in the Black Hills, South Dakota. Intermountain Journal of Sciences 14:78-88.

Lehman, C. P., L. D. Flake, and D. J. Thompson. 2002. Comparison of Microhabitat Conditions at Nest Sites Between Eastern and Rio Grande Wild Turkeys in Northeastern South Dakota. American Midland Naturalist 149:192-200.

Lehman, C. P., C. T. Rota, J. D. Raithel, and J. J. Millspaugh. 2018. Pumas Affect Elk Dynamics in Absence of Other Large Carnivores. The Journal of Wildlife Management 82:344-353.

Lehman, C. P., M. A. Rumble, L. D. Flake, and D. J. Thompson. 2008b. Merriam's Turkey Nest Survival and Factors Affecting Nest Predation by Mammals. The Journal of Wildlife Management $72: 1765-1774$.

Leif, A. P., 2001. Survival, Reproduction, and Home Ranges of Translocated Wild Turkeys in South Dakota. Pages 211-220 in Proceedings of the National Wild Turkey Symposium, volume 8.

Little, T. W., and J. M. Kienzler. 1990. Effects of Fall Either-Sex Hunting on Survival in an Iowa Wild Turkey Population. Proceedings of the National Wild Turkey Symposium 6:119-125. 
Lukacs, P. M., V. J. Dreitz, F. L. Knopf, and K. P. Burnham. 2004. Estimating Survival Probabilities of Unmarked Dependent Young When Detection Is Imperfect. The Condor 106:926-931.

Lutz, R. S., and J. A. Crawford. 1987. Reproductive Success and Nesting Habitat of Merriam's Wild Turkeys in Oregon. The Journal of Wildlife Management 51:783.

McGhee, J. D., J. Berkson, D. E. Steffen, and G. W. Norman. 2008. Density-Dependent Harvest Modeling for the Eastern Wild Turkey. The Journal of Wildlife Management 72:196-203.

McGhee, J. D., and J. M. Berkson. 2007. Estimation of a Nonlinear Density-Dependence Parameter for Wild Turkey. The Journal of Wildlife Management 71:706-712.

Miller, K. F., L. S. Kempf, and V. F. Koopman, 1979. Soil Survey of Grant County, South Dakota. United States Department of Agriculture Soil Conservation Service Technical report.

Mosby, H. S., 1975. The Status of the Wild Turkey in 1974. Pages 22-26 in Proceedings of the National Wild Turkey Symposium, volume 3. Texas Chapter of the Wildlife Society.

National Climatic Data Center, 2010. 1981-2010 U.S. Climate Normals. National Oceanic and Atmospheric Administration Technical report, Asheville, North Carolina.

Over, W. H., and C. S. Thoms. 1921. Birds of South Dakota. University of South Dakota, Vermillion, South Dakota, USA.

Ozoga, J. J., and E. M. Harger. 1966. Winter Activities and Feeding Habits of Northern Michigan Coyotes. The Journal of Wildlife Management 30:809-818.

Paisley, R. N., R. G. Wright, J. F. Kubisiak, and R. E. Rolley. 1998. Reproductive Ecology of Eastern Wild Turkeys in Southwestern Wisconsin. The Journal of Wildlife Management 62:911-916.

Patterson, B. R., L. K. Benjamin, and F. Messier. 1998. Prey Switching and Feeding Habits of Eastern Coyotes in Relation to Snowshoe Hare and White-Tailed Deer Densities. Canadian Journal of Zoology $76: 1885-1897$.

Peterson, L. E., and A. H. Richardson, 1975. The Wild Turkey in the Black Hills. South Dakota Department of Game, Fish and Parks Technical report, Pierre, South Dakota, USA.

Plummer, M., 2003. JAGS: A Program for Analysis of Bayesian Graphical Models Using Gibbs Sampling. in K. Hornik, F. Leisch, and A. Zeileis, editors. Proceedings of the 3rd International Workshop on Distributed Statistical Computing. Vienna, Austria.

Pollentier, C. D., S. D. Hull, and R. S. Lutz. 2014a. Eastern Wild Turkey Demography: Sensitivity of Vital Rates Between Landscapes. The Journal of Wildlife Management 78:1372-1382. 
Pollentier, C. D., R. S. Lutz, and S. D. Hull. 2014b. Survival and Productivity of Eastern Wild Turkey Females in Contrasting Landscapes in Wisconsin. The Journal of Wildlife Management 78:985-996.

Porter, W. F. 1977. Home Range Dynamics of Wild Turkeys in Southeastern Minnesota. The Journal of Wildlife Management 41:434-437.

Porter, W. F., 1978. Behavior and Ecology of Wild Turkey (Meleagris gallopavo) in Southeastern Wisconsin. Dissertation, University of Minnesota, Minneapolis, Minnesota, USA.

Porter, W. F., 1992. Habitat Requirements. Pages 202-213 in J. G. Dickson, editor. The Wild Turkey: Biology and Management. Stackpole Books, Harrisburg, Pennsylvania, USA.

Porter, W. F., G. C. Nelson, and K. Mattson. 1983. Effects of Winter Conditions on Reproduction in a Northern Wild Turkey Population. The Journal of Wildlife Management 47:281-290.

Porter, W. F., R. D. Tangen, G. C. Nelson, and D. A. Hamilton. 1980. Effects of Corn Food Plots on Wild Turkeys in the Upper Mississippi Valley. The Journal of Wildlife Management 44:456-462.

R Core Team, 2018. R: A Language and Environment for Statistical Computing.

Reitsma, K. D., D. E. Clay, C. G. Carlson, B. H. Dunn, A. J. Smart, D. L. Wright, and S. A. Clay, 2013. Estimated South Dakota Land Use Change from 2006 to 2012. South Dakota State University Extension Technical report, Brookings, South Dakota.

Restani, A. M., R. O. Kimmel, J. R. Fieberg, and S. L. Goetz. 2009. Effects of Supplemental Food and Experience on Winter Survival of Transplanted Wild Turkeys. The Wilson Journal of Ornithology 121:366-377.

Robel, R. J., J. N. Briggs, A. D. Dayton, and L. C. Hulbert. 1970. Relationships between Visual Obstruction Measurements and Weight of Grassland Vegetation. Journal of Range Management 23:295-297.

Roberts, S. D., J. M. Coffey, and W. F. Porter. 1995. Survival and Reproduction of Female Wild Turkeys in New York. The Journal of Wildlife Management 59:437-447.

Roberts, S. D., and W. F. Porter. 1998a. Influence of Temperature and Precipitation on Survival of Wild Turkey Poults. The Journal of Wildlife Management 62:1499-1505.

Roberts, S. D., and W. F. Porter. 1998b. Relation Between Weather and Survival of Wild Turkey Nests. The Journal of Wildlife Management 62:1492-1498.

Rolley, R. E., J. F. Kubisiak, R. N. Paisley, and R. G. Wright. 1998. Wild Turkey Population Dynamics in Southwestern Wisconsin. The Journal of Wildlife Management 62:917-924. 
Rota, C. T., J. J. Millspaugh, M. A. Rumble, C. P. Lehman, and D. C. Kesler. 2014. The role of Wildfire, Prescribed Fire, and Mountain Pine Beetle Infestations on the Population Dynamics of Black-Backed Woodpeckers in the Black Hills, South Dakota. PLoS ONE 9.

Royle, J., and R. Dorazio, 2008. Modeling Survival. Pages 347-377 in Hierarchical Modeling and Inference in Ecology: the Analysis of Data from Populations, Metapopulations, and Communities. Academic Press, San Diego, California.

Rumble, M. A., and R. A. Hodorff. 1993. Nesting Ecology of Merriam's Turkeys in the Black Hills, South Dakota. The Journal of Wildlife Management 57:789.

Rumble, M. A., B. F. Wakeling, and L. D. Flake. 2003. Factors Affecting Survival and Recruitment in Female Merriam's Turkeys. Intermountain Journal of Sciences 9:26-37.

Ryder, J. P. 1970. A Possible Factor in the Evolution of Clutch Size in Ross' Goose. The Wilson Bulletin $82: 5-13$.

Schmidt-Nielsen, K. 1997. Animal Physiology: Adaptation and Environment. Cambridge University Press.

Schorger, A. W. 1966. The Wild Turkey: Its History and Domestication. First edition. The University of Oklahoma Press, Norman, Oklahoma, USA.

Shields, R. D., 2001. Ecology of Eastern Wild Turkeys Introduced to Minimally Forested Agricultural Landscapes in Northeastern South Dakota. Thesis, South Dakota State University.

Shields, R. D., and L. D. Flake. 2006. Survival and Reproduction of Translocated Eastern Wild Turkeys in a Sparsely Wooded Landscape in North Eastern South Dakota. Western North American Naturalist 66:298-309.

South Dakota Department of Game Fish and Parks, 2017. South Dakota Wild Turkey Management Plan 2016 2020. South Dakota Department of Game, Fish and Parks Technical report, Pierre, South Dakota, USA.

Spears, B. L., W. B. Ballard, M. C. Wallace, R. D. Applegate, and P. S. Gipson. 2003. Coyote, Canis latrans - Rio Grande Turkey, Meleagris gallopavo intermedia, Interactions. The Canadian FieldNaturalist 117:645-647.

Spears, B. L., M. C. Wallace, W. B. Ballard, R. S. Phillips, D. P. Holdstock, J. H. Brunjes, R. Applegate, M. S. Miller, and P. S. Gipson. 2007. Habitat Use and Survival of Preflight Wild Turkey Broods. The Journal of Wildlife Management 71:69-81. 
Sperry, C. C. 1934. Winter Food Habits of Coyotes: A Report of Progress, 1933. Journal of Mammalogy $15: 286-290$.

Stangel, P. W., P. L. Leberg, and J. I. Smith, 1992. Systematics and Population Genetics. Pages 18-28 in J. G. Dickson, editor. The Wild Turkey: Biology and Management. Stackpole Books, Harrisburg, Pennsylvania, USA.

State of South Dakota, 2018. South Dakota GIS Data. URL http:// opendata2017-09-18t192802468z-sdbit. opendata.arcgis.com/.

Storaas, T. 1988. A Comparison of Losses in Artificial and Naturally Occurring Capercaillie Nests. The Journal of Wildlife Management 52:123.

Stubben, C. J., and B. G. Milligan. 2007. Estimating and Analyzing Demographic Models Using the popbio Package in R. Journal of Statistical Software 22.

Stubbs, M., 2014. Conservation Reserve Program (CRP): Status and Issues. Technical report.

Suchy, W. J., W. R. Clark, and T. W. Little, 1983. Influence of Simulated Harvest on Iowa Wild Turkey Populations. Pages 98-102 in Proceedings of the Iowa Academy of Science, volume 90.

Switzer, C. T., and S. A. Tucker, 2009. Survival, Reproduction, Home Range, and Habitat Use of Translocated Eastern Wild Turkeys in the Wessington Hills, South Dakota. South Dakota Department of Game, Fish and Parks Technical report, Pierre.

Syrotuck, W. 2000. Scent and the Scenting Dog. Barkleigh Productions, Inc., Mechanicsburg, Pennsylvania, USA.

Thompson, M. C., and R. L. Delong. 1967. The Use of Cannon and Rocket-Projected Nets for Trapping Shorebirds. Bird-Banding 38:214-218.

Vander Haegen, W. M., W. E. Dodge, and M. W. Sayre. 1988. Factors Affecting Productivity in a Northern Wild Turkey Population. The Journal of Wildlife Management 51:127-133.

Vangilder, L. D., M. W. Hubbard, and D. A. Hasenbeck, 2001. Reproductive Ecology of Eastern Wild Turkey Females in the Eastern Missouri Ozarks. Pages 53-59 in Proceedings of the National Wild Turkey Symposium, volume 8.

Vangilder, L. D., and E. W. Kurzejeski. 1995. Population Ecology of the Eastern Wild Turkey in Northern Missouri. Wildlife Monographs 130:1-50.

Vangilder, L. D., E. W. Kurzejeski, V. L. Kimmel-Truitt, and J. B. Lewis. 1987. Reproductive Parameters of Wild Turkey Hens in North Missouri. The Journal of Wildlife Management 51:535-540. 
Wertz, T. L., and L. D. Flake. 1988. Wild Turkey Nesting Ecology in South Central South Dakota. The Prairie Naturalist 20:29-37.

Williams, Jr., L. E. 1961. Notes on Wing Molt in the Yearling Wild Turkey. The Journal of Wildlife Management 25:439-440.

Williams, Jr., L. E. 1981. The Book of the Wild Turkey. Winchester Press, Tulsa, Oklahoma, USA.

Wisdom, M. J., L. S. Mills, and D. F. Doak. 2000. Life Stage Simulation Analysis: Estimating VitalRate Effects on Population Growth for Conservation. Ecology 81:628-641.

Wright, R. G., R. N. Paisley, and J. F. Kubisiak. 1996. Survival of Wild Turkey Hens in Southwestern Wisconsin. The Journal of Wildlife Management 60:313-320.

Wunz, G. A. 1984. Rocket-Net Innovations for Capturing Wild Turkeys and Waterfowl. Transactions of the Northeast Section of the Wildlife Society 41:219.

Wunz, G. A., and A. H. Hayden, 1975. Winter Mortality and Supplemental Feeding of Turkeys in Pennsylvania. Pages 61-69 in Proceedings of the National Wild Turkey Symposium, volume 3. 